\title{
FEB 022001
}

\section{HANFORD TECHNICAL} LIBRARY

Copyright ${ }^{\circledR} 1989$ Battelle Memorial Institute

Supplemental Mathematical

Formulations:

The Multimedia Environmental

Pollutant Assessment System (MEPAS)

J. G. Droppo, Jr.

G. Whelan

J. W. Buck

D. L. Strenge
B. L. Hoopes

M. B. Wailter

R. L. Knight

S. M. Brown

December 1989

Prepared for the

U.S. Department of Energy

Assistant Secretary, Environment,

Safety, and Health

under Contract DE-AC06-76RLO 1830

Pacific Northwest Laboratory

Operated for the U.S. Department of Energy

by Battelle Memorial Institute 


\title{
DISCLAIMER
}

This program was prepared as an account of work sponsored by an agency of the United States Government. Neither the United States Government nor any agency thereof, nor Battelle Memorial Institute, nor any or their employees, makes any warranty, expressed or implied, or assumes any legal liability or responsibility for the accuracy, completeness, or usefulness of any information, apparatus, product, or process disclosed, or represents that its use would not infringe privately owned rights. Reference herein to any specific commercial product, process, or service by trade name, trademark, manufacturer, or otherwise, does not necessarily constitute or imply its endorsement, recommendation, or favoring by the United States Government of any agency thereof, or Battelle Memorial Institute. The views and opinions of authors expressed herein do not necessarily state or reflect those of the United States Government or any agency thereof.

\author{
PACIFIC NORTHWEST LABORATORY \\ operated by \\ BATTELLE MEMORIAL INSTITUTE \\ for the \\ UNITED STATES DEPARTMENT OF ENERGY \\ under Contract DE-AC06-76RLO 1830
}

\section{NOTICE}

The Government retains a paid-up nonexclusive, irrevocable woridwide license to reproduce, prepare derivative works, perform publicly and display publicly by or for the Government, including the right to distribute to other Government contractors.

\section{Copyright $\odot 1999$ Battelle Memorial Institute}


PNL -7201

UC $-602,630$

SUPPLEMENTAL MATHEMATICAL

FORMULATIONS :

THE MULTIMEDIA ENVIRONMENTAL

POLLUTANT ASSESSMENT SYSTEM (MEPAS)

J. G. Droppo, Jr.

G. Whelan

J. W. Buck

D. L. Strenge

B. L. Hoopes

M. B. Walter

R. L. Knight(a)

S. M. Brown (a)

December 1989

Prepared for

the U.S. Department of Energy

Assistant Secretary, Environment, Safety, and Health

under Contract DE-AC06-76RL0 1830

Pacific Northwest Laboratory

Richland, Washington 99352

Copyright 1989 Battelle Memorial Institute

(a) $\mathrm{CH}_{2} \mathrm{MH} \mathrm{Hill}_{1}$, Gainesville, Florida 



\section{PREFACE}

The Multimedia Environmental Pollutant Assessment System (MEPAS) is an integrated methodology used to assess relative health impacts from actual and potential releases of hazardous materials into the environment. MEPAS is an enhanced version of the Remedial Action Priority System (RAPS). Both RAPS and MEPAS were developed by the Pacific Northwest Laboratory (PNL) (a) for the U.S. Department of Energy's (DOE's) Office of Environment, Safety, and Health.

This document represents a supplement to the mathematical formulations of RAPS, as documented by whelan et al. (1987)(b), and focuses on those formulations associated with the MEPAS enhancements. This document provides an overview of the MEPAS framework and detailed discussions of the enhancements by major component (i.e., groundwater, surface water and atmospheric transport and exposure assessment). RAPS components that are not affected by these enhancements are discussed in the RAPS formulation report.

This is one of nine reports documenting and analyzing MEPAS and its application to an environmental survey conducted of all DOE sites. Other documents include:

- Multimedia Environmental Pollutant Assessment System (MEPAS): Getting Started with MEPAS This report provides an introduction and overview of MEPAS for individuals just beginning to learn how to use the program. An expanded version of this report is contained in Section 3 of the User's Guide.

- Multimedia Environmental Pollutant Assessment System (MEPAS) Application and Guidance: Volume 1-User's Guide. A description is given of the steps for making a MEPAS application.

(a) Pacific Northwest Laboratory is operated by Battelle Memorial Institute for the U.S. Department of Energy under Contract DE-AC06-76RLO 1830.

(b) Whelan, G., D. L. Strenge, J. G. Droppo, Jr., B. L. Steelman, and J. W. Buck. 1987. The Remedial Action Priority System (RAPS): Mathematical Formulations. DOE/RL/87-09, PNL-6200, Pacific Northwest Laboratory, Richland, Washington. 
- Multimedia Environmental Pollutant Assessment System (MEPAS) Application and Guidance: Volume 2 - Guidelines for Evaluating MEPAS Input Parameters. This volume contains detailed instructions on how to define values for each input parameter along with copies of parameter input worksheets.

- Remedial Action Priority System (RAPS): Mathematical Formulations. Details of the mathematical formulations and algorithms used as the basic framework for the RAPS (and subsequently, MEPAS) methodology.

- Prel iminary Summary Report of the Defense Production Facilities presents the results of a preliminary application of MEPAS to ranking environmental problems at 16 of DOE's defense waste facilities.

- Chemical Oata Bases for the Multimedia Environmental Pollutant Assessment System (MEPAS): Version 1. The MEPAS methodology uses a constituent data base containing values for physical, chemical, and exposure computation. This document lists these data values along with each source.

The following documents are currently in preparation:

- Multimedia Environmental Pollutant Assessment System (MEPAS) Programmer's Guide. This guide will contain details of 1) program structure, 2) parameter definition and usage, 3) input and output file usage, and 4) information needed for program modification.

- Analysis of the Hazard Potential Index (HPI) for Ranking DOE's Environmental Problems. This document will address issues that pertain to the DOE environmental survey process and the MEPAS methodology application to ranking DOE environmental problems.

- Sensitivity Analysis of the MEPAS Model. This document will provide information on the input parameters that influence the MEPAS output parameters.

A complete bibliography is included at the end of this report. 


\section{ABSTRACT}

The Multimedia Environmental Pollutant Assessment System (MEPAS) is a methodology for assessing relative health impacts from the release of hazardous chemical and radioactive materials. MEPAS is an enhanced version of the Remedial Action Priority System (RAPS). This document, a supplement to the RAPS documentation, contains an overview of MEPAS followed by detailed discussions of enhancements.

MEPAS provides outputs of health impact parameters for use in ranking and screening applications. Environmental contaminant concentrations are used to estimate potential health impacts based on major exposure pathways. These concentrations may be input directly or computed by MEPAS components. When needed, MEPAS provides a set of mathematical algorithms to predict the potential contaminant migration from a site to receptors. Groundwater, overland, surface water, and atmospheric pathway components simulate multimedia contaminant transport and dispersion.

MEPAS has been implemented on a personal computer. A MEPAS shell has been developed that guides the user in problem definition, data collection and entry, data review and documentation, and applications.

Enhancements to the groundwater, surface water, overland, atmospheric, and exposure components are documented. These enhancements include a revision in the integration method for the waterborne pathway, a wetland component, a gaseous emission (volatilization) component, an atmospheric complex terrain component, mass budget formulations, and environmental decay of chemical constituents. Several new exposure components are described along with enhancements to the exposure pathways computations. 
. 
The Multimedia Environmental Pollutant Assessment System (MEPAS) provides an integrated methodology of assessing relative health impacts from actual and potential releases of hazardous materials into the environment. In 1987, Pacific Northwest Laboratory (PNL) developed the Remedial Action Priority System (RAPS) for the U.S. Department of Energy's Office of Environment, Safety, and Heaith (DOE-ESH). Since that time, PNL has been developing an enhanced version of RAPS for application in the U.S. Department of Energy's (DOE) Environmental Survey effort. This version is referred to as MEPAS. MEPAS represents an environmental management tool that may be used to assess hazardous and radioactive environmental releases based on health impacts in a scientific and objective manner making optimal use of available site information. MEPAS provides DOE-ESH with a management tool for assistance in prioritizing environmental issues associated with wastes from both operating facilities and inactive waste sites.

This document represents a supplement to, and an update of, the mathematical formulation of RAPS, as documented by whelan et al. (1987). (a) Only those formulations associated with enhanced features to the RAPS methodology (hence, MEPAS) are documented in this report. These enhancements include the following:

- algorithms to address mass-conservation within waterborne, airborne, and exposure components

- back-calculating components and techniques for site-specific caljbrations using measured environmental constituent concentrations

- steady-state groundwater component

- wetlands environment

- complex-terrain model for the atmospheric component

(a) Whelan, G., D. L. Strenge, J. G. Droppo, Jr., B. L. Steelman, and J. W. Buck. 1987. The Remedial Action Priority System (RAPS): Mathematical Formulations, D0E/RL/87-09, PNL-6200, Pacific Northwest Laboratory, Richland, Washington. 
- use of measured contaminant concentrations in the surface water, groundwater, and atmospheric pathways directly in an health impact analys is (no transport modeling required)

- new exposure pathway components

- additional health impact output products

- new algorithms to enhance the efficiency and accuracy of the methodology.

MEPAS is implemented on a personal computer with a data base management program (shell) that helps in 1) problem definition, 2) data collection and entry, 3) data review and documentation, and 4) running transport and exposure scenarios.

MEPAS uses empirically, analytically, and numerically integrated analytical solution based mathematical algorithms to predict the potential for contaminant migration from a site to receptors of concern using pathways analyses. Four major pathways of contaminant migration are considered in MEPAS: groundwater, overland, surface water, and atmospheric. Simplified exposure assessments are performed for important receptors using contaminant concentrations simulated by the transport components of the code. The health impacts associated with the site can then be calculated relative to the risks of other sites for each pathway and for all pathways together.

MEPAS considers 1) specific site information and constituent characteristics associated with the transport pathways; 2) both chemical and radioactive wastes; 3 ) the potential direction of contaminant movement; 4) contaminant mobility and persistence, where applicable; 5) population distributions; 6) various routes of exposure (e.g., inhalation, ingestion, and external exposure); 7) contaminant toxicities; 8) duration of exposure of the surrounding population; and 9) contaminant arrival time to sensitive receptors.

Under the guidance of DOE-ESH, PNL conducted a program to review, analyze, test, and document major aspects of MEPAS. This report represents one product of this program. Other activities include:

- Independent Peer Review - The methodology and mathematical formulations for RAPS have been independently peer reviewed by appropriate experts in the private and public sectors. 
- Independent Public Review - MEPAS will undergo a public review by DOE in the Environmental Survey effort.

- Demonstration of the Methodology - The various components of MEPAS have been implemented at actual sites where contaminant levels have been monitored in the environment. The monitored contaminant levels were then compared to simulated contaminant levels associated with the application of MEPAS to these sites. The purpose of the comparison was to demonstrate the applicability of MEPAS to a variety of hazardous waste sites or releases of contaminants into the environment.

- Sensitivity Analysis - A sensitivity anaiysis has been conducted to determine the effects of 1) specific input parameters, 2) initial and boundary conditions, 3) distributions of input parameters, and 4) interrelationships that exist among input parameters on model response over short and long time frames.

- Ranking Applications Analysis - MEPAS was applied at 16 DOE defense production facilities in a test of the system. The results of this ranking were reported in a preliminary summary report (DOE 1988). These results, supplemented with additional MEPAS analyses, are being used to study implications and uncertainties in various ranking procedures.

- Documentation - Documentation represents a key feature of this program. Key documentation will include the following:

- complete description of MEPAS mathematical formulations

- documentation of the sensitivity and ranking applications studies

- a compilation of the MEPAS data base with source references

- user manual, that include detailed application instructions with definitions and sources of all required input parameters

- guidelines for implementing MEPAS.

Any future modifications to MEPAS will be documented in addenda and appropriately distributed. 


\section{ACKNOWLEDGMENTS}

The development of a multimedia contaminant environmental exposure and risk assessment methodology requires a wide spectrum of engineering and scientific technologies, and involves the specialized expertise of several researchers. One researcher cannot adequately address the complexities associated with an assessment methodology that covers contaminant migration through four major transport environments (i.e., overland, groundwater, surface water, and atmosphere), human dose through four routes of exposure (i.e., ingestion, inhalation, dermal contact, and external dose), and health effects associated with exposure to carcinogenic and noncarcinogenic constituents.

A number of staff helped in the development of MEPAS. C. A. Oster provided input on the integration routine. D. R. Friedrichs helped design the structure for the MEPAS shell. T. M. Poston helped with the development of the fish production portion of the exposure pathway. R. D. Brockhaus provided support in the implementation of waterborne transport components. C. D. Whiteman provided input on processes in complex terrain.

B. L. Steelman assisted in the development of the MEPAS concept and G. L. Andrews provided project management support.

We also wish to acknowledge L. J. Thibodeaux for his helpful suggestions and lecture notes relative to the modeling of volatilization from ponds.

We wish to acknowledge A. Toblin, NUS, for his valuable contributions in the development, testing, and implementation stages of MEPAS. R. L. Knight, J. S. Bays, S. M. Brown, and D. Lincoln of $\mathrm{CH}_{2} M$ Hill provided technical guidance on the MEPAS methodology, and developed the wetlands model. Special thanks go to R. J. Aiken of DOE's Office of Environment, Safety, and Hea\}th (DOE-ESH) for his comments, guidance, and support in the development of MEPAS. This work is supported by DOE-ESH under contract DE-ACO6-76RL0 1830.

Special thanks go to the following additional PNL personnel who made this document possible: editing--M. G. Hefty, D. A. Perez, and W. R. Gorst; word processing--D. K. Mager and J. B. Hawkins. 


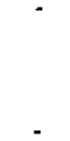




\section{CONTENTS}

PREFACE ............................. . . ABSTRACT ........................ . . . v SUMMARY ............................. . . vi ACKNOWLEDGMENTS ........................ xi

1.0 INTRODUCTION . . . . . . . . . . . . . . . . . . . 1.1

1.1 OBJECTIVE OF REPORT . . . . . . . . . . . . . 1.1

1.2 APPLICATION LIMITATIONS . . . . . . . . . . . 1.2

1.3 STRUCTURE OF THE REPORT . . . . . . . . . . . . 1.4

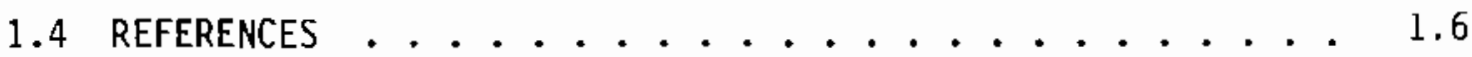

2.0 REVIEW OF RAPS/MEPAS FRAMEWORK . . . . . . . . . . . . 2.1

2.1 GROUNDWATER TRANSPORT PATHWAY . . . . . . . . . . 2.1

2.2 SURFACE WATER PATHWAY . . . . . . . . . . . 2.4

2.3 OVERLAND TRANSPORT PATHWAY ........................ 2.6

2.4 ATMOSPHERIC PATHWAY . . . . . . . . . . . . . 2.7

2.5 EXPOSURE ASSESSMENT COMPONENT . . . . . . . . . . . . 2.9

2.6 SUMMARY . . . . . . . . . . . . . . . 2.12

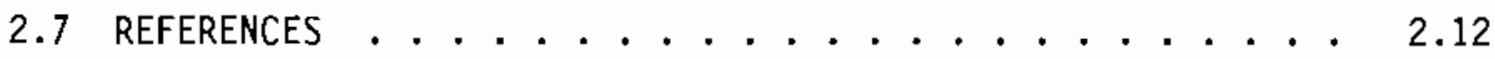

3.0 Integrated Mepas METhOdOLOGY . . . . . . . . . . . . . . 3.1

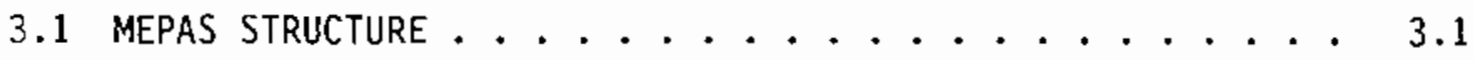

3.2 OVERVIEW OF SHELL . . . . . . . . . . . . . . 3.1

3.2.1 Constituent Library ............. 3.3

3.2.2 File Creation/Update ........... 3.4

3.2.3 Report Preparation . . . . . . . . . . 3.6

3.4 REFERENCES . . . . . . . . . . . . . . . . . 3.7 
4.0 ENHANCED GROUNDWATER COMPONENT $\ldots \ldots . \ldots . \ldots . \ldots . \ldots . \ldots$

4.1 INTEGRATION LIMITS $\ldots \ldots \ldots . \ldots . \ldots . \ldots . \ldots$

4.2 ADAPTIVE SIMPSON'S QUADRATURE INTEGRATION ROUTINE $\ldots 4.5$

4.3 MULTIPLE DEgRADATION . . . . . . . . . . . . . 4.6

4.4 STEADY-STATE GROUNDWATER ALGORITHMS. . . . . . . . 4.10

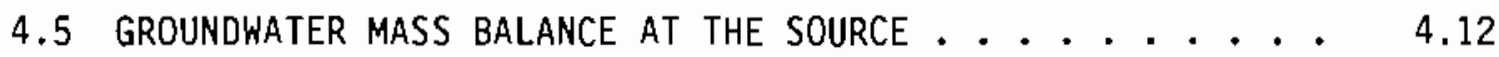

4.6 RETARDATION FACTOR . . . . . . . . . . . . . 4.13

4.7 MEASURED CONCENTRATIONS IN THE GROUNDWATER ENVIRONMENT . . 4.14

4.8 RefERENCES . . . . . . . . . . . . . . . 4.15

5.0 ENHANCED SURFACE WATER COMPONENT $\ldots \ldots . \ldots . \ldots . \ldots . \ldots$

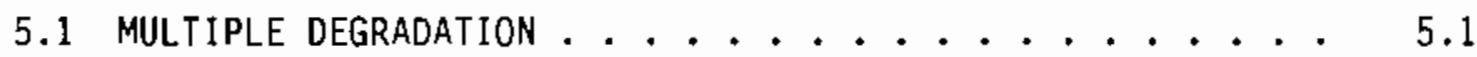

5.2 Surface water mass balance at the SOURCE . . . . . . 5.3

5.3 MEASURED CONCENTRATIONS IN THE SURFACE WATER ENVIRONMENT • 5.3

5.4 WETLANDS ENVIRONMENT . . . . . . . . . . 5.5

5.4 .1 Classes of Wetland ............. 5.6

5.4 .2 Sources of Contaminants . . . . . . . 5.7

5.4 .3 Receptors .............. 5.7

5.4.4 Wetland Processes............. 5.8

5.4 .5 Model Description ............. 5.11

5.5 REFERENCES .............................. 5.15

6.0 ATMOSPHERIC TRANSPORT .......................... 6.1

6.1 VOLATILIZATION COMPONENT . . . . . . . . 6.2

6.1.1 Landfills Without Internal Gas Generation .... 6.3

6.1.2 Landfills with Internal Gas Generation . . . . 6.6

6.1 .3 Surface Contamination - New and 01d ..... 6.7

6.1.4 Water - Ponds, Lagoons, and Free-Standing Water . . 6.12 
6.1 .5 Mass Budget - Al1 Cases .......... 6.14

6.1 .6 Limitations .............. 6.15

6.2 BACK CALCULATION . . . . . . . . . . 6.16

6.3 INITIAL SOURCE DISPERSION ................ 6.17

6.3 .1 Area Source ............... 6.18

6.3 .2 Point Source ............... 6.18

6.3 .3 Discussion ...................... 6.18

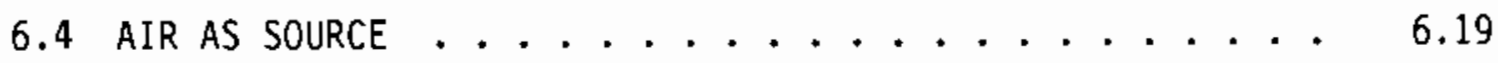

6.5 SHORT-DISTANCE MODULE ......................... 6.19

6.6 DISPERSE REgIONAL RELEASE . . . . . . . . . 6.21

6.7 COMPLEX TERRAIN COMPONENT . . . . . . . . . . 6.23

6.7 .1 Background ............... 6.23

6.7.2 Plume Intersection with Topographical Features . . 6.24

6.7.3 Local Climatological Plume Channeling . . . . 6.25

6.7 .4 Limitations ............... 6.28

6.8 TRANSPORT, DISPERSION, AND DEPOSITION $\ldots \ldots \ldots \ldots . \ldots . . \ldots$

6.8.1 Calm and Missing Wind Conditions ....... 6.28

6.8 .2 Constituent Decay and Removal ........ 6.29

6.8 .3 Source Mass Budget ............ 6.31

6.9 REFERENCES . . . . . . . . . . . . . . . 6.32

7.0 EXPOSURE AND HEALTH IMPACT $\ldots \ldots \ldots \ldots . \ldots \ldots . \ldots . \ldots . \ldots$

7.1 CONTACT EXPOSURE WITH SOILS AT MEASURED CONCENTRATIONS . . 7.1

7.2 INGESTION EXPOSURE OF FOODS AT MEASURED CONCENTRATIONS . $\quad 7.1$

7.3 EXTERNAL DOSE USing MEASUREd Radiation DOSE RATES $\ldots 7.2$

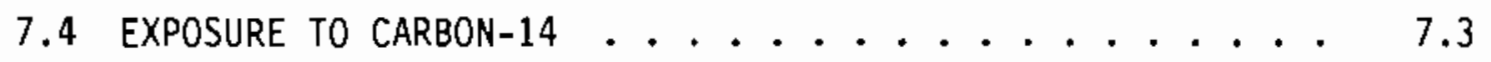


7.5 EXPOSURE PATHWAYS . . . . . . . . . . . 7.5

7.5.1 Food Transfer Factor Correlations . . . . . . 7.5

7.5.2 Deposition Velocity Estimation . . . . . . 7.8

7.5.3 Maximum Individual Exposure . . . . . . . 7.9

7.6 REFERENCES . . . . . . . . . . . . . . 7.10

8.0 BIBLIOGRAPHY $\ldots \ldots \ldots \ldots . \ldots \ldots . \ldots \ldots$

APPENDIX - ERRATA FOR 1987 RAPS FORMULATION DOCUMENT . . . . . A.1 


\section{FIGURES}

2.1 Schematic Diagram Illustrating the Interactions Between the Various Contaminant Transporting Media and How the Contaminants Affect Humans Through Their Environment. . . . . . 2.2

3.1 Main MEPAS Control Menu . . . . . . . . . . . . 3.3

3.2 MEPAS Environmental Problem Configuration . . . . . . . 3.4

3.3 Data Worksheet for MEPAS User-Friendly Shell . . . . . . . 3.5

5.1 Freshwater Wetland Classes .............. . 5.6

5.2 Conceptual Wetlands Pathway Model. . . . . . . . . . . . 5.11

6.1 Schematic of Climatological Nocturnal Wind Channeling Component .............. . . 6.27

\section{TABLES}

5.1 Description of Typical Wetland Classes........... 5.9

5.2 Wetland Pathway Model Assumptions. . . . . . . . . . . 5.15

6.1 Definition of Deposition Classes ............. 6.31

7.1 Parameter Values for Carbon-14 Farm Product Model . . . . . 7.5

7.2 Comparison of Transfer Factor Correlation Formulas . . . . . 7.7 



\subsection{INTRODUCTION}

In recent years, there has been increased concern about potential impacts from the release of contaminants into the environment from a variety of sources. The potential dangers these releases present to humans and the environment is of utmost concern. To protect public health, the federal government enacted legislation to establish effluent and environmental standards controlling toxic pollutants and to help restore and/or maintain the chemical, physical, and biological integrity of the nation's natural resources.

With the passage of the Resource Conservation and Recovery Act (RCRA) of 1976; Comprehensive Environmental Response, Compensation, and Liability Act (CERCLA) of 1980; Superfund Amendments Reauthorization Act (SARA) of 1986; and Hazardous and Solid Waste Amendments (HSWA) of 1984, Congress has mandated a much closer scrutiny of the management of hazardous wastes and of the restoration of contaminated disposal sites. Legislative language, regulatory intent, and prudent judgment call for the use of health impact assessment techniques to aid in the decision-making process. The development and application of an objective, scientifically based methodology for these assessments represents a useful assessment tool.

\subsection{OBJECTIVE OF REPORT}

The objective of this report is to document and explain mathematical supplemental formulations for the Multimedia Environmental Pollutant Assessment System (MEPAS). MEPAS was developed as an assessment methodology to allow prioritization of all identified hazardous and radioactive releases from DOE sites according to potential health impacts. This methodology was designed to make optimal use of available information and to provide a relative assessment of the health effects resulting from possible releases.

Releases of chemical, radioactive, or mixed wastes into the environment can occur through a number of pathways. After contaminants are released into the environment, they may undergo complex processes of transport, 
degradation/decay, transformation, biological uptake, and intermedia transfer between atmospheric, overtand, subsurface (groundwater), and surface water environments.

Within MEPAS, computer-based models are used to simulate the various environmental transport pathways and routes of human exposure. Employing mathematical codes to describe specific site and constituent characteristics minimizes the subjectivity of the assessment. However, to address all of the types of environmental release conditions that exist at the early stages of problem investigation the MEPAS assessment must be composed of computer codes that are not overly complex and/or based on unreasonably onerous data requirements. As a result, screening-level codes best fit the required level of detail.

MEPAS is composed of computer codes that are empirically, analytically, and numerically integrated analytical solution based. The contaminant transport and exposure components simulate contaminant migration (i.e., movement of the contaminant in the environment) and fate (i.e., form and location of the contaminant in the environment) through various environmental media and exposure, as well as health effects associated with exposures to the surrounding populations.

The MEPAS formulations were developed to provide a realistic simulation of environmental transport and exposure. A typical MEPAS analysis will encompass a number of engineering and scientific disciplines--each with its own measure of conservatism and realism. The approach taken in the development of MEPAS is to adopt the current practices for making assessments from each appropriate discipline.

\subsection{APPLICATION LIMITATIONS}

No modeling methodology can be expected to be applicable to all situations. MEPAS is no exception to this rule. The methodology described in this document is designed for use as a risk-based ranking/screening tool. Only in situations in which sufficient data are available to reasonably define the potential environmental concentrations can MEPAS be used to estimate magnitudes of potential human health impacts. 
Limitations occur in problem definition, data input values, and applicability of specific model components. Component limitations are discussed in whelan et al. (1987) and in this volume. Independent evaluations of MEPAS' strengths and weaknesses have been conducted by EPA (1988b) and Morris and Meinhold (1988). Each application will require an assessment of the limitations specific to that application. For example, modeling caveats specific to the Environmental Survey application of MEPAS were listed in DOE 1988.

Although the time series of the exposures are considered as part of this evaluation, the effects of acute exposures are not currently addressed within MEPAS. This implementation of MEPAS is designed to provide a ranking of environmental problems based on projected human-health impacts from long-term exposures.

Applications of MEPAS should be limited to initial screening and comparative rankings of environmental problems. The simplified approaches used in MEPAS components were selected as appropriate for such analyses. Each component of MEPAS has limitations related to the use of simplified approaches as discussed in whelan (1987) and in this document. For studying the details of a problem at a site, a site-specific approach will normally be required.

Detailed mass budgets are computed for each transport scenario, although by design MEPAS does not allocate mass between transport scenarios. This approach is taken 1) to allow for evaluation of multiple transport scenarios in the same media where mass depletion between scenarios is inappropriate (e.g., groundwater transport to a well and groundwater transport linked to surface water transport), and 2) to avoid having one transport scenario incorrectly depleting the mass potentially available for a transport scenario in a different media. An example of the latter would be an air emission computation based on leakage of a clay cap that could incorrectly eliminate the source term for significant groundwater contamination.

All computer codes, no matter how complex, represent simplifications of real-world conditions. Complex codes are usually developed to address detailed mechanistic phenomena, hence, a large number of input parameters are required. Simplified codes handle less detailed phenomena of real-world 
conditions by combining many of these aspects into fewer parameters; therefore, it is difficult to ensure the absolute accuracy of results at all sites under all conditions.

The uncertainties in the MEPAS outputs need to be understood. The U.S. Environmental Protection Agency (EPA) (1988a) provides an introductory discussion of the uncertainty connected with exposure assessment processes. Input uncertainty, modeling uncertainty, and scenario uncertainty are discussed along with approaches for dealing with uncertainty associated with exposure assessment uncertainty. In addition, uncertainties related to the human health response to these exposures need to be addressed.

The degrees of uncertainty will vary with the MEPAS component used, how well these components simulate the site conditions, and the accuracy of inputs. Uncertainty will need to be addressed for each application. Variations occur in the degree of characterization of the environmental problems; applications may vary from being well characterized to having little sitespecific information. The level of uncertainty will generally increase as similarity in sites being compared decreases. The least uncertainty in the sorting of problems can be expected for comparisons of similar problems and constituents at a single site. Comparisons of different types of problems, types of constituents, and/or sites can be expected to increase the uncertainty in the comparisons.

As a result, there is no simple method of quantifying the absolute uncertainty for MEPAS applications associated with the sorting of sites into those that are potentially most hazardous relative to other sites. Given inherent uncertainties in all applications, MEPAS is expected to have at least an order of magnitude of uncertainty in performing most sorting operations.

\subsection{STRUCTURE OF THE REPORT}

This document is a supplement to, and an update of, the mathematical formulation of RAPS, as documented by whelan et al. (1987). Only those formulations associated with enhanced features to the methodology (hence, MEPAS) are documented here. 
Chapter 2.0 provides a review of the original RAPS framework which is also the framework of MEPAS. To emphasize the connection between RAPS and MEPAS, the framework is referred to as the RAPS/MEPAS framework in this chapter. The subsequent chapters provide details on the enhanced RAPS, or MEPAS, which is referred to as MEPAS.

A description of the data management component of MEPAS as implemented on a personal computer is given in Section 3.0. The data management component, the MEPAS shell, was developed to automate problem definition, data entry, error checking, and model execution operations. This shell also provides products that help with data collection, review, and documentation.

Sections $4.0,5.0,6.0$, and 7.0 address the enhancements in the groundwater, surface water, atmospheric, and exposure components, respectively. These enhancements include the following:

- steady-state groundwater component

- wetlands environment

- complex-terrain model for the atmospheric component

- algorithms to address mass-conservation within waterborne, airborne, and exposure components

- back-calculating components and techniques for site-specific calibrations using measured environmental constituent concentrations

- use of measured contaminant concentrations in the surface water, groundwater, and atmospheric pathways directly in health impact analysis (no transport modeling required)

- new exposure pathway components

- additional health impact output products

- new algorithms to enhance the efficiency and accuracy of the methodology.

The appendix contains a listing of errata for the original RAPS formulation document (Whelan et al. 1987). This listing is provided as a supplement to the RAPS framework definition. Note that most of these items have been corrected in recent printings of this document; this listing is provided for users with uncorrected versions. 


\subsection{REFERENCES}

Morris, S. C., and A. F. Meinhold. 1988. Report of Technical Support for the Hazardous Waste Remedial Action Program on Health and Environmental Risks of Inactive Hazardous Waste Sites. BNL-42339, Brookhaven National Laboratory, Long Island, New York.

U.S. Department of Energy. 1988. Environmental Survey Preliminary Summary Report of the defense Production Facilities. DOE/EH-0072, U.S. Department of Energy, Environment, Safety and Health, Office of Environmental Audit, Washington, D.C.

U.S. Environmental Protection Agency. 1988a. Superfund Exposure Assessment Manual. OSWER Directive 9285.5-1, Office of Remedial Response, Office of Sol id Waste and Emergency Response, U.S. Environmental Protection Agency, Washington, D.C.

U.S. Environmental Protection Agency. 1988b. Analysis of Alternatives to the Superfund Hazard Ranking System. Prepared by Industrial Economics, Incorporated, Cambridge, Massachusetts.

Whelan, G., D. L. Strenge, J. G. Droppo, Jr., B. L. Steelman, and J. W. Buck. 1987. The Remedial Action Priority System (RAPS): Mathematical Formulations. D0E/RL/87-09, PNL-6200, Pacific Northwest Laboratory, Richland, Washington. 


\subsection{REVIEW OF RAPS/MEPAS FRAMEWORK}

MEPAS is an enhancement of the Remedial Action Priority System (RAPS). Both the MEPAS and RAPS methodologies address contaminant release, migration, fate, exposure, and risk through and among four major environmental transport pathways (i.e., groundwater, overland, surface water, and atmospheric). These four transport and exposure components are illustrated in Figure 2.1, the RAPS/MEPAS framework. The mathematical formulations underlying RAPS are included in whelan et al. (1987). This section provides a brief review of the original structure of RAPS, which forms the framework for MEPAS, while providing an overview of the MEPAS approach.

For contaminants that decay, the parent contaminants are initially treated as conservative substances (i.e., no decay products or degradation). Upon reaching the environmental receptor, radiological decay is corrected in a separate calculation, and the code subsequently computes the temporal distribution of each decay product. The Bateman equation is then used to calculate the concentrations of all important decay products in the chain (Bateman 1910, as reported by Codell et al. 1982). The approach for analyzing each of the pathways considered in RAPS/MEPAS is briefly discussed below.

\subsection{GROUNDWATER TRANSPORT PATHWAY}

The MEPAS groundwater pathway component simulates the transport and dispersion in the environment. The MEPAS implementation allows the definition of the release rate (source term) into the groundwater by several methods. The user may input the release rate, or have the model compute the release rate. Surface and subsurface (including direct groundwater injection) inputs of release rates are allowed.

The definition of the leachate, or the water that carries the contaminants through the subsurface environment, is a critical part of the groundwater transport component. The quantity of leachate likely to be generated during the operational lifetime of a facility, and beyond, is a major factor controlling the degree to which a site will require analysis. The site leachate quantity is controlled by local meteorologic, geologic, and 


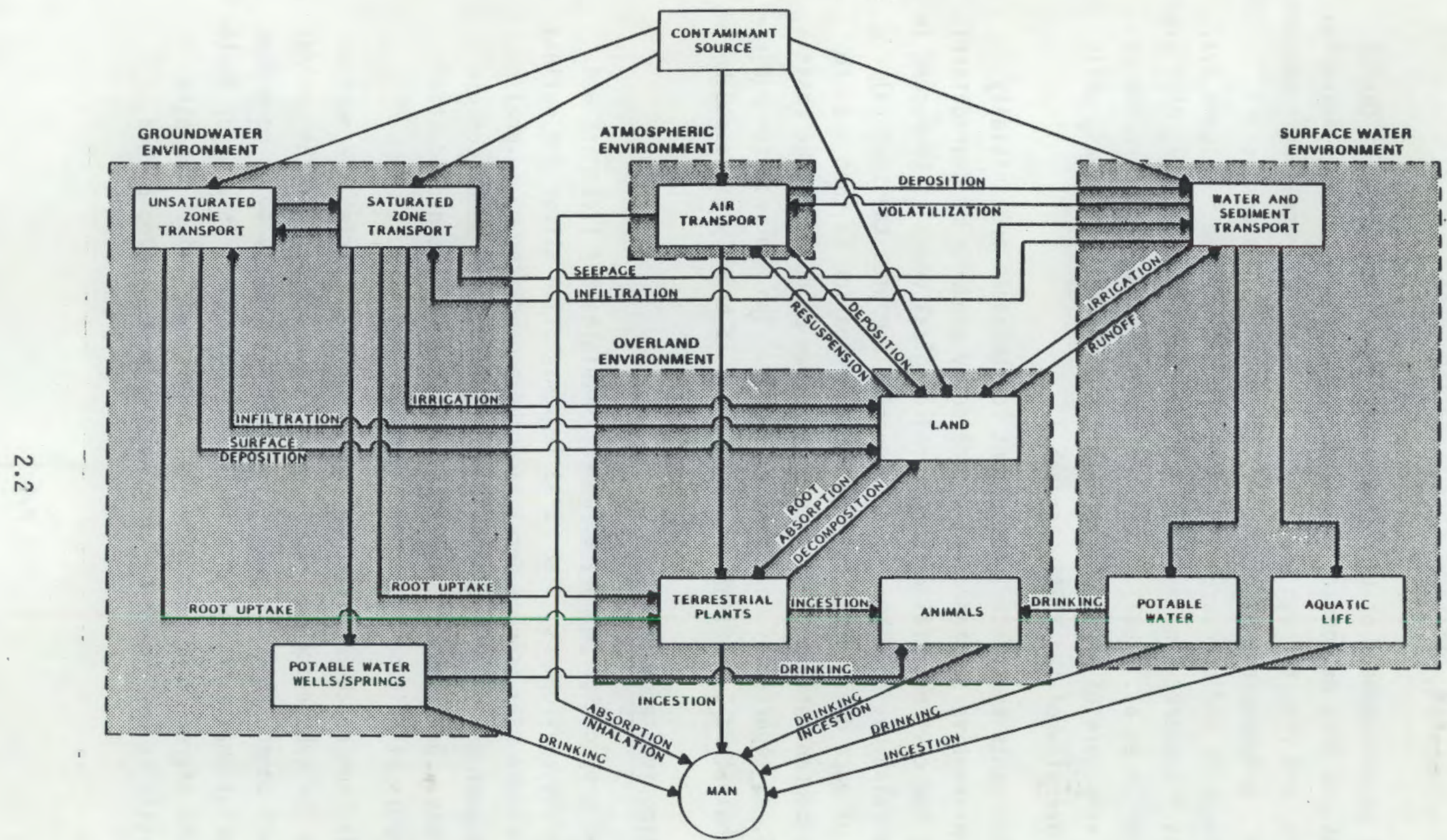

FIGURE 2.1. Schematic Diagram Illustrating the Interactions Between the Various Contaminant Transporting Media and How the Contaminants Affect Humans Through Their Environment (After Whelan et al. 1983) 
hydrologic conditions and the design and operation of the facility. Given the limited availability of literature data on leachate quantities generated by landfills, available estimation techniques are used to quantify the leachate.

A modified method of the one proposed by Thornthwaite and Mather (1955, 1957), fenn et al. (1975), and Dass et al. (1977) is used for computing leachate quantities from landfills. The methodology is based on a waterbudget analysis; it estimates the quantity of leachate produced at a given landfill site and involves a water-balance calculation, using monthly estimates of precipitation, potential evapotranspiration, temperature, and runoff. The principal source of moisture is precipitation (rainfall and snowfall) over the landfill site. Of the precipitation that falls on a landfill site, a portion runs off, via the overland flow pathway, some is lost to evapotranspiration, and the remainder percolates through the landfill. Water that percolates through the landfill eventually exits as leachate. Simpler methods have been proposed (e.g., Knight et al. 1980); however, these methods are not nearly as precise. More complex methods also have been proposed and developed (e.g., ICF 1984; Schroeder et al. 1984), but their complexity precludes their use in a preliminary ranking system scheme. A review of the mathematical algorithms that describe the technique for computing leachate quantities from landfills is provided by whelan et al. (1987).

Contaminants exiting the bottom of a landfill migrate through a partially saturated or saturated groundwater zone. In the partially saturated zone, the model assumes that flow is in a vertical direction. The RAPS/MEPAS methodology uses a one-dimensional, unsteady, semianalytical code to simulate contaminant leaching and movement through the partially saturated zone. The solution algorithm to the advective-dispersive equation is based on homogeneous and isotropic soil parameters (see Van Genuchten and Alves 1982; Donigian et al. 1983). The moisture content is assumed to fluctuate between field capacity and saturation. The partially saturated soil beneath the release site is assumed to be at a unit potential hydraulic gradient. This assumption influences the estimation of leachate movement through the partially saturated zone. If the infiltration rate (leach rate) from the release site is less than the soil transmission rate (i.e., hydraulic 
conductivity at saturation), the leachate moves through the soil at the infiltration rate (see the general equation for liquid flow in the partially saturated zone in Hanks and Ashcroft 1980; Hillel 1980). For an infiltration rate equal to or greater than the transmission rate, the leaching water is assumed to move at the transmission rate.

The predominant movenent of the leachate in the saturated zone is in the direction of the groundwater flow. A three-dimensional advective-dispersive equation describes the migrating plume as it disperses and attenuates through the saturated aquifer. Advection represents the transport of solute caused by the mass motion of water, while dispersion represents solute transport by unaccounted variations in the fluid velocity and molecular motion. Dispersion is considered in the longitudinal, lateral, and vertical directions.

Soil properties are assumed to be homogeneous, and the flow is assumed steady and only in the longitudinal direction.

Solutions for the advective-dispersive equations for the partially saturated and saturated zones have been formulated in terms of an instantaneous contaminant release (i.e., a pulse release). The RAPS/MEPAS methodology generalizes these solutions for application to arbitrary time-varying releases.

The RAPS/MEPAS groundwater component computes contaminant levels at wells and at the edge of streams, and calculates solute fluxes from the groundwater environment to the surface water environment. The solution algorithms are based on Green's functions and have been reported by several researchers (e.g., Yeh 1981; Codell et al. 1982; Van Genuchten and Alves 1982). Figure 2.1 illustrates the potential interactions between the groundwater pathway and the other environmental transport pathways addressed by the RAPS/MEPAS methodology. A review of the mathematical algorithms describing the groundwater pathway was presented by whelan et al. (1987).

\subsection{SURFACE WATER PATHWAY}

Nontidal rivers, estuaries, freshwater and saltwater open water bodies, open coasts, wetlands, etc., represent many of the surface water components that could be included in the RAPS/MEPAS methodology. Of the many surface water components, RAPS/MEPAS is currently capable of addressing nontidal 
rivers and wetlands. Freshwater open water bodies (e.g., lakes, reservoirs, and impoundments) have been integrated into the main body of the methodology. Nontidal rivers refer to freshwater bodies with unidirectional flow in definable channels. Because RAPS/MEPAS is compositely coupled, other surface water pathways can be added when necessary.

By assuming a continuous release, contaminant releases to the surface water environment in RAPS/MEPAS are relatively long term. Because transient solutions for contaminant migration and fate calculations are most applicable for batch and infrequent releases over relatively short periods of time (Codell et al. 1982), steady-state solutions to the advective-dispersive equation are most applicable. The three-dimensional, steady-state, vertically integrated mass balance equation for contaminant transport in a riverine environment (where longitudinal advection dominates longitudinal dispersion) forms the basis for the river water solution algorithm (Codell et al. 1982). Contaminants released into a river are transported through the system by the processes of advection and dispersion. Dispersion is considered in the longitudinal and lateral directions. A description of contaminant movement is based on steady, unidirectional flow in a straight, rectangular channel.

The freshwater open water body component addresses a wide variety of aquatic environments ranging from small ponds to natural lakes and man-made impoundments. No single simple model can adequately address the range of mixing processes and various contaminant sources and risks found in the various types of open water body environments. In RAPS/MEPAS, environmental complexity is handled using a suite of relatively simple algorithms that involve different boundary conditions and idealized solutions optimized for specific process assumptions. The selection process provides criteria to objectively evaluate available data and potential transport pathways. The general advective-dispersive equation with steady, unidirectional flow is used to describe contaminant transport in the open water body environment. The spatial effects of mixing processes for determining contaminant concentrations are utilized using several different open water body types, including 1) well-mixed case, 2) two-layer, horizontally well-mixed case, and 
3) vertically well-mixed case with horizontal gradients in one dimension (i.e., well suited to long, narrow lakes and run-of-the-river impoundments). Time-dependent sources are modeled as a series of instantaneous releases into the environment. An open-water-body component has been developed, but the integration of this component was not complete at the time of preparation of this documentation. Figure 2.1 illustrates the potential interactions between the surface water pathway and the other environmental transport pathways addressed in RAPS/MEPAS. A review of the mathematical algorithms describing nontidal rivers is provided by whelan et al. (1987) and Knight and Brown (1987).

Wetlands are transitional areas between uplands and aquatic habitats. They are characterized by plant communities that are adapted to life in saturated soil conditions. Wetlands have been classified by the U.S. Fish and Wildlife Service (Cowardin et al. 1979) based on life form, water regime, substrate type, and water chemistry. Although the original RAPS formulations did not include wetlands, the MEPAS does include wetlands (see Section 5.0).

\subsection{OVERLAND TRANSPORT PATHWAY}

The overland transport or flow is that portion of precipitation and snowmelt that ultimately appears as flowing water on the ground surface. Overland transport occurs primarily because of excess water after evapotranspiration and infiltration. The overland transport pathway component in MEPAS has two main functions.

The first function is to use the results from the overland transport in computing the leachate quantities. The overland component estimates the long-term, average monthly runoff volumes for use in the water-balance calculations for estimating leachate quantities that percolate into the groundwater. These calculations are based on monthly averaged local climatology data (precipitation, temperature, wind speed, cloudiness, and humidity).

The second function of the overland transport pathway component is to estimate the migration and fate of contaminated water and sediment that moves across contaminated surface soil (e.g., exposed landfills and deposition from atmospheric releases). The overland transport of contaminated water is based 
on monthly average precipitation event and snowmelt, and the soil type characteristics. The sediment (soil loss) overland transport is based on site characteristics, such as slope of land, vegetation cover, land use, and soil erodibility factors and intense precipitation events from thunderstorms.

The water movement portion of the overland transport pathway is based on estimation techniques of the Department of Agriculture's Soil Conservation Service (SCS) curve number, as presented by SCS (1972, 1982), Kent (1973), USBR (1977), and Haun and Barfield (1978). The SCS curve number technique incorporates soil classification, soil cover, land use, hydrologic conditions for infiltration, location of site, antecedent moisture conditions, and potential maximum moisture retention. The driving mechanism is based on overland water flow estimated with local monthly precipitation and temperature data; the results are annual average contaminated water flow from the site.

The overland transport of contaminated sediment is estimated using the Universal Soil Loss Equation (USLE). The USLE is empirically derived from 10,000 plot-years of erosion field research data. The USLE considers 1) the erosive force and intensity of precipitation and runoff in a normal year, 2) the susceptibility of the soil particles to detach and be transported by precipitation and runoff, 3) the combined effects of slope length and gradient, and 4) the soil loss from lands under varying vegetation conditions (Goldman et al. 1986). The results from the sediment transport portion of the overland transport pathway is an average-annual contaminated sediment loss from the site.

The overland transport component does not link directly with the exposure component of the MEPAS methodology but links with the surface water transport component, which is then linked to the exposure component.

\subsection{ATMOSPHERIC PATHWAY}

Complex phenomena are associated with the migration and fate of contaminants released to the atmosphere (Cupitt 1980). The atmospheric component of the RAPS/MEPAS methodology considers release mechanisms and characteristics, dilution and transport, washout by cloud droplets and precipitation, and deposition on the underlying surface cover. The atmospheric pathway model 
provides a realistic computation of these processes within the constraints of using limited, readily available site information. The interaction and coupling between the atmospheric pathway and exposure assessment components of RAPS/MEPAS are illustrated in Figure 2.1. A review of the mathematical algorithms describing the atmospheric pathway is provided by whelan et al. (1987).

The prediction of contaminant movement through the atmospheric pathway involves using codes that address atmospheric suspension/emission, transport, diffusion, and deposition. Input to the codes includes site-specific climatologic information such as wind direction, wind speed, and precipitation. Output from the models consists of average air and surface contaminant levels that are then used as input to the exposure assessment component. Contaminant transport is assumed to occur sufficiently fast that chemical transformations can be neglected.

The atmospheric pathway is modeled in a manner that maximizes the validity of comparisons between sites. The suspension/emission rates are based mainly on empirical relationships using site characteristics. The atmospheric transport and dispersion are computed in terms of sector-averaged values using Gaussian dispersion principles similar to that proposed by Busse and Zimmerman (1973) and examined by Culkowski (1984). Deposition is computed as the sum of outputs from empirical wet and dry deposition algorithms.

The relative importance of the atmospheric pathway between different sites is controlled by a combination of geographic and climatic influences. Distances, directions, winds, and atmospheric stability are controlling parameters. The dispersion relationships used in the atmospheric component depend on local site characteristics. Because the dispersion is a strong function of downind distance from the source, the physical distances between the contaminant sites and population centers are of prime importance. The relative proximity of sites and population centers is important in terms of the local frequencies of wind directions, particularly in areas with topographic channeling of winds. The relative rates of atmospheric dilution between the sites are mainly a function of local wind speeds and atmospheric stability parameters. 
The atmospheric pathway component computes contaminant levels as a function of the direction and distance that coincides with population centers surrounding the site. Inhalation represents the major route of exposure to contaminants via the atmospheric pathway. RAPS/MEPAS also considers the ingestion route of exposure through the food chain, from wet and dry deposition on vegetation, and subsequent ingestion of contaminated food materials derived from the soils. In addition, external dose can be addressed, though its effects are usually insignificant as compared to the inhalation exposure route.

\subsection{EXPOSURE ASSESSMENT COMPONENT}

The RAPS/MEPAS methodology is based on evaluation of long-term average environmental exposures resulting from the release of contaminants. The analyses are performed assuming no changes in current land use, groundwater, or surface water practices (such as remedial actions or population changes). The potential health exposure associated with the migration and fate of contaminants from a release site may continue for hundreds to thousands of years, particularly for the groundwater transport pathway. The exposure analys is component of RAPS/MEPAS is currently based on 70-year increments (i.e., approximately one human life span), with average concentrations being defined for each one.

The RAPS/MEPAS methodology makes an interpretation of the exposure values in terms of human health impacts. Potential health impacts for individuals and the total population exposed are estimated for all exposure pathways defined for the analysis. Health impact outputs are provided both with and without time discounting.

The individual health hazard index is referred to as the maximum individual index (MII), and the population health hazard index is referred to as the HPI. The health index values are based on one of three contaminant types under consideration: 1) radionuclides, 2) carcinogenic chemicals, and 3) noncarcinogenic chemicals. The health indices calculated for each contaminant type must be comparable. The RAPS/MEPAS analys is is based on a 
risk Tevel of 10-6(a) as the point of comparability between radiological exposure and exposure to chemical carcinogens. For noncarcinogenic chemicals the point of comparison is exposure at the reference dose level; exposure at the reference dose level is assumed to be equivalent to exposure to radiation and carcinogens at a risk level of 10-6.

Resulting contaminant concentrations from each of the four transport pathways are used in the exposure assessment component for each important waste site contaminant. The exposure assessment component considers potential exposure of the surrounding population through the following exposure routes: 1) external dermal contact to chemicals; 2) external dose from radiation; 3) inhalation of airborne contaminants; and 4) ingestion of contaminated drinking water, soil, crops, animali products, and aquatic foods. First, the important exposure routes and populations at risk are defined. Then, based on the air, water, and soil contaminant levels provided by the transport pathway analyses, an estimate is made of the average daily human exposure to each contaminant. Estimation of the daity exposure is based on simple multiplicative models describing the transfer of pollutants from air, water, or soil to humans.

One key feature of the exposure assessment component is the estimation of the average exposure. The exposure modes included in RAPS/MEPAS are as follows:

- drinking water ingestion - for groundwater, overland, and surface water transport pathways. Factors may be applied to the water concentration to account for purification of the water in a treatment plant.

- aquatic food ingestion (fish and invertebrates) - for overland, surface water, and groundwater transport pathways. Average daily intake is estimated using bioconcentration factors and average daily ingestion rates for aquatic foods.

- crops - for all transport pathways. Crops may be contaminated from irrigation with contaminated water or by direct deposition onto

(a) EPA (1986) noted that guidance on response actions under CERCLA "requires that the analys is of cleanup alternatives include options in the $10^{-4}$ to $10^{-7}$ risk range with at least one alternative utilizing a $10^{-6}$ risk level ..." (EPA 1985a). A typical option of choice is a 10-6 risk level. 
plants and soil. Two crop types are considered: leafy vegetables with the edible portion subject to direct deposition, and other crops such as root and pod vegetables and fruit. Crop concentrations are estimated using soil-to-plant transfer factors and air-to-edible-plant transfer factors. Average daily intake is estimated using average daily ingestion rates for vegetables and leafy vegetables.

- animal products - for all transport pathways. Contaminated animal products result from animal ingestion of contaminated water and contaminated feed. Feed contamination may occur from direct deposition onto feed crops or pasture from air or through use of contaminated irrigation water. Use of contaminated animal drinking water is only considered for the three water transport pathways (i.e., overland, groundwater, and surface water). The concentration of contaminant in animal meat and milk is estimated using animalingestion-to-animal-product transfer factors. Average daily intake for exposed individuals is estimated using average daily ingestion rates for meat and milk.

- water immersion (domestic bathing and swimming) - for groundwater and surface water transport pathways. Dernal contact (for chemicals) and radiation exposure are included for domestic bathing for both water transport pathways. Exposure from swimming in contaminated water is also considered for the surface water pathway. For chemicals, an equivalent daily intake amount is estimated based on dernal contact time and adsorption characteristics of the chemical pollutant. For radiation exposures, the dose from immersion in water is estimated using dose conversion factors. A contribution to the radiation dose may also be included for recreational boating and shoreline fishing.

- soil ingestion - for the atmospheric transport pathway. Contaminated soil is assumed to be ingested each day with the ingestion rate based on a lifetime average.

- inhalation - for the atmospheric transport pathway. The daily average intake is estimated using an average inhalation rate for the exposed population.

The exposure assessment portions of RAPS/MEPAS are based on models recommended by the U.S. Nuclear Regulatory Commission (NRC) (1977) that are similar to models used by other organizations involved in radiological exposure assessments. These models use current environmental conditions at a site that are assumed to remain unchanged indefinitely into the future. While changes are likely, they are also difficult to predict. Rather than make estimates of future changes (which would be very uncertain), the assumption of no change is made as a reasonable approach for determining 
relative health hazards between sites. The human health impact assessment is based on exposures over a human lifetime, taken to be 70 years. During the 70-year period human intake and exposure patterns are assumed to be constant. This is consistent with use of EPA lifetime cancer potency factors and reference doses, and with the radiation dose evaluations (70-year exposure period).

The interaction and coupling between the exposure assessment component and the transport pathways of the RAPS/MEPAS methodology are illustrated in Figure 2.1. A review of the mathematical algorithms describing the exposure and health effects assessments is provided by whelan et al. (1987).

\subsection{SUMMARY}

The RAPS/MEPAS methodology prioritizes potential environmental releases of hazardous materials in a scientific and objective manner. RAPS/MEPAS bases its approach on site and constituent (i.e., chemical and radionuclide) characteristics. RAPS/MEPAS makes use of available input data. It considers four major transport pathways for contaminant migration: groundwater, overland, surface water, and atmospheric. Each pathway is described by standard mathematical algorithms that provide a variety of output products describing environmental concentrations and potential health impacts. Ranking using MEPAS is based on a dimensionless parameter, the HPI, which reflects population-based potential health impacts. MEPAS also provides release, transport, and exposure alternative outputs for interpretation of these rankings. These potential impacts, based on HPIs or other MEPAS outputs, provide an objective basis for ranking environmental problems.

\subsection{REFERENCES}

Bateman, H. 1910. "The Solution of a System of Differential Equations Occurring in the Theory of Radioactive Transformations." Proc. Cambridge Phi]. Soc. 16:423-427.

Busse, A. D., and J. Zimmerman. 1973. User's Guide for the Climatological Dispersion Model. EPA-RA-73-024, U.S. Environmental Protection Agency, Research Triangle Park, North Carolina. 
Codell, R. B., K. T. Key, and G. Whelan. 1982. A Collection of Mathematical Models for Dispersion in Surface Water and Ground Water. NUREG-0868, U.S. Nuclear Regulatory Commission, Office of Nuclear Reactor Regulation, Washington, D.C.

Cowardin, L. M., V. Carter, F. L. Golet, and E. T. LaRoe, 1979.

Classification of Wetlands and Deepwater Habitats of the United States.

FWS/OBS-79/31, U.S. Fish and Wildlife Service, Washington, D.C.

Culkowski, W. M. 1984. An Initial Review of Several Meteorological Models Suitable for Low-Level Waste Disposal Facilities. NUREG/CR-3838, U.S. Nuclear Regulatory Comnission, Washington, D.C.

Cupitt, L. T. 1980. Fate of Toxic and Hazardous Materials in the Air Environment. EPA-600/3-80-084, U.S. Environmental Protection Agency, Research Triangle Park, North Carolina.

Dass, P., G. R. Tamke, and C. M. Stoffel. 1977. "Leachate Production at Sanitary Landfills." J. Environ. Eng. Division. Proc. Am. Soc. Civil Eng. 103:EE6.

Donigian, A. S., Jr., T. Y. R. Lo, and E. W. Shanahan. 1983. Rapid Assessment of Potential Groundwater Contamination Under Emergency Response Conditions. Prepared by Anderson-Nichols and Co., Inc., for the U.S. Environmental Protection Agency, Athens, Georgia.

Eagleson, P. S. 1970. Dynamic Hydrology. McGraw-Hill, New York.

EPA (see U.S. Environmental Protection Agency).

Fenn, D. G., K. J. Hanley, and T. V. DeGeare. 1975. Use of the Water Balance Method for Predicting Leachate Generation from Solid Waste Disposal Sites. SW-168, U.S. Environmental Protection Agency, Washington, D.C.

Hanks, R. J., and L. Ashcroft. 1980. Applied Soil Physics. SpringerVerlag, New York.

Haun, C. F., and B. J. Barfield. 1978. Hydrology and Sedimentology of Surface Mined-Lands. University of Kentucky, Lexington, Kentucky.

Hillel, D. 1980. Fundamentals of Soil Physics. Academic Press, New York.

Hjelmfelt, A. T., Jr. 1976. Modeling of Soil Movement Across a Watershed. Completion Report for Project A-076-M0, University of Missouri, Missouri Water Resources Center, Columbia, Missouri.

ICF. 1984. The Risk-Cost Analys is Model: Phase III Report. Prepared by ICF Incorporated for the Office of Solid Waste, Economic Analys is Branch, U.S. Environmental Protection Agency, Washington, D.C. 
Kent, K. M. 1973. A Method for Estimating Volume and Rate of Runoff in Small Watersheds. SCS-TP-149, U.S. Department of Agriculture, Soil Conservation Service, Washington, D.C.

Knight, G., E. H. Rothfuss, and K. D. Yard, 1980. FGD Sludge Disposal Manual. 2nd ed. EPRI CS-1515, Electric Power Research Institute, Palo Alto, California.

Knight, R., and S. M. Brown. 1987. Wetland Pathway Model: Documentation Report and User's Manual. Prepared by CH2M Hill for Pacific Northwest Laboratory, Richland, Washington.

Schroeder, P. R., A. C. Gibson, and M. D. Smolen. 1984. The Hydrologic Evaluation of Landfill Performance (HELP) Model. U.S. Environmental Protection Agency, Cincinnati, Ohio.

Soil Conservation Service (SCS). 1972. "Hydrology Guide for Use in Watershed Planning." SCS National Engineering Handbook, Section 4, Hydrology, Supplement A. U.S. Department of Agriculture, Soil Conservation Service, Washington, D.C.

Soit Conservation Service (SCS). 1982. SCS National Engineering Handbook, Section 4, Hydrology, 1982 Update. U.S. Department of Agriculture, Soil Conservation Service, Washington, D.C.

Thornthwaite, C. W., and J. R. Mather. 1955. "The Water Balance." In Publications in Climatology, Vol. VIII, No. 1. Drexel Institute of Technology, Laboratory of Climatology, Centerton, New Jersey.

Thornthwaite, C. W., and J. R. Mather. 1957. "Instructions and Tables for Computing Potential Evapotranspiration and the Water Balance." In Publications in Climatology, Vol. $x$, No. 3. Drexel Institute of Technology, Laboratory of Climatology, Centerton, New Jersey.

U.S. Department of the Interior, Bureau of Reclamation (USBR). 1977. Design of Small Dams. Government Printing Office, Washington, D.C.

U.S. Environmental Protection Agency. 1985. Alternative Concentration Limit Guidance Based on Section 264.94b Criteria. Part I. Information Required in ACL Demonstrations. U.S. Environmental Protection Agency, Washington, D.C. (Oraft).

U.S. Environmental Protection Agency. 1986. "Hazardous Waste Management Land Disposal Restrictions; Proposed Rule," Part III. U.S. Environmental Protection Agency, 40 CFR (260) Fed. Reg. 1601-1766 (January 14, 1986).

U.S. Environmental Protection Agency. 1988. Superfund Exposure Assessment Manual. OSWER Directive 9285.5-1, Office of Remedial Response, Office of Solid Waste and Emergency Response, U.S. Environmental Protection Agency. 
U.S. Nuclear Regulatory Commission. 1977. Calculation of Annual Doses to Man from Routine Releases of Reactor Effluent for the Purpose of Evaluating Compliance with 10 CRF Part 50, Appendix I. Regulatory Guide 1.109, U.S. Nuclear Regulatory Commission, Washington, D.C.

Van Genuchten, M. T., and W. J. Alves. 1982. Analytical Solutions of the One-Dimensional Convective-Dispersive Solute Transport Equation. Technical Bulletin No. 1661, U.S. Department of Agriculture, Washington, D.C.

Whelan, G. 1980. Distributed Model for Sediment Yield. Master's Thesis, Iowa Institute of Hydraulic Research, University of Iowa, Iowa City, Iowa.

Whelan, G., F. L. Thompson, and S. B. Yabusaki. 1983. Multimedia Contaminant Environment Exposure Assessment Methodology as Applied to Los Alamos, New Mexico. PNL-4546, Pacific Northwest Laboratory, Richland, Washington.

Whelan, G., D. L. Strenge, J. G. Droppo, Jr., and B. L. Steelman. 1987. Development of the Remedial Action Priority System (RAPS): Preliminary Mathematical Formulations. PNL-6200, prepared by Pacific Northwest Laboratory for the Office of Environment, Safety, and Health, U.S. Department of Energy, Washington, D.C.

Witinok, P. M. 1979. Distributed Watershed and Sedimentation Model. Master's Thesis, University of Iowa, Iowa City, Iowa.

Witinok, P. M., and G. Whelan. 1980. "Distributed Paraneter Sedimentation Model." Proc. Iowa Acad. Sci. 87(3)103-111.

Yeh, G. T. 1981. AT123D: Analytical Transient One-, Two-, and ThreeDimensional Simulation of Waste Transport in the Aquifer System. Publications No. 1439, ORNL-5602, Oak Ridge National Laboratory, Oak Ridge, Tennessee. 
• 


\subsection{INTEGRATED MEPAS METHODOLOGY}

A description of the MEPAS shell is included as part of the formulations. The MEPAS she1l is the data management component of MEPAS that integrates the operation of all of MEPAS' components (Hoopes et al. 1988).

\subsection{MEPAS STRUCTURE}

Each transport pathway addressed by MEPAS has a set of components that simulate the migration and fate of contaminants. These transport pathway codes are systematically integrated with an exposure assessment component that considers the type, time, and duration of exposure and the location and size of the population exposed. Figure 2.1 presents a simplified diagram outlining the various pathways and their interactions as considered by MEPAS.

MEPAS makes use of two types of data sources. First, the investigator inputs site and regional data. These data will be used to define the source term, transport pathway, and exposure scenarios. Second, MEPAS accesses a constituent database that contains chemical, physical, environmental, exposure, and toxicity data for each constituent. The constituent data base is documented by Strenge and Peterson (1989).

To implement MEPAS for a site, the investigator designates how the environmental concentrations for the health impact computation are to be defined. The investigator is then prompted to supply site and constituent information. The exposure route to the population is integrated into the analysis, and the transport and exposure models are run to calculate the relative human health impact to the population.

\subsection{OVERVIEW OF SHELL}

The MEPAS methodology is implemented on a desktop computer. An interactive program, referred to as the MEPAS shell, was developed to allow efficient application of MEPAS at a large number of sites. The MEPAS shell automates problem definition, data entry, documentation, and exposure computations. It allows the user interactive problem definition, data entry, and 
environmental pathway analysis. It also provides easy access and manipulation of site data and files for assessing potential health impacts from environmental releases of hazardous materials.

The implementation of the enhanced RAPS/MEPAS formulations contained in this report and Whelan et al. (1987) are designed to run as a unit without the MEPAS shell. However, the MEPAS shell greatly improves the ease and accuracy for making MEPAS applications by automating file creations, making range checks on inputs, and organizing data required for MEPAS analysis. Although the MEPAS shell is most useful for applications with a large number of cases for analysis, these quality control aspects of the shell increase its utility for assessments involving a small number of cases as well.

The MEPAS shell provides user-friendly operation of data entry, file creation, and case assessment codes. An IBM PC(a) (or 100\% compatible) with 640K RAM, a 20-Mb hard disk, and a 132-column printer are required. A math co-processor is not required, but it will greatly improve model performance. The data capture and storage programs are written in compiled dBase III Plus. The MEPAS transport and exposure models are written in FORTRAN, and intermediate linkage programs are in 'C.' Installation requires approximately $1 \mathrm{Mb}$ of disk space. This is a file-based application; all data are stored and exchanged between major components by file input/output.

Facility, Ranking Unit, and Release Unit are terms that have been implemented because of the nature of the application for which the shell was initially to be used. The terms Site and Waste Unit can be substituted wherever appropriate without changing the meaning.

Figure 3.1 depicts the main menu of the MEPAS shell. The menu options provide access to the following components:

- Constituent Library - The investigator can view the physical properties of radionuclides and chemicals used in the MEPAS model.

- Utility Routines - Various utilities allow the investigator to reindex data base files, define the printer, and set up a color monitor.

(a) IBM PC is a registered trademark of International Business Machines Corporation, Boca Raton, Florida. 


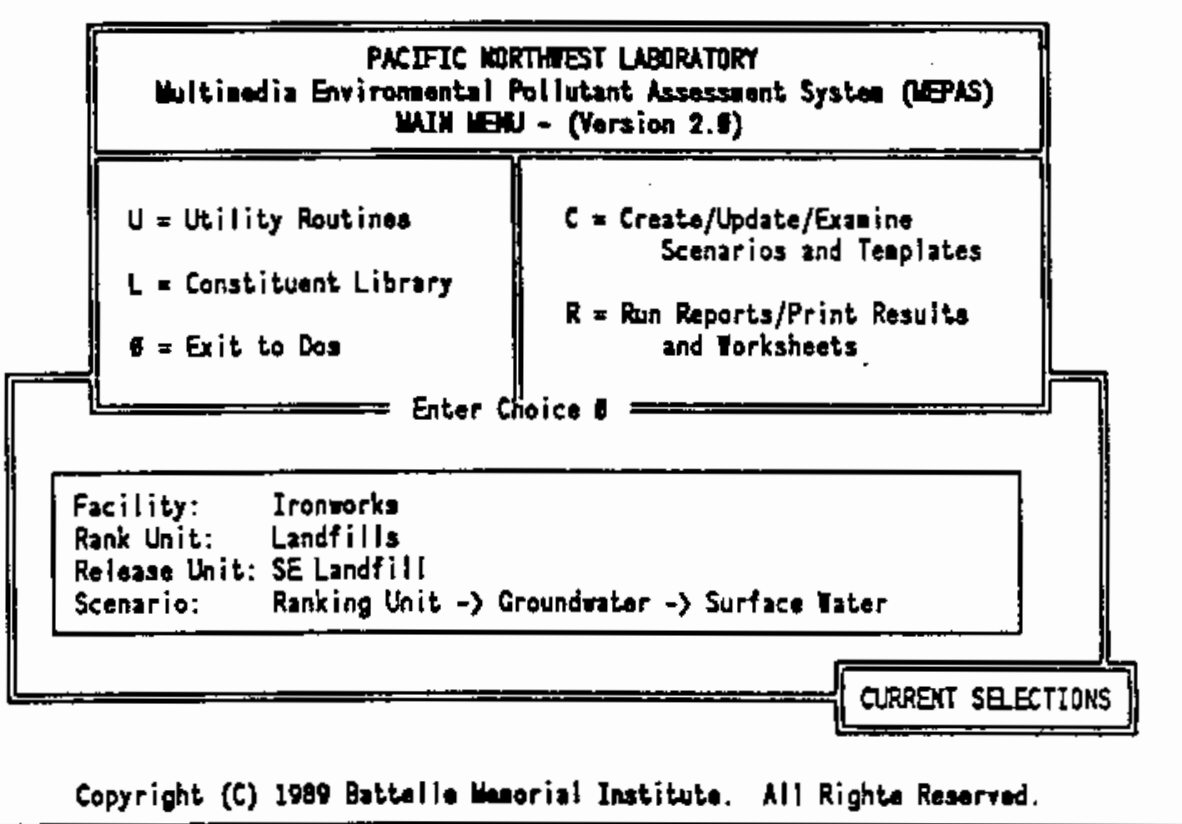

FIGURE 3.1. Main MEPAS Control Menu

- Create/Update/Examine - All data entry, edit, and review functions take place under this broad heading.

- Run/Print Reports/Worksheets - A submenu of this selection enables the investigator to specify run-time parameters, create run files, and invoke the MEPAS model. Similarly, all printing is done from this menu option, including generation of input data lists and intermediate and final reports.

For the purposes of this overview, we will describe only the Constituent Library, Create/Update/Examine, and Run/Print Reports/Worksheets components in further detail.

\subsubsection{Constituent Library}

From the main menu, the investigator has a view-only window to the constituent library. The view includes a tabular list of the properties of the constituent required by the exposure model. Properties of the constituents required by the model include 1) physical properties, such as vapor pressure, Henry's law constant, and molecular weight; 2) exposure data, such as reference dose, cancer potency factor, and bioaccumulation factor; and 3) typical 
values for site data, such as $K_{0 w}, K O C$, and $K_{d} s$. To maximize consistency in application, the investigator cannot alter the contents of this library.

\subsubsection{File Creation/Update.}

Figure 3.2 shows the structure for definition of cases for analysis by MEPAS. File creation starts with the designation of the appropriate facility. This is followed by the designation of the environmental issue to be assessed. MEPAS refers to this issue as the Ranking Unit. A facility may have one or more environmental issues (Ranking Units). The environmental issues may in turn be composed of one or more releases into the environment (Release Units). Thus, MEPAS provides for multiple Release Units within a defined environmental issue. In defining each Release Unit, up to 20 constituents may be identified for assessment.

After Facility, Ranking Unit, Release Unit, and transport and exposure pathway data input is complete, the investigator can enter site data into the shell in preparation for analysis. The required site data have been grouped logically and formatted into templates that can be selectively edited and printed as worksheets.

The investigator is provided only the specific templates required to complete the scenario data in preparation for an analysis. This template

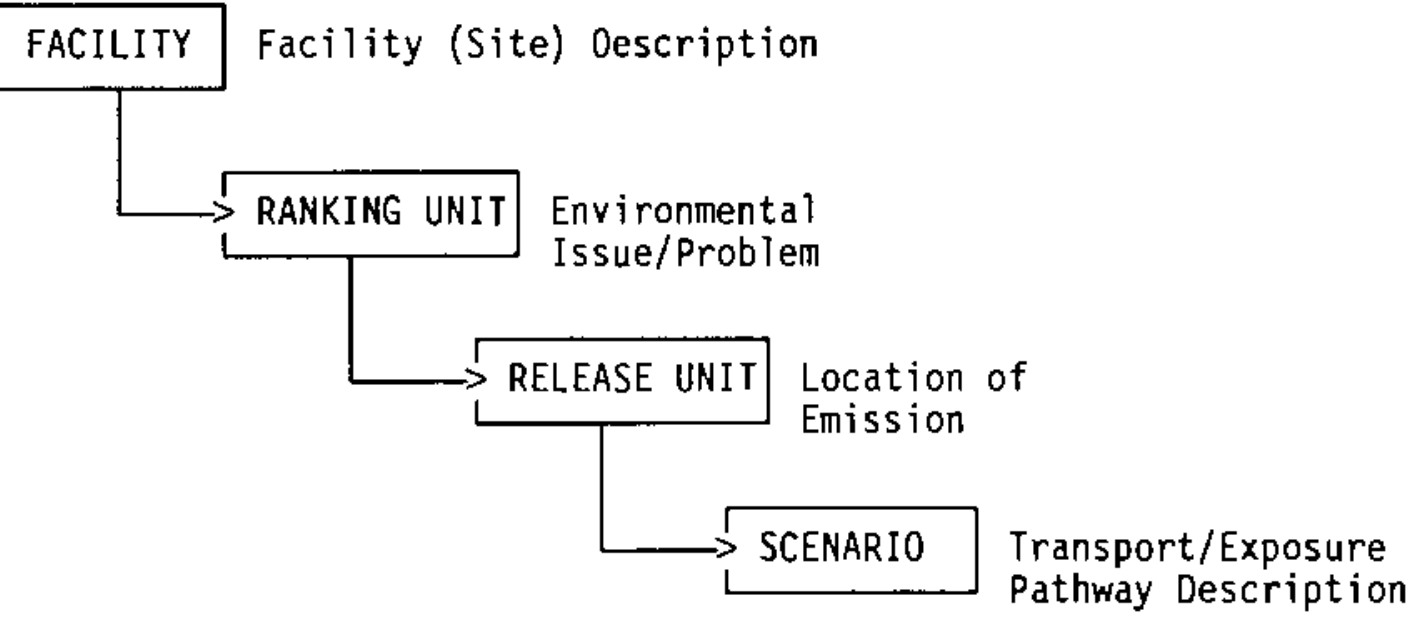

FIGURE 3.2. MEPAS Environmental Problem Configuration 
selection algorithm is an important feature of the shell as the automatic determination of the required templates saves the investigator from locating unneeded data.

All data entered into the shell must be accompanied by appropriate references. Most template data have associated optional reference numbers. In situations where data source referencing is required, a reference system is included. These references can be added, modified, and searched by reference number. Reference lists can also be printed.

An example of a data worksheet is shown in Figure 3.3. A description of each required datum is provided on a line format. The first line of the screen (entitled "2.4 - partially saturated zone" in Figure 3.3) tells the user the section number and name of this worksheet. This corresponds to the section in the guidelines documentation where these data are fully described. Each line item includes the number of the item as it appears in the guidelines, the encoded parameter name, and unit of measure. In some cases, typical values may be enclosed in brackets, []. These values are provided

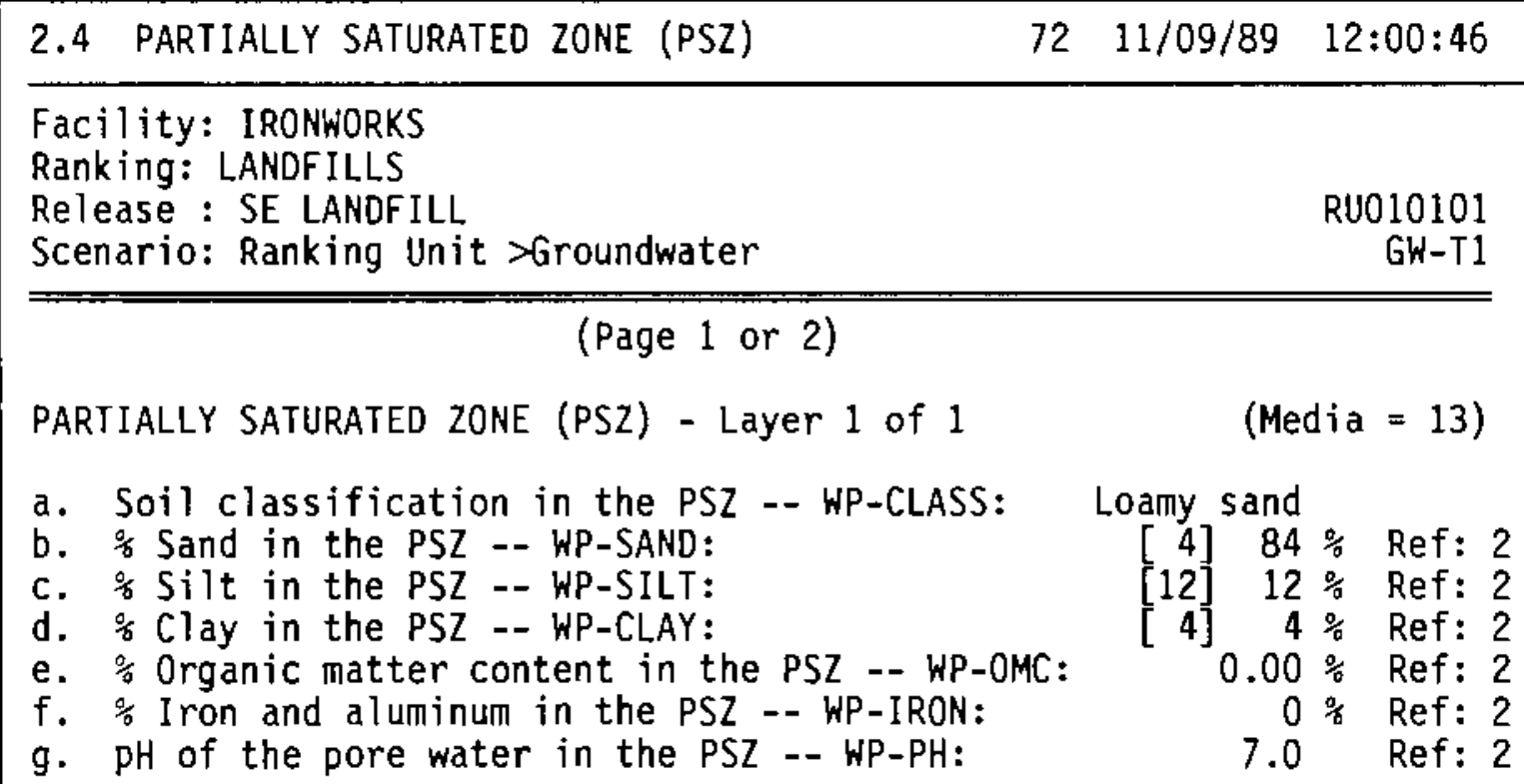

Move cursor $=\wedge X^{\wedge} Y, P G U P, P G D N . \quad$ Quit/Save - END. Abort - ESC.

FIGURE 3.3. Data Template for MEPAS User-Friendly Shell 
for informational use only. They allow the investigator to identify erroneous or nontypical input data. They also can be used as inputs if more site-specific data are not available.

An additional automatic range check is made by the MEPAS shell for entry of each input value. This range check is based on a model input range that has been defined for all input parameters. This range is a maximum credible range rather than a normal environmental range.

Other features are designed to minimize data input errors. These include allowing the investigator to copy environmental setting data (c)imatology, soil characteristics, and exposure locations) from an existing Facility or Ranking Unit (this is helpful for ranking units that are close to each other and have the same hydrogeology and atmospheric properties); and importing joint frequencies and population distribution data from external sources (this saves the investigator from having to input these large data matrices). The investigator exits a worksheet with the quit/save command, in which case the entered data is stored in the MEPAS data base.

\subsubsection{Report Preparation}

The investigator can 1) print the worksheets, 2) create data files for input to the MEPAS mode1, 3) invoke the mode1, and 4) print intermediate results from the model run.

\subsubsection{Printing the Worksheets}

After the scenario configuration is complete, required worksheets can be printed. These printed worksheets have several functions. If printed early in the cycle, they can be used to assist in compiling the data before entering it into the shell. They can be printed at any time to reflect the current state of the data bases, and when the analysis is complete, they can accompany the analysis documentation for QA/QC. The contents of the reference list can also be printed from this option.

\subsubsection{Creating Data Files and Running MEPAS}

The data set creation procedure retrieves the data required for a MEPAS analysis of the particular scenario(s) and structures the data in a format acceptable to the model. Any scenario for which all required templates are 
complete can be included in an analysis. Each run configuration is called a data set, and the investigator provides a description and file ID for each data set. All of the MEPAS model intermediate files, results, and data sets will have this user-defined ID as a file name. Any data sets already created can be selected for rerun to incorporate changed data, and new data sets can be created. The configuration of a data set can be changed as desired, but will include a Facility, Ranking Unit, and up to 10 scenarios selected by the investigator.

\subsubsection{Invoking the Model}

To run MEPAS, one or more data sets must be selected. When the selection is completed, the model will be invoked for each data set specified. As the model runs, each program name is echoed to the monitor as it is invoked, and in the major components, the progression through each scenario is echoed.

\subsubsection{Printing Results}

Result and/or important intermediate files of the MEPAS model can be printed. The investigator first may select files for printing by data set or by file type. Intermediate files can be printed. If a run is not completed normally, or the results are in question, the intermediate files should help identify the reasons for the behavior.

\subsection{REFERENCES}

Hoopes, B. L., J. W. Buck, D. L. Friedrichs, and R. J. Aiken. 1988. "The Multimedia Environmental Pollutant Assessment System (MEPAS) User-Friendly Shel1." In Proceedings of the DOE Model Conference, October 3-7, 1988, Oak Ridge, Tennessee.

Strenge, D. L., and S. R. Peterson. 1989. Chemical Databases as Applied to the U.S. Department of Energy Environmental Survey. PNL-7145, Pacific Northwest Laboratory, Richland, Washington.

Whelan, G., D. L. Strenge, J. G. Droppo, Jr., B. L. Steelman, and J. W. Buck. 1987. The Remedial Action Priority System (RAPS): Mathematical Formulations. D0E/RL/87-09, PNL-6200, Pacific Northwest Laboratory, Richland, Washington. 
. 


\subsection{ENHANCED GROUNDWATER COMPONENT}

This chapter describes enhancements to the groundwater component of the RAPS methodology, as described in whelan et al. (1987). The objectives of these enhancements are to help the methodology 1) run more efficiently, 2) increase accuracy in the results, and 3) provide the investigator with more flexibility for addressing complexities associated with assessing a hazardous waste site. This chapter is divided into eight sections. The following is a brief overview of each:

- Integration Limits - This section describes a new procedure for estimating the limits associated with the numerical integration of the convolution integral for solution to the advective-dispersive equation.

- Adaptive Simpson's Quadrature Integration Routine - This section briefly describes the new integration scheme that is employed in the MEPAS methodology. This new procedure significantly increases the efficiency of implementing the groundwater component of the methodology while maintaining appropriate accuracy.

- Multiple Degradation - This section describes the algorithms used to assess degradation/decay at the source of contamination only, in the environment only, or both.

- Steady-State Groundwater Algorithms - This section describes the algorithms used in describing steady-state solutions to the advectivedispersive equation for contaminant transport in the partially saturated and saturated zones.

- Groundwater Mass Balance at the Source - This section briefly describes the features included in the groundwater portion of the methodology to ensure that mass is conserved in the analysis.

- Retardation Factor - This section briefly describes the algorithm that is currently being used by the MEPAS methodology for defining the retardation factor.

- Measured Concentrations in the Groundwater Environment - This section describes the option within the methodology of using measured environmental contaminant levels in the assessment of health impacts to surrounding sensitive receptors as opposed to performing transport calculations to estimate these environmental concentrations.

- References - This section includes the references cited in this chapter. 


\subsection{INTEGRATION LIMITS}

Whelan et al. (1987) use a partial differential equation to describe advective, dispersive contaminant transport with degradation/decay through the subsurface environment; this equation is conmonly referred to as the advective-dispersive equation. A modified form of the equation is presented as follows [very similar to Equation (5.10) of whelan et al. 1987]:

$$
\frac{\partial C}{\partial t}+u^{\star} \frac{\partial C}{\partial x}=E_{x}^{\star} \frac{\partial^{2} C}{\partial x^{2}}+E_{y}^{\star} \frac{\partial^{2} C}{\partial y^{2}}+E_{z}^{\star} \frac{\partial^{2} C}{\partial z^{2}}-\lambda C
$$

in which $u^{*}=u / R_{f}$

$E^{*}=E / R_{f}$

$\mathrm{Rf}_{\mathrm{f}}=1+\beta \mathrm{K}_{\mathrm{d}} / \mathrm{n}_{\mathrm{e}}$ (for saturated zone)

$R_{f}=1+\beta K_{d} / \theta$ (for partially saturated zone)

where $\quad C=$ dissolved concentration in the liquid phase in voids filled with flowing water $(\mathrm{g} / \mathrm{mL}$ or $\mathrm{Ci} / \mathrm{mL})(\mathrm{a})$

$\lambda=$ decay constant $\left[=(\ln 2) /(\right.$ half-life) $]\left(s^{-1}\right)$

$u=$ pore water velocity ( $x$ component in the saturated zone and $z$ component in the partially saturated zone) $(\mathrm{cm} / \mathrm{s})$

$R_{f}=$ retardation factor [Equation (5.5) in whelan et al. 1987]

$E_{x}, E_{y}, E_{z}=$ dispersion coefficients in the flowing voids in the $x-, y-$, and $\mathrm{z}$-directions, respectively $\left(\mathrm{cm}^{2} / \mathrm{s}\right)$

$\beta=$ bulk density $(\mathrm{g} / \mathrm{mL})$

$K_{d}=$ equilibrium (partition or distribution) coefficient $(\mathrm{mL} / \mathrm{g})$

$\theta=$ moisture content (fraction)

$n_{e}=$ effective porosity (fraction)

(a) When two sets of units are provided, the first refers to chemical, and the second refers to radionuclides. 
This equation (i.e., Equation 4.1 ) is very similar to Equation (5.10) in Whelan et al. (1987); the difference between the equations is due to the different definitions associated with the retardation factor $\left(R_{f}\right)$. For more information on the retardation factor, see Section 4.6 in this chapter.

Solution to the advective-dispersive equation [i.e., Equation (4.1)] for an instantaneous release has been provided by whelan et al. (1987) in Equations (5.12) through (5.32). These equations are generalized for arbitrary time-varying releases by using the convolution integral [see Equation (5.33) of whelan et a1. 1987].

$$
C(\tau)=\int_{0}^{\tau} f(t) C i(\tau-t) d t
$$

where $C(\tau)=$ contaminant concentration at time $\tau(\mathrm{g} / \mathrm{mL}$ or $\mathrm{Ci} / \mathrm{mL})$

$\tau=$ time over which contaminant concentration is computed (s)

$f(t)=$ source term expressed as a temporally varying contaminant flux $(\mathrm{g} / \mathrm{s}$ or $\mathrm{Ci} / \mathrm{s})$

$\mathrm{Ci}=$ instantaneous solute concentration at location $x, y$, and $z$, and time " $\tau-t$ " for an instantaneous source release $(\mathrm{cm}-3)(\mathrm{a})$

Whelan et al. (1987) evaluated Equation (4.6) by a standard Simpson's rule for numerical integration. In an attempt to preserve computational accuracy and to help ensure an efficient implementation run time, upper and lower integration limits were defined such that a reasonable and efficient time frame could be developed for defining the source term for routing contaminants through successive media. The method identified by whelan et al. (1987), that is, using the argument of the error function of the areasource solution [i.e., Equation (5.42) of whelan et al. 1987], works well under most situations, but the range that defines the lower and upper limits of integration [i.e., Equations (5.48), (5.49), and (5.50), respectively in Whelan et al. 1987] was found to be too large at times, resulting in

(a) Based on unit mass in grams. When included in an equation, " $\mathrm{Ci}$ " refers to instantaneous solute concentration; otherwise, it refers to the unit "curies." 
computational inefficiencies. The integration limits identified by whelan et al. (1987), although correct, were found to be too conservative for groundwater analyses where the flow is relatively slow (e.g., integration of excess zero values). In addition, if the source-term boundary condition (i.e., $f(t)$ in Equation (5.33) in whelan et al. 1987] has a duration less than the integration interval " $\mathrm{dt}$ " [see Equation (5.33) in whelan et al. 1987], (a) the integration limits could miss an important portion of the integration, depending on the pore-water velocity of the groundwater flow.

To ensure that the analys is is covering only the significant portion of the integration, the upper and lower limits of the integration are based on the temporal location of the inflection points on the rising and falling limbs of the response function. These integration limits are then checked against 1) a solution of the product of the response function and sourceterm flux and 2) the final solution, to ensure that only the significant portion of the integration is included in the analysis.

The integration limits can be approximated by 1) assuming a point source and its accompanying analytical Green's function solution in the direction of flow [e.g., Equation (5.17) or (5.21) of Whelan et al. 1987], 2) taking the second derivative with respect to time, 3) setting the derivative to zero, and 4) iteratively solving for the upper and lower integration limits. The point source solution is used as opposed to the line or area source solution, because tests indicate that it provides an accurate estimation of integration limits under all conditions and because its formulation is less complicated than that of the line or area source. Using a similar expression to Equation (5.17) from whelan et al. (1987) as an example, we have

$$
x_{1}=\left(\frac{1}{4 \pi E_{x}^{*} t}\right)^{1 / 2} \exp (-\lambda t) \exp \left[-\left(\frac{\left(x-u^{\star} t\right)^{2}}{4 E_{x}^{\star} t}\right)\right]
$$

where $X_{1}=$ Green's function for the point source solution in the $x$ direction with the flow in the $x$-direction only $\left(\mathrm{cm}^{-1}\right)$

(a) Note that "dt" is defined by the difference in the upper and lower integration limits divided by the number of integration steps;

therefore, the upper and lower integration limits, as determined by the tolerance term " $\gamma$," define "dt." 
Setting the second derivative to zero provides the appropriate solution as follows:

$$
\begin{aligned}
& \frac{d^{2}\left(x_{1}\right)}{d t^{2}}=0=\left(\frac{-2\left(u^{\star}\right)^{2}}{4 E_{x}^{\star} t}\right)-\left[\frac{16 u^{\star} E_{x}^{\star}\left(x-u^{\star} t\right)}{\left(4 E_{x}^{\star} t\right)^{2}}\right]-\left[\frac{32\left(E_{x}^{\star}\right)^{2}\left(x-u^{\star} t\right)^{2}}{\left(4 E_{x}^{\star} t\right)^{3}}\right]+ \\
& \left\{\left[-\frac{2 u^{\star}\left(x-u^{\star} t\right)}{4 E_{x}^{*} t}\right]-\left[\frac{4 E_{x}^{\star}\left(x-u^{\star} t\right)^{2}}{\left(4 E_{x}^{*} t\right)^{2}}\right]+\lambda\right\}^{2}+ \\
& \left\{\left[-\frac{2 u^{\star}\left(x-u^{\star} t\right)}{4 E_{x}^{\star} t}\right]-\left[\frac{4 E_{x}^{\star}\left(x-u^{\star} t\right)^{2}}{\left(4 E_{x}^{\star} t\right)^{2}}\right]+\lambda\right\}\left(\frac{1}{t}\right)+\frac{3}{4 t^{2}}
\end{aligned}
$$

The upper and lower integration limits are iteratively solved for using Equation (4.8).

\subsection{ADAPTIVE SIMPSON'S QUADRATURE INTEGRATION ROUTINE}

To help increase the computational efficiency and flexibility of the MEPAS methodology for effectively simulating contaminant transport in a series of environmental media, a new integration scheme was instituted. The convolution integrations identified by Equation (4.6) (Whelan et al. 1987) were solved by standard Simpson's rule for numerical integration. This procedure has been modified to help improve computational efficiency and accuracy. Typical problems encountered using standard Simpson's rule for numerical integration included the following:(a)

- When the difference in the error functions used in the area source analys is [see Equation (5.18) of Whelan et al. 1987] approaches zero, a round-off error can be propagated in the integration.

(a) Note that Simpson's rule for numerical integration forms the basis for many specialized integration techniques, including the Adaptive Simpson's Quadrature briefly outlined in this section. 
- The integration is based on a chosen fixed time step (i.e., dt). As the time step approaches zero, the integration should approach the true solution. Unfortunately, as the time step approaches zero, the computational efficiency decreases.

To correct these concerns, a modified Simpson's quadrature procedure called the Adaptive Simpson's Quadrature routine is used that varies the magnitude of the integration time step to more accurately reflect variations in the function. In addition, the solution algorithms allow for a dynamic check on accuracy.

The Adaptive Simpson's Quadrature routine is an adaptive numerical integration procedure designed to approximate definite integrals to a specified precision. As used here, an adaptive algorithm is one that automatically changes the solution strategy as the problem being solved becomes easier or more difficult. In simplified form, this procedure is as follows: the integration process is a calculation of the area under a function $f(t)$, where $t$ lies within specified time limits. Numerically, this is done by breaking the range of $t$ into a number of time steps, and approximating the area within each. The approximation of the integral is then the sum of the area associated with the individual time steps. More time steps are needed where $f(t)$ changes rapidly than when $f(t)$ changes gently. An adaptive routine automatically determines when $f(t)$ is rapidly changing based on concentration gradients, and reduces the size of each time step.

The adaptive Simpson's Quadrature routine is based on Simpson's rule and uses an accuracy control feature that dynamically adjusts the tolerance (required accuracy) of the integrand. The tolerance of the integrand is computed by estimating the peak concentration for the integrand and setting the tolerance to be $1.0 \mathrm{E}-4$ of the peak concentration (this tolerance has been tested and is based on the required accuracy of the groundwater model). This accuracy control feature provides reduced computational times while maintaining the desired accuracy of the results. Specific algorithms used are described in Lyness (1969, 1970).

\subsection{MULTIPLE DEGRADATION}

Whelan et al. (1987) describe standard and well-accepted algorithms for calculating the transport and fate of contaminants in the environment. 
Included in these calculations are algorithms that address degradation of chemicals or decay of radionuclides. When a contaminant has been disposed of, it spends a portion of its time at the source (e.g., landfill) prior to release into the environment and a portion of its time migrating in the environment (e.g., through the groundwater system).

The time frame associated with the solutions to the advective-dispersive equations with flux boundary conditions (see Chapter 5 of whelan et al. 1987) inherently includes the total time (i.e., time the contaminant is at the source and in the environment) in its calculations. As with most numerically integrated analytical solution transport formulations, degradation/decay occurs over this total simulation time frame. After assessing a number of waste sites, it became apparent that this time frame was not necessarily the dominant simulation time. The use of total simulation time is only appropriate if the contaminant degrades/decays at the same rate at the source as in the environment. For example, if placed in a landfill, a radionuclide will decay at the same rate at the source and in the environment. Under other circumstances, use of the total simulation time (which is standard practice) is inappropriate; examples are as follows:

- A production facility continually produces a waste at a given contaminant level; the waste is continually disposed of at a waste site (i.e.. source). The contaminant then leaches or is directly released into the environment to migrate.

Inder this scenario, the source is continually replenished with new waste at the original contaminant level. In effect, there is no apparent reduction in the contaminant level at the source (i.e., no degradation/decay). The only degradation/decay occurs while the contaminant is in the environment. The simulation time used in computing the degradation/decay should be equal to the time of travel in the environment only.

- A waste is disposed of at a waste facility, and its only significant degradation occurs at the source (e.g., photodegradation); no significant degradation occurs in the environment at this particular site.

Lnder this scenario, the waste degrades at the source but not in the environment. The simulation time used in computing degradation should cnly be equal to the time the contaminant remains at the source.

- A waste is disposed of at a waste facility, and the only significant cegradation occurs in the environment (e.g., microbial degradation); no significant degradation occurs while the waste is in the waste site froper at this particular site. 
Under this scenario, the waste degrades in the environment but not at the source. The simulation time used in computing degradation should be equal to the travel time in the environment only.

- A waste is disposed of at a waste facility, and after a certain period of time, it is released into the environment. In the environment, it is transported through several environmental media (e.g., three partially saturated zones, one saturated zone, and a nearby river). Degradation/decay of the contaminant occurs at the source and in the environment.

Under this scenario, the contaminant degrades/decays over the entire simulation time frame through the first environmental medium (i.e, uppermost partially saturated zone sharing a common boundary with the waste site). When simulating degradation/decay through subsequent environmental media, using the flux from the previous medium as a boundary condition for the succeeding medium (i.e., sequential modeling of media), only the travel times through the succeeding media should be included in the simulation for calculating subsequent degradation/decay. If the total simulation time is included in the degradation/decay calculation, then degradation/decay at the source will be accounted for more than once.

The MEPAS methodology has been enhanced to handle all of the situations described above, because it allows the user to specify the correct conditions at the site under which the contaminants will degrade/decay. (a) Based on these discussions, three conditions for calculating degradation/decay can exist. They are as follows:

1. Degradation/Decay at the Source and in the Environment

$$
t_{d}=t s+\sum_{i=1}^{i=n} t e_{i}
$$

in which

$$
t_{s}=t-t e 1
$$

(a) It should be noted that only one degradation rate can be specified; the degradation/decay rate assumed at the source is equal to that in the environment, if degradation/decay occurs in both. Different degradation rates are not possible using the semianalytical solutions in the MEPAS methodology; mass balance would be violated if different rates were identified. The user has to decide a priori where degradation/decay will dominate (i.e., at the source, in the environment, or in both), based on the characteristics at the site. 
where $t_{d}=$ time used in the decay calculations $(s)$

$$
\begin{aligned}
t s= & \text { time contaminant is at the source }(s) \\
i= & \text { index on medium } \\
n= & \text { number of sequential media through which a contaminant } \\
& \text { migrates (e.g., for three partially saturated zones, one } \\
& \text { saturated zone, and one river, } n \text { equals five) } \\
t e_{i}= & \text { travel time in the } i \text {-th environmental medium (s) } \\
t= & \text { total simulation time (see Equation } 4.7 \text { as an example) (s). }
\end{aligned}
$$

For the partially saturated zone, the travel time in the environment is defined as follows:

$$
\begin{aligned}
t_{i}=d / v_{\ell} & \text { for } v_{\ell} \leq v_{t} \\
t e_{j}=d / v_{t} & \text { for } v_{t}<v_{\ell}
\end{aligned}
$$

where $d=$ thickness of the $i$-th partially saturated zone layer $(\mathrm{cm})$

$$
\begin{aligned}
& v_{\ell}=\text { leach rate into the } i \text {-th partially saturated zone layer }(\mathrm{cm} / \mathrm{s}) \\
& v_{t}=\text { transmission rate of the partially saturated zone layer }(\mathrm{cm} / \mathrm{s})
\end{aligned}
$$

For the saturated zone, the travel time in the environment is defined as follows:

$$
\text { te } i=x / u^{\star}
$$

where $x=$ distance from the centroid of the waste site to the well or surface water body $(\mathrm{cm})$.

2. Degradation/Decay at the Source Only

$$
\text { ts }=t-t_{1}
$$


3. Degradation/Decay in the Environment 0nly

$$
t_{d}=\sum_{i=1}^{i=n} t_{i}
$$

\subsection{STEADY-STATE GROUNDWATER ALGORITHMS}

As noted in Section 4.1, Whelan et al. (1987) describe the migration and fate of contaminants in the environment with solutions to the unsteady, three-dimensional advective-dispersive equation. The solutions to these equations assume flux boundary conditions; as such, they are not specifically developed to efficiently analyze steady-state problems. In addition, the transient solutions also assume that the mass of liquid entering the saturated zone is insignificant relative to the volume of groundwater at the point of analysis (i.e., well or water body). If it is significant, the predicted concentrations could be higher than those measured at the source. This potential problem is typical of transient, numerically integrated analytical solutions with flux boundary conditions and is not restricted to any particular code. To address these concerns, steady-state solutions were incorporated into the MEPAS methodology to 1) be used when steady-state problems are being analyzed and 2) help ensure that the predicted transient concentrations are never greater than the concentrations measured at the source.

The steady-state, one-dimensional, advective-dispersive equation with degradation/decay is used to describe steady-state contaminant transport through the partially saturated zone and is presented as follows:

$$
u^{\star} \frac{\partial C}{\partial z}=E_{z}^{\star} \frac{\partial^{2} C}{\partial z^{2}}-\lambda C
$$

The solution to Equation (4.16) has been reported by Van Genuchten and Alves (1982) and is presented as follows: 


$$
\begin{aligned}
& C(z)=\left[\frac{2 u^{\star} C_{0}}{u^{\star}+\left[\begin{array}{lll}
\left(u^{\star}\right) & +^{2} 4 \lambda & E_{z}^{*}
\end{array}\right]^{1 / 2}}\right] \exp \left[\left(\frac{z}{2 E_{z}^{*}}\right)\right. \\
& \left.\left(u^{\star}-\left(\left(u^{\star}\right)^{2}+4 \lambda E_{z}^{\star}\right)^{1 / 2}\right)\right]
\end{aligned}
$$

where $C(z)=$ contaminant concentration at location $z(g / m L$ or $C i / m L)$

$$
\text { Co }=\text { initial contaminant concentration }(\mathrm{g} / \mathrm{mL} \text { or } \mathrm{Ci} / \mathrm{mL})
$$

The steady-state, vertically averaged, three-dimensional, advectivedispersive equation with degradation/decay is used to describe steady-state contaminant transport through the saturated zone and is presented as follows:

$$
u^{\star} \frac{\partial C}{\partial x}=E_{x}^{*} \frac{\partial^{2} C}{\partial x^{2}}+E_{y}^{\star} \frac{\partial^{2} C}{\partial y^{2}}-\lambda C
$$

The solution to Equation (4.18) has been reported by Sayer (1973) and Reckhow and Chapra (1983) and is presented as follows:

$$
\begin{aligned}
C(x, y)= & {\left[\frac { Q _ { c } } { 2 \pi h ( E _ { x } ^ { \star } E _ { y } ^ { \star } ) } \frac { 1 / 2 } { 2 } \operatorname { e x p } ( \frac { u ^ { \star } x } { 2 E _ { x } ^ { \star } } ) \left\{K _ { 0 } \left[\left(x^{2}+\frac{E_{x}^{\star} y^{2}}{E_{y}^{\star}}\right)^{1 / 2}\right.\right.\right.} \\
& {\left.\left[\frac{\lambda}{E_{x}^{\star}}+\left(\frac{u^{\star}}{2 E_{x}^{\star}}\right)^{2}\right]^{1 / 2}\right\} }
\end{aligned}
$$

where $C(x, y)=$ contaminant concentration at location $x$ and $y(g / m L$ or $C i / m L)$

$$
\begin{aligned}
Q c & =\text { contaminant flux (boundary condition) }(\mathrm{g} / \mathrm{s} \text { or } \mathrm{Ci} / \mathrm{s}) \\
\mathrm{h}= & \begin{array}{l}
\text { depth of saturated aquifer (as defined by Section } 5.6 .1 \text { of } \\
\text { Whelan et al. 1987) }(\mathrm{cm})
\end{array} \\
\mathrm{K}_{0}= & \text { modified Bessel function of the second kind, zero order }
\end{aligned}
$$




\subsection{GROUNDWATER MASS BALANCE AT THE SOURCE}

The analytical algorithms; in particular Equations (5.35) and (5.41) described in Chapter 5 of Whelan et al. (1987), by definition, conserve mass as the contaminant migrates through the groundwater environment.

$$
\begin{aligned}
& F i=n e_{0}^{\int_{0}^{h} m} \int_{-\infty}^{+\infty}\left(u C i-E_{x} \frac{\partial C i}{\partial x}\right) d y d z \\
& F(\tau)=\int_{0}^{\tau} f(t) F i(\tau-t) d t
\end{aligned}
$$

where $F i=$ instantaneous contaminant flux resulting from an instantaneous release $(\mathrm{g} / \mathrm{s}$ or $\mathrm{Ci} / \mathrm{s})$

$$
\begin{aligned}
h_{m}= & \text { vertical distance over which contaminant is assumed } \\
& \text { to be uniformly distributed }\left(0<h_{m} \leq h\right)(\mathrm{cm}) \\
h= & \text { depth of saturated aquifer }(\mathrm{cm})
\end{aligned}
$$

As a mass balance check on the information supplied by the investigator, the MEPAS methodology requires that the contaminant inventory be estimated for a particular waste site. This order-of-magnitude input requirement helps to ensure that the investigator cannot simulate more mass migrating from the site than is present at the waste site. This information also helps to ensure that the conceptualization of the problem at a site is correctly formulated. As such, the MEPAS methodology has been modified to include a contaminant mass balance control check at the source. The investigator indicates the contaminant mass that is entering the environment from the waste site, the mass balance check then sums the contaminant mass over time using the following equation:

$$
M_{T}=\int_{0}^{\tau} Q C d t
$$

where $M_{T}=$ total mass being released from the waste site $(g)$

$$
\tau=\text { time at which the release from the waste site ends (s) }
$$


$Q C=$ mass flux from the waste site $(g / s)$

This total mass is then compared to the inventory $\left(M_{i}\right)$ at the waste site; if the user-defined inventory is less, the time duration associated with the release from the waste site $(\tau)$ is adjusted until the mass of the contaminant being released equals the inventory at the site. If the mass being released from the waste site is less than the inventory at the site, no action is required.

\subsection{RETARDATION FACTOR}

The retardation factor represents the ratio between the groundwater pore water velocity to the rate of movement of the contaminant. Whelan et al. (1987) presented four different ways for defining the retardation factor, each with its own set of assumptions. The original retardation factor was defined by using Equation (5.4) in whelan et al. (1987)

$$
R_{f}=\frac{n}{n_{e}}+\frac{\beta}{n_{e}} K_{d}
$$

where $R_{f}=$ retardation factor (dimensionless)

$$
\begin{aligned}
\Pi_{0} & =\text { total porosity (fraction) } \\
\Pi_{e} & =\text { effective porosity (fraction) } \\
\beta & =\text { bulk density }(\mathrm{g} / \mathrm{mL}) \\
K_{d} & =\text { equilibrium coefficient }(\mathrm{mL} / \mathrm{g}) .
\end{aligned}
$$

In this equation, it is assumed that dead-end pore spaces exist in the porous medium through which no water or contaminants flow. The equation is also based on the assumption that the contaminants diffuse (i.e., matrix diffusion) into these pore spaces to sorb and desorb on the soil matrix to the same extent as contaminants do in the pore spaces through which water flows. A further assumption is that the contaminant concentration in the dead-end pore spaces is equivalent to that in the free-flowing spaces and the dispersion coefficients in both locations are the same. This equation was replaced with Equation (5.5) in Whelan et al. (1987). 


$$
\mathrm{R}_{\mathrm{f}}=1+\frac{\beta}{\mathrm{n}_{\mathrm{e}}} \mathrm{K}_{\mathrm{d}}
$$

where the ratio of total-to-effective porosity is set to unity. This equation assumes that matrix diffusion does not take place.

Equation (4.24) is currently employed in the groundwater algorithms because it allows the user more flexibility in defining the retardation of a contaminant with respect to groundwater movement. Using Equation (4.24) allows the user to set the retardation factor to unity (for a $K_{d}$ equaling zero), thereby resulting in a more conservative calculation as the contaminant movement is now retarded to a lesser degree. If Equation (4.23) was employed, the porosity and effective porosity would have to be equivalent for the retardation factor to equal unity (for a $K_{d}$ equaling zero). By using Equation (4.24), the user has more flexibility in any calibration processes associated with the groundwater component of MEPAS.

\subsection{MEASURED CONCENTRATIONS IN THE GROUNDWATER ENVIRONMENT}

Often, contaminant levels have been measured in nearby drinking-water or observation wells prior to a complete remedial investigation at a waste site. Instances also occur where monitored contaminant levels are available, but the nature, extent, and sometimes source of contamination are unknown. An endangerment assessment methodology should be flexible enough to handle those situations where only monitored information is available from which to perform an analysis. The intent of this enhancement to MEPAS is to provide the user with as much flexibility in assessing an environmental problem as possible.

The MEPAS methodology is structured to al low investigators to assess the human health impact to waterborne exposure by directly using the monitored information (i.e., contaminant concentrations) for the contaminants of concern in the risk analysis. No waterborne transport modeling is performed. If monitoring information is used, the MEPAS methodology requires the investigator to supply a representative concentration for each constituent being 
analyzed. This single concentration value is assumed to be temporally constant, although first-order degradation/decay can be included in the analysis.

Using measured concentrations in the groundwater environment for estimating the health impact to surrounding sensitive receptors represents a significant enhancement for MEPAS. Now, as opposed to relying only on transport modeling with its inherent uncertainties to predict contaminant concentrations, actual observed concentrations can be used in the assessment.

\subsection{REFERENCES}

Lyness, J. N. 1969. "Notes on the Adaptive Simpson Quadrature Routine, J." ACM 16, pp. 483-495.

Lyness, J. N. 1970. "Algorithm 379 SQUANK, Simpson Quadrature Used Adaptive - Noise Killed." Communications of the ACM, Vol. 13(4):260-263.

Reckhow, K. H., and S. C. Chapra. 1983. Engineering Approaches for Lake Management. Volumes I and II. Butterworth Publishers.

Sayer, W. W. 1973. "Natural Mixing Processes in Rivers." Chapter 6. In Environmental Impact on Rivers (River Mechanics III). ed. H. W. Shen, p. 6.9. Colorado State University, Fort Collins, Colorado.

Van Genuchten, M. T., and W. J. Alves. 1982. Analytical Solutions of the One-Dimensional Convective-Dispersive Solute Transport Equation. Tech. Bull. No. 1651. U.S. Department of Agriculture, Washington, D.C.

Whelan, G., D. L. Strenge, J. G. Droppo, Jr., B. L. Steelman, and J. W. Buck. 1987. The Remedial Action Priority System (RAPS): Mathematical Formulations. D0E/RL/87-09, PNL-6200, prepared for U.S. Department of Energy, Office of Environment, Safety, and Health by Pacific Northwest Laboratory, Richland, washington. 


\subsection{ENHANCED SURFACE WATER COMPONENT}

This chapter describes enhancements to the surface water component of the RAPS methodology, as described in whelan et al. (1987). The objectives of these enhancements are to help the methodology 1) run more efficiently, 2) increase accuracy in the results, and 3) provide the investigator with more flexibility for addressing complexities associated with assessing a hazardous waste site. This chapter is divided into four sections. The following is a brief overview of each:

- Multiple Degradation - This section describes the algorithms used to assess degradation/decay at the source of contamination only, in the environment only, or both.

- Surface Water Mass Balance at the Source - This section briefly describes the features included in the surface water portion of the methodology to ensure that mass is conserved in the analysis.

- Measured Concentrations in the Surface Water Environment - This section describes the option within the methodology of using measured environmental contaminant levels in the assessment of health impacts to surrounding sensitive receptors as opposed to performing transport calculations to estimate these environmental concentrations.

- Wetlands Environment - This section presents the algorithms that describe the wetland environment in MEPAS.

- References - This section includes the references cited in this chapter.

\subsection{MULTIPLE DEGRADATION}

As with the groundwater component of the MEPAS methodology, the surface water component provides the user various options for describing the correct degradation/decay at a waste site. The MEPAS methodology has been enhanced to handle all of the situations described in Section 4.3 as they apply to the surface water component. Based on conditions similar to those for the groundwater environment, three conditions for calculating degradation/decay can exist for the surface water environment.

1. Degradation/Decay at the Source and in the Environment. Equations (4.9) and (4.10) from Chapter 4.0 are applicable for the surface water environment just as they are applicable to the groundwater environment and are presented as follows: 


$$
t_{d}=t_{s}+\sum_{i=1}^{i=n} t_{i}
$$

$$
\text { in which } \quad t s=t-t e 1
$$

where $t_{d}=t$ ime used in the decay calculations (s)

$$
\begin{aligned}
& \text { ts }=\text { time contaminant is at the source (s) } \\
& i=\text { index on medium }
\end{aligned}
$$

$\mathbf{n}=$ number of sequential media through which a contaminant migrates (e.g., for three partially saturated zones, one saturated zone, and one river, $n$ equals five)

te $_{i}=$ travel time in the $i$-th environmental medium (s)

$t=$ total simulation time (see Equation 4.7 as an example) (s)

The travel time in the surface water environment is defined differently from that of the groundwater environment and is presented as follows:

$$
t_{i}=x / u
$$

where $x=$ distance from the centroid of the waste site to a sensitive receptor in the direction of flow $(\mathrm{cm})$

$u=$ surface water flow velocity $(\mathrm{cm} / \mathrm{s})$

2. Degradation/Decay at the Source Only Equation (4.14) is applicable for the surface water environment just as it is applicable to the groundwater environment and is presented as follows:

$$
t s=t-t e 1
$$

3. Degradation/Decay in the Environment Only As with Equation (4.15) for the groundwater case, the time used in the decay calculations for degradation/decay in the environment only can be defined by summing the travel time in the environmental media. For the surface water environment, this time is presented as follows: 


$$
t_{d}=\sum_{i=1}^{i=n} t_{i}
$$

\subsection{SURFACE HATER MASS BALANCE AT THE SOURCE}

In addition to degradation/decay in the environment, the mass loss by volatilization is considered as an exponential loss during the travel time in the surface water. The loss is evaluated using the travel time in the surface water and a surface water volatilization half-time.

Because the solutions to the surface water transport algorithms, described in Chapter 6 of Whelan et al. (1987), are exact and in a closed form, the analytical algorithms, by definition, conserve mass as the contaminant migrates through the surface water environment. Note that this equation conserves mass once the contaminant has been released into the environment and does not account for the amount of contaminant remaining in the waste site.

As a mass balance check on the information supplied by the investigator, the MEPAS methodology requires that the contaminant inventory be estimated at a particular waste site. This order-of-magnitude input requirement helps to ensure that the investigator cannot simulate more mass migrating from the site than is present at the waste site. This information also helps to ensure that the conceptualization of the problem at the site is correctly formulated. As such, the MEPAS methodology has been modified to include a contaminant mass balance control check at the source. Refer to Section 4.5 for the mass balance equation (4.22).

\subsection{MEASURED CONCENTRATIONS IN THE SURFACE WATER ENVIRONMENT}

Contaminant levels have been measured many times in surface water bodies prior to a complete remedial investigation at a waste site. Instances also occur where monitored contaminant levels are available, but the nature, extent, and sometimes source of contamination are unknown. An endangerment assessment methodology should be flexible enough to handle those situations where only monitored information is available from which to perform an 
analysis. The intent of this enhancement to MEPAS is to provide investigators with as much flexibility in assessing an environmental problem as possible.

The MEPAS methodology is structured to allow assessment of the human health impact to waterborne exposure by directly using the monitored information (i.e., contaminant concentrations) for the contaminants of concern in the risk analysis. No waterborne transport modeling is performed. If monitored information is used, the MEPAS methodology requires that a representative concentration be supplied for each constituent being analyzed. This single concentration value is assumed to be temporally constant, although first-order degradation/decay can be included in the analysis.

If a measured contaminant level is used, as opposed to modeling contaminant transport from the source to the receptor, the investigator should understand the meaning of the measured value and the implications associated with using a measured concentration. For example, if a waste site is being assessed for radionuclides, measured contaminant levels for heavy metals at an intake structure should not necessarily be attributed to that particular waste site and indiscriminantly used for that site's assessment. Also, an observed concentration implies that the concentration is constant with respect to time; this assumption may be conservative or nonconservative, depending on whether the contaminant plume has passed or is still approaching the receptor location.

If monitoring information is available at a receptor location and the nature, extent, and source of contamination are known, then the monitored information can be used to back calculate (i.e., calibrate) the transport modeling to ensure that the entire migrating plume is appropriately included in the assessment. Following the transport exercise, the monitored value is correlated to the simulated value, both spatially and temporally. Input parameters are modified, as appropriate, to ensure that the simulated and observed values match. Back calculation is an extremely powerful tool that can be used to ensure that any assumptions associated with the modeling scenario are appropriate.

Using measured concentrations in the surface water environment for estimating the health impact to surrounding sensitive receptors represents a 
significant enhancement for MEPAS. Now, instead of relying only on transport modeling with its inherent uncertainties to predict contaminant concentrations, actual observed concentrations can be used in the assessment.

\subsection{WETLANDS ENVIRONMENT}

The wetlands component of MEPAS is based on work by Knight and Brown (1988). Unlike most riverine environments that are generally alluvial in nature, wetlands are transitional areas between uplands and aquatic habitats. Wetlands often have diverse and productive biological components and indirectly act as buffers between upland development and recreational water bodies. Wetlands can act as a means to transport contaminants either through uptake by plant and animals or as an intermediate pathway to other surface water bodies. As significant seasonal repositories of surface waters, wetlands can provide a critical pathway for the transport of chemical substances to humans and to downstream environmental components. Wetlands naturally harbor wildlife and plant species that are used directly or indirectly by humans for food or other life-support needs. In certain areas of the country, wetlands are frequently in the chain of water flows from upland waste sites to downhill aquatic receiving waters.

Given a wetland's unique characteristics and ecological diversity, the steady-state advective-dispersive equation for riverine environments [i.e., Equation (6.5) in whelan et al. 1987] does not suitably describe contaminant movement through a wetland. Thus, a separate set of algorithms must be used to describe the wetland environment.

Knight and Brown (1988) developed a method for estimating contaminant fate in wetlands for incorporation into the MEPAS methodology. The following criteria were considered in developing the wetlands component:

- The model must be consistent in level of detail with other transport components in MEPAS.

- The model must be structured for easy incorporation into MEPAS.

- The model must have data requirements consistent with information available at most DOE sites. 
This wetlands model has been incorporated into the MEPAS waterborne transport methodology.

\subsubsection{Classes of Wetland}

Wetland types have been classified by the U.S. Fish and Wildlife Service (USFWS) in Cowardin et al. (1979) based on life form, water regime, substrate type, and water chemistry. Wetlands are defined by system, subsystem, class, subclass, dominance type, and special modifiers. The most general wetland classes are 1) aquatic bed (deeper water characterized by free-floating or rooted-floating aquatic plants); 2) emergent wetland (characterized by rooted, erect, herbaceous hydrophytes and typically called marshes, sloughs, or prairies); 3) scrub-shrub wetlands (dominated by woody-wetland plants less than $6 \mathrm{~m} \mathrm{tal1);} \mathrm{and} \mathrm{4)} \mathrm{forested} \mathrm{wetlands} \mathrm{(characterized} \mathrm{by} \mathrm{trees} \mathrm{or} \mathrm{shrubs}$ greater than $6 \mathrm{~m}$ tall and commonly referred to as swamps, bottomlands, or hammocks). Figure 5.1 presents a summary of the freshwater wetland classes.

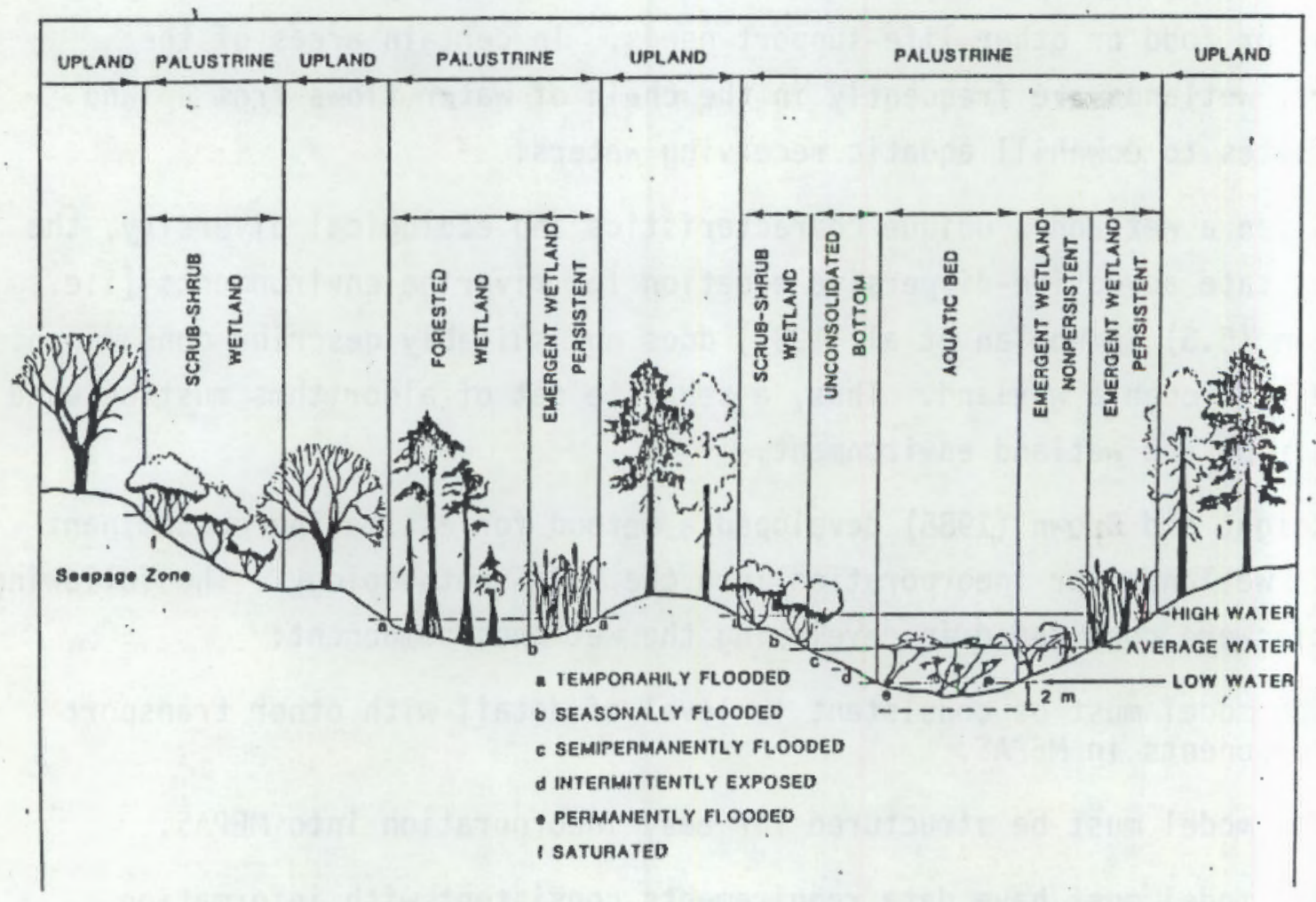

FIGURE 5.1. Freshwater Wetland Classes 


\subsubsection{Sources of Contaminants}

Potential sources of contaminants to wetlands may include all types of media such as groundwater, surface run-off, surface water, and air deposition. Wetlands are often located downgradient from neighboring uplands providing a surface outlet for migrating groundwater. Consequently, wetlands receive some of their inflow from groundwater under seasonal conditions. Some wetlands are perched above the surficial groundwater at least seasonally because of low permeability sediments. Wetlands are probably equally as likely to be recharged by, as well as discharged to, groundwater, but flow rates tend to be low.

Because most wetlands are downhill from surrounding uplands, they generally receive surface water run-off during rainy weather. The amount of run-off is a function of surrounding land use, water balance, and weather conditions. Direct discharge of contaminants to wetlands has occurred in the past when drums and other containers have been disposed of in seasonal wetlands. As low areas destined to be "reclaimed," wetlands have sometimes been used as landfills. Wetlands may also occur in conjunction with streams, Takes, rivers, and estuaries. Wetlands can receive contaminants transported within any of these surface water bodies and modify these waste concentrations before recycling them back. Wetlands can receive volatile or adsorbed contaminants from atmospheric dry fallout or from precipitation. Wetlands generally occur in areas where rainfall is abundant.

\subsubsection{Receptors}

hetlands are home to a variety of plant and animal species. Many of these species may passively or actively accumulate chemicals and, if used by man, may pass the chemical on to humans. While exposure of environmental receptors (biota) is of interest in terms of the environmental effects of waste releases, MEPAS is oriented primarily toward human exposure; therefore, primary wetland biota of concern are game fish and wildlife species and several types of plants. Fish and wildlife species of concern include water fowl (e.g., ducks and geese), game fish, shorebirds (e.g., snipe and woodcock), mannals (e.g., squirrels, deer, wild hogs, black bear, raccoon, etc.), shellfish (e.g., clams, oysters, crayfish, shrimp, etc.), and reptiles (e.g., alligators are legal game in some states). These organisms spend some or all 
of their lives in wetlands and can accumulate significant body burdens of some organic compounds. While the general public does not consume large quantities of these organisms, small segments of the population may be very dependent upon wild game as a protein source.

In some wetlands, plant species are harvested for human use or consumption. Timber is harvested from wetlands at the Savannah River Plant $(S R P)$. Human exposure to hazardous wastes or radionuclides could be increased by use of lumber from these trees for building construction. In addition, a small amount of direct human contact in wetlands does occur. For example, hunters wade in wetland areas and may drink surface water.

\subsubsection{Wetland Processes}

Because of thejr variability in occurrence, type, and physical environment, wetlands naturally include a broad diversity of physical, chemical, and biological processes. Those processes determined a priori to be the most generally important for contaminant migration and fate are described below.

\subsubsection{Hydrology}

The hydrology of wetlands can vary dramatically because they can range from being perennially flooded to being seasonally wet. Including only wetlands with rooted plants (omitting aquatic bed habitats with only floating plants), wetland types vary in average depth from less than $0.1 \mathrm{~m}$ (4 in.) to over $3 \mathrm{~m}$ (10 ft) (Knight and Bays 1986). Individual wetland types can vary in daily water depth from dry to as much as $2 \mathrm{~m}(7 \mathrm{ft})$, and the period of time flooded (i.e., the hydroperiod) may vary from less than 1 month per year to the entire year. Table 5.1 presents a general hydrological description for the four general wetland classes discussed above. These wetlands may also vary seasonally or from type to type in terms of flow regime, changing from nearly stagnant to rapidly flowing surface water systems.

\subsubsection{Chemistry}

Wetland chemistry is dependent on sources of surface water (precipitation, surface water, and/or groundwater), native sediments, and biological processes (see Schwartz 1985; Sharitz and Gibbons 1982; Mitch and Gosselink 1986). Some variable factors that can effect pollutant dynamics in wetlands 
TABLE 5.1. Description of Typical Wetland classes

\begin{tabular}{|c|c|c|c|c|c|c|c|c|}
\hline \multirow[b]{2}{*}{ Wetland Class(a) } & \multirow[b]{2}{*}{ Description } & \multicolumn{3}{|c|}{ Hydroperiod(b) } & \multirow[b]{2}{*}{ Water Quality $(c, d, e)$} & \multirow{3}{*}{$\begin{array}{c}\text { Sediment } \\
\text { Type } \\
\text { Uineral }\end{array}$} & \multirow{3}{*}{$\begin{array}{l}\text { Bionasso } \\
\left(\mathrm{kg} / \mathbf{m}^{2}\right) \\
0.6\end{array}$} & \multirow{3}{*}{$\begin{array}{c}\text { Void } \\
\text { Fraction } \\
0.75-1.6\end{array}$} \\
\hline & & $\begin{array}{l}\text { Avg Depth } \\
\text { (a) }\end{array}$ & $\begin{array}{l}\text { Max/Min } \\
\text { Depth (a) }\end{array}$ & $\begin{array}{c}\text { Duration } \\
\end{array}$ & & & & \\
\hline Aquatic Bed & $\begin{array}{l}\text { Free floating or rooted } \\
\text { floating plants. }\end{array}$ & $6.5->3.6$ & $>3.6 / 6.6$ & $80-100$ & $\begin{array}{l}\text { D.0.: } 0.4-16 \mathrm{mg} / \mathrm{l} \\
\text { pH: } 8.9-9.9 \\
\text { Color: } 20-40 \mathrm{Pt} \\
\text { Conduct ivity: } 208-860 \\
\\
\text { pho/ca }\end{array}$ & & & \\
\hline Eergent Tetland & $\begin{array}{l}\text { Rooted, erect, energent, } \\
\text { herbaceous plants (marshes } \\
\text { sloughs, prairies, fens, } \\
\text { bogs, ete.) }\end{array}$ & 0.1-1.6 & $2.0 / 0.0$ & $20-160$ & 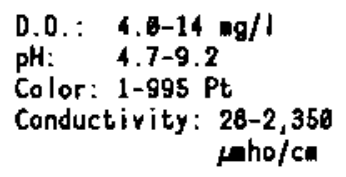 & $\begin{array}{l}\text { Mineral } \\
\text { or } \\
\text { Organic }\end{array}$ & $1-3$ & $0.1-6.3$ \\
\hline Scrub-Shrub Wet land & $\begin{array}{l}\text { Woody plants less than 6-n } \\
\text { tall (pocosins, titi } \\
\text { swanps, etc.) }\end{array}$ & $\langle 0.1-0.5$ & $1.0 / 6.0$ & $26-5 b$ & 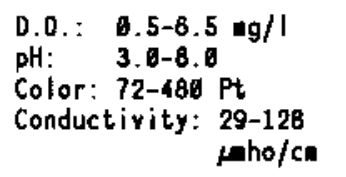 & Organic & $1-16$ & $0.3-0.5$ \\
\hline Forested Wetland & $\begin{array}{l}\text { Trees or Shrubs greater } \\
\text { than B-n tall (swanps } \\
\text { floodplain forest, botton- } \\
\text { lands, hannocks, cypress } \\
\text { doess, otc.) }\end{array}$ & 0.1-1. & $32.0 / 0.0$ & $19-99$ & 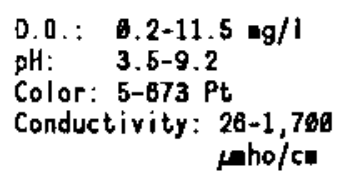 & $\begin{array}{l}\text { Uineral } \\
\text { or } \\
\text { Organic }\end{array}$ & $14-38$ & ๑.5-6.8 \\
\hline
\end{tabular}

\footnotetext{
(a) Covardin et al. (1979)

(b) Knight and Bays (1988)

(c) Schwartz (1995)

(d) Sharitz and Gibbons (1982)

(e) Vitch and Cosselink (1986)
} 
include $\mathrm{pH}$, redox potential, dissolved solids, hardness, alkalinity, temperature, and salinity. Water quality of particular wetlands can often be determined by minimal site investigations and field measurements $(\mathrm{pH}$, temperature, conductivity, salinity, and dissolved oxygen). Table 5.1 presents general ranges for some important water quality parameters in the four general wetland classes; the parameter values in Table 5.1 are representative of water quality conditions prior to contamination by hazardous wastes.

\subsubsection{Sediments}

Wet lands may have a range of sediment types from purely mineral (sands or clays) to largely organic (peats). Major sediment types within each wetland class are presented in Table 5.1. Sedimentation and resuspension of sediments may occur in wetlands but are generally not of sufficient magnitude to justify their inclusion in the MEPAS model. Sediments are considered to include detritus (dead organic plant and animal materials). In fact, this detritus buffers chemical transfer between the actual sediments and the overlying water column in many wetlands.

\subsubsection{Biology}

The biology of natural wetlands is often variable in response to variable physical, chemical, and climatic factors. Within the general plant morphological types presented in Table 5.1, wetlands can be populated by hundreds of different plant species based on geography, climate, soils, fire, and previous disturbances. However, the general classes of wetlands may function similarly subject to their particular physical and chemical surroundings. For example, a southern cypress forested wetland ecosystem is analogous to a northern spruce forested wetland in terms of biological diversity and fish and wildlife production. The important biological parameter for application to the MEPAS model is total above-ground plant biomass. Plant uptake of dissolved chemicals in wetlands is of importance because of the significant effect that this uptake can have on ambient water concentrations. 


\subsubsection{Model Description}

\subsubsection{General}

A conceptual model for a wetland is shown in Figure 5.2. It consists of

- a steady-state or time-varying chemical mass flux from upstream pathways (e.g., air, surface water, and/or groundwater)

- a water column of constant depth and surface area

- a constant plant biomass

- a constant detritus/sediment mass.

Because of the basic differences in the characteristics of the wetland and the riverine environment (e.g., physical geometry, biological activities, flow through rates, etc.), the first-order degradation rate (e.g., for hydrolysis, photolysis, biodegradation, etc.), as supplied by the user, is internally supplemented by the methodology with a reaeration rate for volatilization. The chemical of interest is allowed to partition between the water column, detritus/sediments, and plant biomass. Also, the chemical can volatilize at a rate determined by the reaeration rate, decay following first

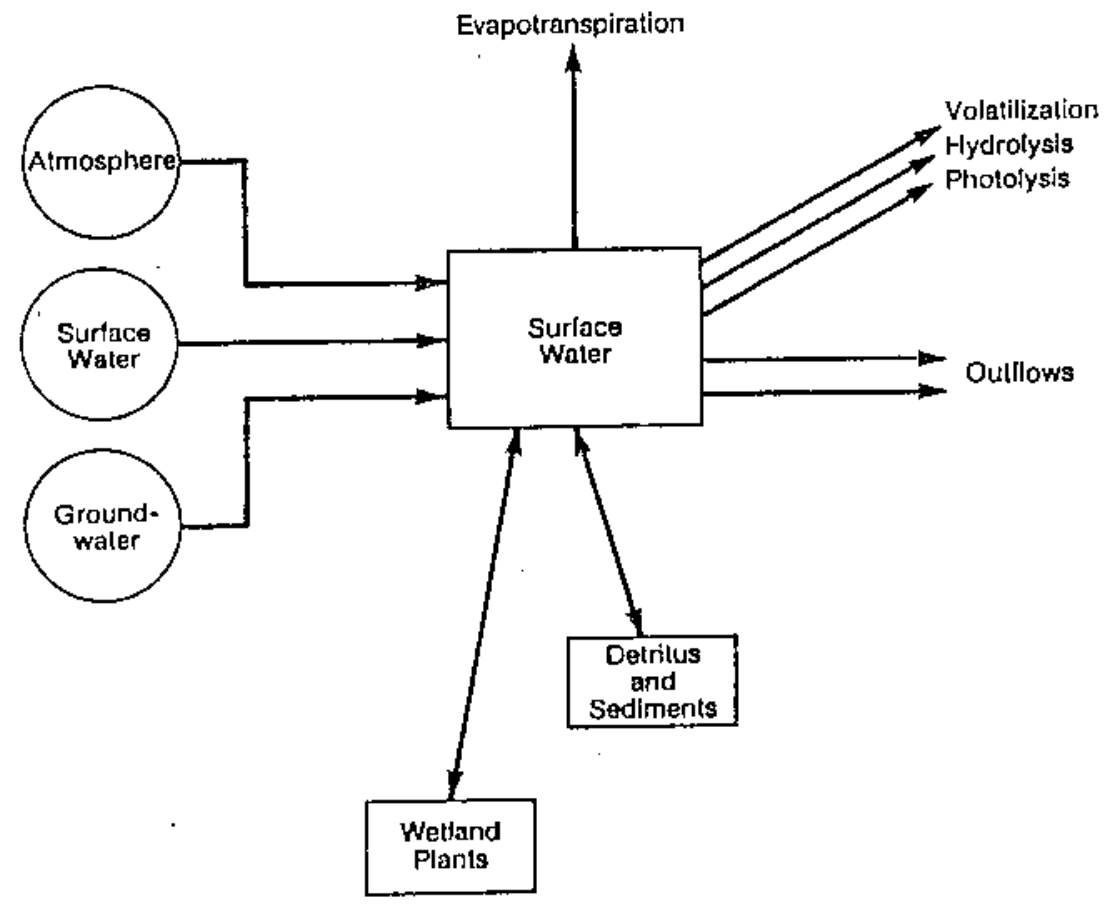

FIGURE 5.2. Conceptual Wetlands Pathway Mode1 
order kinetics, or leave the wetland by water flow. The animal uptake of chemicals from the wetland is handled by the exposure assessment model in MEPAS.

\subsubsection{Mathematical Description}

The overall mass balance equation for the wetland model is

$$
\frac{d W}{d t}=\text { Win - Wrol - Wdeg - Wout }
$$

where $W=$ total chemical mass in wetland $(g)$

$$
\begin{aligned}
\mathrm{t} & =\text { time }(\mathrm{s}) \\
\text { Win } & =\text { mass flux into wetland }(\mathrm{g} / \mathrm{s}) \\
\text { Wvol } & =\text { mass flux due to volatilization }(\mathrm{g} / \mathrm{s}) \\
\text { Wdeg } & =\text { mass flux due to degradation }(\mathrm{g} / \mathrm{s}) \\
\text { Wout } & =\text { mass flux out of wetland }(\mathrm{g} / \mathrm{s}) .
\end{aligned}
$$

The total mass of chemical in the wetland can be partitioned into three phases (dissolved, adsorbed, and plant biomass).

$$
w=W w+W s+W b
$$

where $W_{w}=$ mass of chemical dissolved in the water column $(g)$

$$
\begin{aligned}
W s= & \text { mass of chemical adsorbed to sediment/detritus }(\mathrm{g}) \\
W b= & \text { mass of chemical adsorbed to or taken up by plant } \\
& \text { biomass }(\mathrm{g}) .
\end{aligned}
$$

At equilibrium, the mass of chemical in the adsorbed and biomass phases can be related to the dissolved phase:

$$
\begin{aligned}
& W_{s}=W_{w} \text { Sed } K_{d} / V_{w} \\
& w_{b}=W_{w} \text { Bio BCF } / V_{w}
\end{aligned}
$$

where Sed $=$ detritus/sediment mass in wetland $(g)$

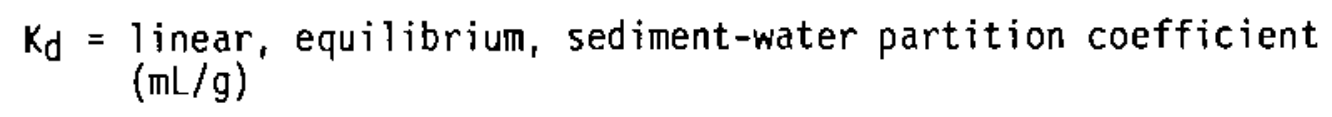




$$
\begin{aligned}
V_{w} & =\text { volume of wetland water column }\left(\mathrm{cm}^{3}\right) \\
B i o & =\text { plant biomass in wetland }(\mathrm{g}) \\
B C F & =\text { bjoconcentration factor }(\mathrm{mL} / \mathrm{g}) .
\end{aligned}
$$

The volatilization rate (Wvol) can be estimated from the wetland reaeration rate adjusted to reflect differences in chemical and oxygen diffusion rates (Thibodeaux 1979).

$$
\text { Wrol }=\mathrm{kr} W \mathrm{~W} \sqrt{\mathrm{MWo} / \mathrm{MWc}}
$$

where $k r=$ reaeration rate $\left(s^{-1}\right)$

$$
\begin{aligned}
& \text { MWo = molecular weight of oxygen }=32 \mathrm{~g} / \mathrm{mole} \\
& \text { MWC = molecular weight of chemical }(\mathrm{g} / \mathrm{mole}) \text {. }
\end{aligned}
$$

The degradation flux can be estimated for the dissolved and sorbed phases assuming a first-order reaction:

$$
W d e g=k w W+k s w s
$$

where $\mathbf{k w}=$ degradation rate for dissolved phase $(s-1)$

$$
k s \text { = degradation rate for sorbed phase }\left(s_{-1}\right)
$$

The mass flux out of the wetland can be estimated by

$$
\text { Wout }=W_{W} Q / W_{W}
$$

where $Q$ is the water discharge from wetland $\left(\mathrm{cm}^{3} / \mathrm{s}\right)$.

The fraction of $Q$ discharging to surface water and groundwater can be used to estimate mass fluxes for input to other MEPAS pathway models. 
Combining the above equations produces a mass-balance equation written in terms of the chemical mass in the dissolved phase:

$$
\begin{aligned}
\frac{d\left(W_{w}\right)}{d t}= & \left(W_{i n}-W_{W}\left((k r \text { MWo } / M W c)+\left(k w+k s \text { Sed } K_{d} / V_{W}\right)\right.\right. \\
& \left.\left.+Q / W_{w}\right)\right) /\left(1+\text { Sed } K_{d} / W_{W}+B i o B C F / V_{W}\right)
\end{aligned}
$$

If the volume of water in the wetland is known, the dissolved phase concentration can be calculated.

If the chemical flux into the wetland remains constant for a given time interval, the mass of chemical dissolved in the water column can be calculated by

$$
\begin{aligned}
W w\left(t_{2}\right)= & W w\left(t_{1}\right) \exp \left(-B\left(t_{2}-t_{1}\right)\right) \\
& -\left(W_{i n} / A\right)\left[1-\exp \left(-B\left(t_{2}-t_{1}\right)\right)\right]
\end{aligned}
$$

in which $A=k r \sqrt{M W_{0} / \overline{M W C}}+\left(k_{w}+k s\right.$ Sed $\left.K_{d} / V_{W}\right)+Q / V_{W}$

$$
B=A /\left(1+\operatorname{Sed} K_{d} / V_{W}+B i o B C F / V W\right) \text {. }
$$

where $W_{w}\left(t_{2}\right)=$ mass of dissolved chemical at time $t_{2}(g)$

$$
W_{w}\left(t_{1}\right)=\text { mass of dissolved chemical at time } t_{1}(g)
$$

The above steady-state solution is solved for each chemical flux input to the model.

\subsubsection{Limitations}

Several critical assumptions have been made in developing the wetlands pathway model. A brief discussion of the generality of these assumptions is given in Table 5.2. The assumptions made include that annual average conditions are accurate, contaminant partitioning is instantaneous and reversible, there is no spatial heterogeneity in the wetland, and there is no sediment burial in the wetland. Most of these assumptions will result in conservative estimates (i.e., higher values) of human exposure. 
TABLE 5.2. Wetland Pathway Model Assumptions

Assumption
Annual averages used
for volume, depth,
biomass, and discharg

Linear, equilibrium
partitioning (no
kinetics).

No spatial heterogeneity.

No sediment transport or sediment burial.

Rationale
MEPAS calculates long-
term exposure levels:
seasonal variation in
exposure is not
critical.

Kinetics are generally short-term (hours or days) compared to annual average values. Data rarely available on nonlinear partitioning.

Not concerned about distribution within wet land.

Rates for these processes are variable in wetlands and are not generally known.

\author{
Implication \\ May miss acute \\ exposures. \\ May overestimate or \\ underest imate water \\ concentration and \\ exposure through biota.
}

Actual exposure may be underestimated or overest imated.

Results in overestimate of exposure.

\subsection{REFERENCES}

Cowarcin, L. M., V. Carter, F. L. Golet, and E. T. LaRoe. 1979. Classification of Wetlands and Deepwater Habitats of the United States. FWS/OBS79/31, U.S. Fish and Wildlife Service, Washington, D.C.

Knight, R. L., and J. S. Bays. 1986. Florida Effluent Wetlands - Hydroecolocy. Wetland Technical Reference Document Series No. 2, CH2M Hill, Tallarassee, Florida.

Knight, R. L., and S. M. Brown. 1988. Wetland Pathway Model: Documentation Report and User's Manual. Prepared for Pacific Northwest Laboratory by CH2M Hill, Gainesville, Florida.

Mitscr, W. J., and J. G. Gosselink. 1986. Wetlands. Van Nostrand Reinhold Compary, New York.

Schwartz, L. 1985. Water Quality of Freshwater Wetlands in Florida.

Florica Department of Environmental Regulation. 
Sharitz, R. R., and J. W. Gibbons. 1982. The Ecology of Southeastern Shrub Bogs (Pocosins) and Carolina Bays. A Community Profile. FWS/OBS-82/04, U.S. Fish and Wildife Service, Washington, D.C.

Thibodeaux, L. J, 1979. Chemodynamics. Wiley, New York.

Whelan, G., D. L. Strenge, J. G. Droppo, Jr., B. L. Steelman, and J. W. Buck. 1987. The Remedial Action Priority System (RAPS): Mathematical Formulations. DOE/RL/87-09, PNL-6200, prepared for U.S. Department of Energy, Office of Environment, Safety, and Health by Pacific Northwest Laboratory, Richland, Washington. 


\subsection{ATMOSPHERIC TRANSPORT}

The atmospheric transport component has been enhanced with additional components and options. Several of these enhancements are designed to allow the investigator to make more efficient use of available data. Others represent an expansion of the applications to which MEPAS can be applied.

Atmospheric releases may occur by a number of mechanisms as described in Whelan et al. (1987). These releases may be characterized as being from either area sources (surface contamination, landfills, lagoons, etc.) or point sources (stacks, vents, etc.). The methods to estimate the initial dispersion for these two types of releases are given in Section 6.3.

The implementation of MEPAS allows the investigator to employ several methods to define atmospheric release rates. For both point sources and area sources the investigator may input the release rate of contaminants. For area sources, the investigator may alternatively input site characteristics and have a MEPAS component compute the emission rate. The formulation for suspension of particulates is given in whelan et al. (1987) and for the emission of gases (volatilization) is given in Section 6.1. A third option for both point and area sources is to use long-term environmental monitoring data to back calculate an apparent emission rate. The formulations for the back-calculation component are given in Section 6.2 .

A number of modules have been added to the atmospheric component to allow additional applications. The special case where the impact of a uniform regional concentration pattern needs to be evaluated is allowed using the air-as-source component described in Section 6.4. Short distance and disperse regional release formulations are given in Sections 6.5 and 6.6 . respectively. The formulations for a component to account for local terrain effects are given in Section 6.7.

Supplemental formulations for atmospheric transport, dispersion, and depos:tion are given in Section 6.8. These formulations include the handling of ca'm conditions, removal processes, and mass budgets. 


\subsection{VOLATILIZATION COMPONENT}

The volatilization pathway is usually a secondary pathway of concern when compared with groundwater, surface water, stacks, and suspension. However, under certain conditions, the volatilization pathway can dominate the human health impact of an environmental problem. An example of this would be a landfill of organic compounds that has no receptor wells or surface water within a 50-mile radius. In a case like this a volatilization pathway is required to evaluate the potential human health impacts. The following is a description of MEPAS volatilization pathway component.

MEPAS is designed to be applicable to environmental emissions of potentially hazardous materials. When such materials are in accident/ disposal/storage areas such as landfills, spills, and ponds, the volatile components may be emitted directly to the air in a gaseous form. The processes by which this exchange to the air occurs is called volatilization. This section presents the mathematical formulations adopted within MEPAS for volatilization.

Computation of environmental concentrations in the atmospheric pathway from areas with contaminated soil or water requires a definition of both potential atmospheric gaseous and particulate emissions. The mathematical formulations for particulate emissions have been documented in whelan et al. (1987).

MEPAS provides two methods of addressing volatilization: 1) either the volatilization rates are input by the investigator, or 2) the volatilization rates are computed by the model. For the input method, emission rates are obtained from sources such as flux measurements at the contaminant source, computation with an alternative volatilization model, or back calculation using monitoring data. For the computation method, MEPAS provides a component for computing potential volatilization rates based on the constituent and site characteristics.

The mathematical formulations for the MEPAS atmospheric volatilization computation component are given below. Gaseous emissions of constituents from landfills, spills, and ponds are computed using physical characteristics of the contaminant source and chemical properties of the contaminants. 
A number of models have been proposed for computing volatilization rates from soil and water surfaces [see for example, EPA (1980), Farino et al. (1983), Thibodeaux (1981), Shen (1981), Thibodeaux and Hwang (1982), MacKay and Leinonen (1975), and Lyman et al. (1982)]. The resolution of these models is generally at best an order-of-magnitude estimate of the volatilization rate for a given constituent contaminant. The complexity of the interactions, both between the contaminants and their containment media, limit the accuracy expected from these models.

Volatilization formulations contained in the Superfund Exposure Assessment Manual (EPA 1988) were used as a starting point for developing the MEPAS volatilization mathematical formulations. Some components are used directly, others are modified to simplify input data requirements, and one component has been completely replaced with a new model.

Mathematical formulations for computing volatilization from three different types of contaminant sources are included in MEPAS. These Ranking Units are as follows:

1. covered landfills - with and without internal gas generation

2. surface contamination - new and old

3. water - ponds, lagoons, and free-standing water.

The MEPAS mathematical formulations for each of these Ranking Units are given below.

\subsubsection{Landfills Without Internal Gas Generation}

The model for computing volatilization rates from landfills is based on Fick's first law of steady-state diffusion as developed by Farmer et al. (1978). Diffusion from the landfill to the atmosphere is assumed to occur from a planar surface within the landfill. The subsurface soil concentrations are assumed to be uniform. As a result, subsurface measurements are used to define a representative average concentration. Processes such as biodegradation, transport in water, adsorption, and landfill gas production are not included in the calculation; the diffusion of the constituent in the soil is assumed to be the controlling mechanism for vapor transport. 
Farmer's method was modified and simplified by EPA (1980), Farino et al. (1983), and Shen (1981). The soil was assumed to be completely dry to provide maximum volatilization rates based on the fact that diffusion in air is greater than diffusion in water. The concentration of the contaminant was assumed to be zero at the soil/air interface. The assumption of a completely dry soil is inappropriate for MEPAS applications aimed at obtaining comparisons based on factors such as climatologic differences. Thus, MEPAS uses an expression that is modified to allow for soil moisture. The resultant equation for volatilization is

$$
E_{i}=D_{i} C_{s} \text { A } P_{s} M_{i} / d_{S C}
$$

where $E_{j}=$ emission rate of constituent $i(g / s)$

$$
\begin{aligned}
D_{i}= & \text { diffusion coefficient of constituent } i\left(\mathrm{~cm}^{2} / \mathrm{s}\right) \\
C_{s i}= & \text { saturated vapor concentration of constituent } i\left(\mathrm{~g} / \mathrm{cm}^{3}\right) \\
A= & \text { exposed area }\left(\mathrm{cm}^{2}\right) \\
P_{S}= & \text { the ratio of air-filled soil porosity to total soil } \\
& \text { porosity (dimensionless) } \\
M_{i}= & \text { weight fraction of constituent } i \text { in the waste }(\mathrm{g} / \mathrm{g}) \\
d_{s C}= & \text { effective depth of soil cover }(\mathrm{cm}) .
\end{aligned}
$$

The soil moisture is accounted for by replacing the total soil porosity with a porosity ratio term. This replacement was suggested by Millington and Quirk (1961). They define this ratio as

$$
P_{s}=\left(P_{a}\right) 10 / 3 / P_{t}^{2}
$$

where $P_{t}$ is the total soil porosity (dimensionless) and $P_{a}$ is the air filled soil porosity (dimensionless).

The total soil porosity and the air filled porosity are computed once the soil types are defined. The percentage sand, silt, and clay are to be obtained from SCS reports. In the rare case where the soil is completely dry, the air-filled porosity becomes the total soil porosity, and $P_{S}$ becomes 
$\mathrm{Pt} 4 / 3$ as occurs in the original formulation of Equation (6.1). The total soil porosity is calculated as

$$
P_{t}=1.0-(\beta / \rho)
$$

where $\beta$ is the bulk density of the soil $\left(\mathrm{g} / \mathrm{cm}^{3}\right)$ and $\rho$ is the particle density $\left(\mathrm{g} / \mathrm{cm}^{3}\right)$ usually 2.65 for mineral material.

The bulk soil density can be obtained once the soil type is known. The air-filled porosity, $P_{d}$, can be calculated using the total soil porosity minus the soil's field capacity for water. This information can be obtained from EPA (1988), Fenn et a1. (1975), Lynsley et al. (1975), Eagleson (1970), Hanks and Ashcroft (1980), and Israelsen and Hansen (1962). The equation for computing air-filled porosity is

$$
P_{a}=P_{t}-\theta
$$

where $\theta$ is the soil's percent field capacity for water (dimensionless).

If the diffusion coefficient for the constituent is unknown, it can be calculated using the following empirical relationship ( $0^{\prime}$ Connor and Muller 1980):

$$
0_{i}=1.9\left(\mathrm{MW}_{i}\right)^{-0.6667}
$$

where $D_{i}=$ air diffusion coefficient for constituent $i\left(\mathrm{~cm}^{2} \mathrm{~s}-1\right)$

$M W_{i}=$ molecular weight of constituent $i(g$ mole-1).

Representative regional values of climatologic parameters such as average air temperature and pressure are to be obtained for the nearest, or most representative, National Weather Service Station. A Local Climotological Data summary for these stations is available from the National Climatic Data Center in Asheville, North Carolina.

The molecular weight and volume of a constituent are needed to compute the vapor concentration, $C_{S i}$, using an equation from EPA (1980): 


$$
C_{s i}=\frac{V P_{i} M W_{j}}{R T}
$$

where $C_{s i}=$ saturated vapor concentration of constituent $i\left(\mathrm{~g} / \mathrm{cm}^{3}\right)$

$$
\begin{aligned}
V P_{i} & =\text { saturated vapor pressure of the constituent } i(m \mathrm{mg}) \\
M W_{j} & =\text { molecular weight of constituent } i(g / \text { mole }) \\
R & =\text { molar gas constant }\left(6.23 \times 10^{4} \mathrm{~cm}^{3} \mathrm{~mm} \mathrm{Hg} /{ }^{\circ} \mathrm{K} / \mathrm{mole}\right) \\
\mathrm{T} & =\text { annual average air temperature }\left({ }^{\circ} \mathrm{K}\right) .
\end{aligned}
$$

Since the saturated vapor concentration of the constituent in the soil is used, this assumes that contaminant concentrations are constant throughout the soil layer. This assumption provides an upper limit for the volatilization rate.

\subsubsection{Landfills with Internal Gas Generation}

Landfills with significant organic waste material content will have a potential for internal gas generation that can greatly enhance the volatilization rates of gaseous materials. An example is a landfill with a combination of municipal and industrial waste incorporated into their soils. For situations of this kind. Thibodeaux (1981) developed the following equation for estimating these enhanced gaseous emission rates:

$$
E_{j}=C_{i} V_{y} A
$$

where $E_{i}=$ emission rate of constituent $i(g / s)$

$$
\begin{aligned}
& C_{i}=\text { concentration of constituent } i \text { in the soil pore spaces }\left(\mathrm{g} / \mathrm{cm}^{3}\right) \\
& V_{y}=\text { mean landfill gas velocity } \\
& A=\text { area of landfill }\left(\mathrm{cm}^{2}\right) .
\end{aligned}
$$

The decay of organic material in municipal waste can result in internal gas generation in the soil (e.g., $\left.\mathrm{H}_{2}, \mathrm{CH}_{4}, \mathrm{CO}_{2}\right)$. The movement of excess quantities of these gases through the soil to the atmosphere will move other soil gases with them. This upward movement of the excess gas produced by 
decay of municipal waste is normally much faster than gas movement in soil by Fickian diffusion processes.

The actual concentration of constituent in the soil space, $C_{j}$, is a quantity that is not often measured and as a result is not expected to always be known. As a maximum case alternative, the saturated vapor concentration of the constituent, $C_{s i}$, may be used as defined in Equation (6.6).

The mean landfill gas velocity, $v_{y}$, is also a difficult value to define for specific sites. Many sites will need to use a typical literature value for most sites expected to have internal gas generation. Thibodeaux (1981) reports an average gas velocity of $1.63 \times 10^{-3} \mathrm{~cm} / \mathrm{s}$ derived from data reported by Dewalle et al. (1978). This velocity is based on measurements of gas velocities at pumped extraction wells. The gas velocities measured varied with time and other factors, but they were all within an order of magnitude $\left(7.29 \times 10^{-4}\right.$ to $\left.1.13 \times 10^{-3} \mathrm{~cm} / \mathrm{s}\right)$. The gas extraction velocity value will provide an upper limit value for the assessment of potential health impact.

\subsubsection{Surface Contamination - New and 01d}

Issues involving surface soil contamination from a number of different causes will fit into this category. Although based on equations developed for a spill situation, the equations can be applied to other sources of surface ground contamination. As long as the location and condition of the constituents in the soil fit modeling constraints for the "spills" discussed below, the mathematical formulations can be used to estimate potential emission rates.

A new spill is defined as a spill where there is a pool of the contaminant on the surface. A spill is no longer a new spill when volatilization of the contaminant has developed a dry zone within the soil surface. As an example, the new spill model might be applied to computing emissions from a spill on a relatively impermeable surface. In general, the new spill model is seen as having limited applications in the MEPAS framework and is mainly included to provide a comprehensive volatilization computation component. 
Thibodeaux and Hwang (1982) proposed a method of estimating the volatilization rates from new spills. Their equation as modified by Farino et al. (1983) is

$$
E_{i}=K_{i g} C_{i} A
$$

where $E_{j}=$ emission rate of constituent $i(g / s)$

$$
\begin{aligned}
K_{i g} & =\text { gas-phase mass transfer coefficient of constituent }(\mathrm{cm} / \mathrm{s}) \\
C_{i} & =\text { vapor concentration of constituent } i\left(\mathrm{~g} / \mathrm{cm}^{3}\right) \\
A & =\text { area of landfill }\left(\mathrm{cm}^{2}\right) .
\end{aligned}
$$

The gas-phase mass transfer coefficient determines the diffusion rate from liquid to air. The gas-phase mass transfer coefficient of the constituent can be estimated using a method presented by Hwang (1982). This method is based on computing mass transfer coefficients by reference to constituents whose base values are known. Experiments by Owens et al. (1964), Smith et al. (1979), and Thibodeaux (1978) used oxygen as a reference compound for liquid-phase mass transfer and water as a reference for air-phase mass transfer. Hwang used equations derived by Cohen et al. (1978), Mackay and Matsugu (1973), Owens et al. (1964), Thibodeaux (1978), and Reinhart (1977) to obtain equations for liquid- and gas-phase mass transfer coefficients for a given constituent.

The equation for computing liquid-phase mass transfer coefficients for natural surfaces is

$$
\mathrm{K}_{1 i}=\left(\left(\mathrm{MWO2}_{0} / \mathrm{MWi}_{\mathrm{j}}\right)^{0.5}\right)(\mathrm{T} / 298) \mathrm{K}_{10}
$$

where $k_{1} i=$ liquid-phase mass transfer coefficient $(\mathrm{cm} / \mathrm{s})$

$$
\begin{aligned}
\mathrm{MWO}_{2} & =\text { molecular weight of } \mathrm{O}_{2}(32.0 \mathrm{~g} / \mathrm{g} / \mathrm{mole}) \\
\mathrm{MWi}_{\mathrm{i}} & =\text { molecular weight of constituent } i(\mathrm{~g} / \mathrm{g} / \mathrm{mole}) \\
\mathrm{T} & =\text { annual average air temperature }\left({ }^{\circ} \mathrm{K}\right)
\end{aligned}
$$




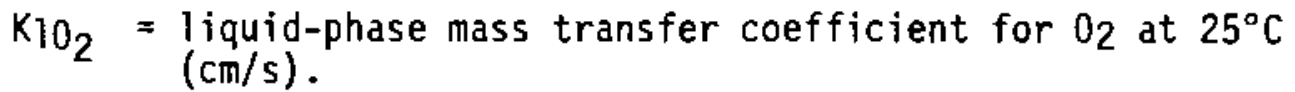

Hwang (1982) has evaluated the liquid-phase mass transfer coefficient for oxygen at $25^{\circ} \mathrm{C}$ for natural and turbulent surfaces. The coefficient values he obtained are $3.01 \mathrm{~cm} / \mathrm{s}$ for natural surfaces and $3185.0 \mathrm{~cm} / \mathrm{s}$ for turbulent surfaces.

The equation for computation of gas-phase mass transfer coefficients for natural surfaces is

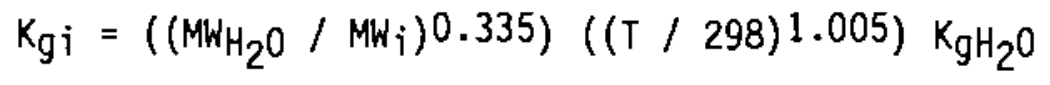

where $\mathrm{K}_{\mathrm{gi}}=$ gas-phase mass transfer coefficient $(\mathrm{cm} / \mathrm{s})$

$$
\begin{aligned}
\mathrm{MWH}_{2} \mathrm{O} & =\text { molecular weight of } \mathrm{H}_{2} \mathrm{O}(18.0 \mathrm{~g} / \mathrm{g} / \mathrm{mole}) \\
\mathrm{MW}_{\mathrm{i}} & =\text { molecular weight of constituent } \mathrm{i}(\mathrm{g} / \mathrm{g} / \mathrm{mole}) \\
\mathrm{T} & =\text { annual average air temperature }\left({ }^{\circ} \mathrm{K}\right) \\
\mathrm{KgH}_{2} \mathrm{O} & =\begin{array}{l}
\text { gas-phase mass transfer coefficient for } \mathrm{H} 0 \text { at } 25^{\circ} \mathrm{C} \\
(\mathrm{cm} / \mathrm{s}) .
\end{array}
\end{aligned}
$$

Hwang (1982) computed gas-phase mass transfer coefficients for water at $25^{\circ} \mathrm{C}$ of $1.0 \times 10^{-3} \mathrm{~cm} / \mathrm{s}$ for natural and $1.7 \times 10^{-2} \mathrm{~cm} / \mathrm{s}$ for turbulent surfaces.

In Equation (6.8), if the pore space concentration is not known, the saturated vapor concentration for the constituent may be used as a conservative value estimate. Also, because Equation (6.8) does not consider soilphase mass-transfer resistance and liquid-phase resistance, this formulation should be used only for situations where the resistance may be controlling the volatilization rates.

An old spill is defined as a case where the spill materials have soaked into soil and are no longer pooled on the surface. Loss of volatile materials from the soil to the air develops a "dry layer" at the soil surface with low concentrations of these materials. The old spill formulations are expected to find wider MEPAS applications than the new spill formulations. 
Appropriate situations may be the result of past operations, which may have involved spilling, leaking, spraying, washing, treating, or just dumping of materials onto a ground surface.

An old spill model developed by Thibodeaux and Hwang (1982) is used in MEPAS. The loss of contaminant is computed as a function of time assuming that the soil-phase controls the vapor diffusion. Also, the concentration in the contaminant pool is assumed to remain constant until all the liquid-phase contaminant has been entirely lost to the atmosphere. A layering of the contaminant is assumed to occur in the soil consisting of a "dry" surface layer with low-contaminant concentrations located over a "wet" layer with high-contaminant concentrations. The terms, "wet" and "dry," refer to the presence or absence, respectively, of significant quantities of the contaminant in liquid form. The contaminant is assumed to have pooled in the wet layer and, thus, has uniform concentrations within the layer.

The emission rate for the old spill model is computed according to Thibodeaux and Hwang (1982) using

$$
E_{i}=\frac{D C_{S i} A}{((d 2)+2 D t)^{0.5}}
$$

where $E_{i}=$ emission rate of the constituent $i(g / s)$

$D=\underset{\left(\mathrm{cm}^{2} / \mathrm{s}\right)}{\operatorname{total} \text { diffusion from both liquid-phase and gas-phase }}$

$C_{s i}=$ liquid-phase concentration of $i$ in the soil $\left(\mathrm{g} / \mathrm{cm}^{3}\right)$

$A=$ contaminated surface area $\left(\mathrm{cm}^{2}\right)$

$d=$ depth of the dry layer at time for which analysis begins $(\mathrm{cm})$

$t=$ time measured from time for which analysis begins $(s)$.

Total diffusion from both liquid-phases and gas-phases is defined in terms of the flux of the constituent. The constituent first evaporates into voids in the soil and then diffuses into the atmosphere through the dry layer. This value can be estimated by the following equation: 


$$
D=D_{i} P_{s} H_{i}{ }^{\prime}
$$

where $D_{i}=$ air diffusion coefficient of constituent $i(\mathrm{~cm} 2 / \mathrm{s})$

$$
\begin{aligned}
P_{S}= & \text { the ratio of air filled to total porosity (Equation 6.2) } \\
\text { (dimensionless) } & \\
H_{i}{ }^{\prime}= & \begin{array}{l}
\text { Henry's law constant in concentration form } \\
\text { (dimensionless). }
\end{array}
\end{aligned}
$$

Henry's law constant in concentration form, $\mathrm{Hi}^{\prime}$, is defined as the ratio of near-surface air concentration to soil concentration of the constituent. This constant is computed using the following method given by Lyman et al. (1982):

$$
H_{j}{ }^{\prime}=\frac{H_{i}}{R T}
$$

where $H_{i}=$ Henry's law constant of constituent $i$ (atm $\mathrm{m}^{3} / \mathrm{mole}$ )

$$
\begin{aligned}
& \mathrm{R}=\text { gas constant }\left(8.2 \times 10^{-5} \mathrm{~atm} \mathrm{~m}^{3} / \mathrm{mole}^{\circ} \mathrm{K}\right) \\
& \mathrm{T}=\text { annual average air temperature }\left({ }^{\circ} \mathrm{K}\right) .
\end{aligned}
$$

As noted above, this method of estimating the volatilization rate from old spills assumes that a constant pool of concentration of the constituent exists in the soil until all of the constituent has been volatilized to the atmosphere. Based on this assumption, Hwang (1982) provides an equation for computing the dry-out time of the spill as

$$
t_{d}=\frac{\left(h^{2}\right)-\left(d^{2}\right)}{2 D}
$$

where $t_{d}=t i m e$ it takes all of the constituent $i$ to vaporize (s)

$$
\begin{aligned}
& h=\text { the depth to the botton of the contamination }(\mathrm{cm}) \\
& d=\text { depth of the dry layer }(\mathrm{cm}) \\
& D=\text { total diffusion coefficient to the atmosphere }(\mathrm{cm} 2 / \mathrm{s})
\end{aligned}
$$




\subsubsection{Water - Ponds, Lagoons, and Free-Standing Water}

A model is used that includes both sediment-to-water transfer and water-to-air transfer processes. Mackay and Leinonen (1975) proposed a steady-state water-to-air transfer model for estimating volatilization from bodies of water like lagoons or ponds. However, in many cases the sedimentto-water transfer controls emission rates. Following a method suggested by Thibodeaux(a) a model was developed using a set of mass transfer coefficients that control the diffusion of volatile chemicals from the sediment to the water and then from the water to the air. This method is based on experimental work done by Imboden and Emerson (1977) and Thibodeaux and Becker (1982). The combination of this work and the work by Mackay and Leinonen (1975) provides the basis for the MEPAS formulation for computing gaseous emission rates from a pond or lagoon. The atmospheric emission rates are computed using

$$
E_{i}=\frac{K_{w a} W_{a} A}{f_{S w} k_{S w}}
$$

where $E_{j}=$ the emission rate of constituent $(g / s)$

$$
\begin{aligned}
K_{W a} & =\text { overall mass transfer coefficient for system }(\mathrm{cm} / \mathrm{s}) \\
W_{a} & =\text { constituent concentration in sediment }(\mathrm{g} / \mathrm{g}) \\
A & =\text { area of the body of water }\left(\mathrm{cm}^{2}\right) \\
f_{\text {SW }}= & \text { sediment-water interface factor (dimensionless) } \\
k_{\text {SW }}= & \begin{array}{l}
\text { partition coefficient between sediment and water concentrations } \\
(\mathrm{mL} / \mathrm{g}) .
\end{array}
\end{aligned}
$$

Equation (6.17) uses the constituent concentration in the sediment since this phase controls the release rate of the constituent. The sediment-water interface factor is given by

(a) Thibodeaux, L. J. 1986. Lecture notes from Dr. Thibodeaux's Chemodynamics 4253 class taught in spring of 1986 at Louisiana State University. Agriculture and Mechanical College at Baton Rouge, Louisiana. (Subsequent documentation of the formulation for ponded volatilization is available in Thibodeaux 1989.) 


$$
f_{s w}=\frac{\left(k_{s w}+k_{w a}+h_{s} k_{r}\right)\left(k_{w s}+k_{s w}\right)-\left(k_{s w}\right)^{2}}{k_{w S} k_{s w}}
$$

where $f s w=$ sediment-water interface factor (dimensionless)

$k_{w s}=$ mass transfer coefficient from water to sediment $(\mathrm{cm} / \mathrm{s})$

$k_{s w}=$ mass transfer coefficient from sediment to water $(\mathrm{cm} / \mathrm{s})$

$h_{S}=$ depth of contaminated sediment $(\mathrm{cm})$.

$k_{r}=$ reaction rate constant in the column of water $\left(s^{-1}\right)$

The mass transfer coefficient for the sediment can be computed using

$$
k_{w s}=D_{w} P_{a} 1.33 / h_{s}
$$

where $D_{w}$ is the molecular diffusivity in water $\left(\mathrm{cm}^{2} / \mathrm{s}\right)$ and $P_{a}$ is the airfilled porosity of the sediment (dimensionless).

The water diffusion coefficient $\left(D_{W}\right)$ can be estimated using the empirical relationship ( $0^{\prime}$ Connor and Muller 1980).

$$
D_{W}=0.00022(M W)-0.6667
$$

where $M W$ is the molecular weight of the constituent and the coefficient has units associated with it that give values of molecular diffusivity in $\mathrm{cm}^{2} / \mathrm{s}$.

The mass transfer coefficient from sediment to water, $k_{5 w}$, as proposed by Thibodeaux and Becker (1982) is based on a study of the movement of benzoic acid in a wind-water tank. Using the results of this study, they developed the following general formula for computing $k_{s w}$.

$$
k_{S W}=\frac{9.95 \times 10^{-4} C_{D} V_{A}{ }^{2} H_{W} 1.25 \delta_{a}}{L M 0.5 \delta_{W}}
$$

where $k_{S W}=$ mass transfer coefficient from sediment to water $(\mathrm{cm} / \mathrm{min})$

$9.95 \times 10^{-4}=$ empirical correction factor $\left.[(\mathrm{g} / \mathrm{mole}))^{1 / 2}(\mathrm{~min} / \mathrm{cm}) 1.25\right]$

$$
C_{D}=\text { drag coefficient at the water-air interface (dimensionless) }
$$


$V_{A}=$ wind speed over the water at 10 meters $(\mathrm{cm} / \mathrm{min})$

$H_{w}=$ average depth of the water column $(\mathrm{cm})$

$\delta_{a}=$ density of the $\operatorname{air}\left(\mathrm{g} / \mathrm{cm}^{3}\right)$

$L=$ average length of the wind fetch $(\mathrm{cm})$

$M=$ gram molecular weight of the constituent $(g / m o l e)$

$\delta_{W}=$ density of the water $\left(\mathrm{g} / \mathrm{cm}^{3}\right)$.

The constant $9.95 \times 10^{-4}$ in Equation (6.18) is the product of empirical factors and the correction for the molecular weight of benzoic acid. Also, wind and/or thermal forces are assumed to be sufficient that a well-mixed situation exists in the water.

The overall water-to-air mass transfer coefficient can be estimated by using equations given by Liss and Slater (1974) as

$$
\frac{1}{K_{i}}=\frac{1}{K_{i l}}+\frac{R T}{H_{i} K_{i g}}
$$

where $K_{i}=$ overall mass transfer coefficient $(\mathrm{cm} / \mathrm{s})$

$K_{i l}=$ liquid-phase mass transfer coefficient $(\mathrm{cm} / \mathrm{s})$ (Equation 6.9)

$\mathrm{R}=$ gas constant $\left(8.2 \times 10^{-5} \mathrm{~atm} \mathrm{m^{3 } / \mathrm { mole } /} /{ }^{\circ} \mathrm{K}\right)$

$\mathrm{T}=$ annual average air temperature $\left({ }^{\circ} \mathrm{K}\right)$

$H_{i}=$ Henry's Law constant for constituent $i$ (atm $\mathrm{m}^{3} / \mathrm{mole}$ )

$K_{i g}=$ gas-phase mass transfer coefficient $(\mathrm{cm} / \mathrm{s}$ ) (Equation 6.10).

\subsubsection{Mass Budget - All Cases}

Source depletion is incorporated in the MEPAS component for computing volatilization (see Section 6.8.3). For all cases except the old surface concentration, this module reduces the volatilization rate as material is lost by emission to the atmosphere. 
For the old spill case, no emissions occur after the computed dry-out period [see Equation (6.16)]. For all cases, this module assures that the total computed emissions never exceed the inventory of available material.

The total long-term mass losses of materials may be limited by either the emission rates or the total mass of material contained in the landfili, spil1, or pond. The atmospheric pathway component computes average lifetime exposures of environmental concentrations based on a 70-year time period. For materials with a relatively rapid volatilization rate, a significant reduction in emissions will occur over this time period, and these computed concentrations will be mainly a function of the total amount of material released rather than initial emission rates. In such a case, the values of computed environmental concentrations are a function of the initial site inventory rather than the computed emission rate. At sites where the exact inventory is not known, an upper limit inventory should be computed to ensure that the computed emission rates do not result in an evaluation based on a release of an unreasonably large mass of material. That is, without input of the total mass available for a constituent, MEPAS will assume the same emission rate over the entire 70 -year period.

For materials that volatilize relatively slowly, the environmental concentrations will be a direct function of the emission rates computed with the above relationships. However, even for many of these materials, the mass budget limitation can significantly reduce the emission rate over a 70 -year time period.

\subsubsection{Limitations}

The volatilization formulations given above are simplified estimation procedures that allow the approximation of release rates based on site and contaminant properties. Although these methods do not account for all the factors that can control these release rates, the estimated release rates should provide the order-of-magnitude estimates of potential release rates required for the MEPAS ranking applications. For site-specific applications requiring additional resolution, verification of computed release rates by monitoring data is recommended by EPA (1988). 
The accuracy of the volatilization estimate depends directly on how well the problem is characterized. . The types, forms, and quantities of chemicals need to be defined along with the physical and chemical properties of the various media. Environmental problems can only be ranked according to the resolution with which the problem is defined. If the release rate is in error by an order-of-magnitude, then the rankings cannot have better than an order-of-magnitude resolution.

Because the current methodology does account for contaminant loss at the source if the inventory is known, the potential exposures are limited to the amount of material available. However, in cases where the inventory is unknown, there may be a possibility of releasing more material than is really associated with the environmental problem. The total releases for high ranking cases with undefined inventories should be checked to be certain that such quantities are realistic. Particularly for the more volatile chemicals, an inventory should be defined, even if that inventory is a maximum credible amount for the specific environmental problem.

\subsection{BACK CALCULATION}

In cases where regional air concentration measurements of a given constituent are available, MEPAS provides the option of back calculation of an apparent emission rate. This emission rate is computed by assuming that the emission rate will scale directly with the ratio of the measured and computed concentrations. The measured concentrations should be long-term average values; preferably annual (or longer) average values are used. This calibration of emission rates is accomplished by the investigator inputting an increment of the measured long-term average concentration that is directly attributable to the source to be modeled. For each constituent the emissions are computed using

$$
Q b=Q C C m(x, d i s) / C c(x, d i s)
$$

where $Q b=$ back-calculated emission rate $(g / s)$

$$
\begin{aligned}
& Q C=\text { unit emission rate }(\mathrm{g} / \mathrm{s}) \\
& \mathrm{Cm}=\text { measured average air concentration }\left(\mathrm{g} / \mathrm{m}^{3}\right)
\end{aligned}
$$


$C c=$ air concentration computed using a unit release rate $\left(\mathrm{g} / \mathrm{m}^{3}\right)$.

A similar procedure is implemented for back calculation of apparent emission rates from measured soil concentrations.

In situations where the contribution of a measured airborne concentration can be determined, the back calculation approach may be the best option for definition of the emission rates. In situations where the contribution of background and other local sources cannot be determined, this approach can easily give inaccurate results and should not be used. The soil concentration back calculation is provided for special case studies and is not considered a reliable method of calibrating emission rates. The air backcalculation component has been incorporated into the MEPAS shell.

A number of limitations apply to the use of this back-calculation approach. The time period for monitoring data and release rates should match. If the release rates for the long-term assessment are expected to be different than those during the monitoring program, a separate "calibration" run may be required to compute an effective monitoring period release rate for determining a release rate for the long-term assessment.

The assumption inherent in the making of a back-calculation is that all the error in estimating environmental concentrations occurs in the definition of a release rate. This will be valid as long as transport and dispersion simulations are reasonable approximations of conditions at a site. Back calculations should not be performed using monitoring data from locations where there are strong local meterological influences that will not be adequately simulated by the model.

\subsection{INITIAL SOURCE DISPERSION}

The original formulation document (Whelan et al. 1987) stated that an initial source dispersion is to be included. Since a sector average model does not have a horizonal dispersion parameter, the initial dispersion is based on increasing the vertical dispersion parameter. 


\subsubsection{Area Source}

For an area source, the distance of travel is increased to account for the initial dispersion. This distance increase or virtual distance is set equal to one half of the dimension of the area along the path of the wind.

$$
x^{\prime}=x+x a / 2
$$

where $x^{\prime}=$ distance for definition of vertical dispersion parameter (m)

$x=$ distance downwind from center of release $(m)$

$x a=$ dimension of area along wind axis $(\mathrm{m})$.

\subsubsection{Point Source}

For a point source, the initial value of the vertical dispersion parameter is set equal to the radius of the release area. This assumes that the plume from a stack or vent has an initial size on the order of the exit size.

$$
\sigma z^{\prime}=\left(\sigma z^{2}+r s^{2}\right)^{0.5}
$$

where $\sigma z^{\prime}=$ resultant vertical dispersion parameter $(m)$

$\sigma \mathbf{z}=$ atmospheric vertical dispersion parameter $(\mathrm{m})$

$r s=$ radius of release point $(m)$.

\subsubsection{Discussion}

The different treatment of area and point releases should be kept in mind when deciding which type of source release best fits a situation. The point source assumes an initial dispersion equal to the size of the release, whereby the area source only allows for the effect of a longer travel distance.

The initial source dispersion will only significantly affect the exposures computed at distances very close to the release point (i.e., distances on the same order of magnitude as the dimensions of the release). 
For most cases, the initial source dispersion will not be a major factor in the determination of overall rankings.

\subsection{AIR AS SOURCE}

The air-as-source component is an input option that allows the investigator to input a uniform regional air concentration of a contaminant. The exposure pathways are computed based on having the same concentrations and deposition rate everywhere over the region. That is,

$$
C(x, d i r)=C i
$$

where $C(x$, dir $)$ is the air concentration at distance, $x$, and direction, dir $\left(\mathrm{g} / \mathrm{m}^{3}\right)_{i}$ and $\mathrm{Ci}$ is the input value for ambient air concentrations $\left(\mathrm{g} / \mathrm{m}^{3}\right)$.

Applications for the air-as-source component are mainly for evaluation of background concentrations from sources of distant and/or poorly defined origin. The air-as-source component may also be used to approximately evaluate impacts from a disperse regional source term such as roadways. The air-as-source component has been incorporated into the MEPAS shell.

\subsection{SHORT-DISTANCE MODULE}

A short-distance indoor air concentration component was added to allow special evaluations of long-term climatological exposures in residences located closer than the 100-m minimum distance for the atmospheric plume dispersion module.

The residence structure is considered to be within one of the computation sectors. The assumption was made that if the width of the residence was smaller than the width of the 22.5-degree-wide sector being used to evaluate concentrations in the atmospheric component, then the average fraction of released material entering the building is equal to the ratio of the widths of the building and sector:

$$
\begin{array}{ll}
F b=W b / W s & \text { for } W b<W s \\
F b=1 & \text { for } W b \geq W s
\end{array}
$$


where $\mathrm{Fb}=$ fraction of release entering building (dimensionless)

$$
\begin{aligned}
& W b=\text { width of building }(m) \\
& W s=\text { width of sector at building (m). }
\end{aligned}
$$

The dispersion of material within the building is set equal to the internal volume of the building. The indoor concentration for a unit release is equal to

$$
\mathrm{Ci}=\mathrm{Fb}(1-\mathrm{Fr}) / \mathrm{U} / \mathrm{V}
$$

where $\mathrm{Ci}=$ indoor air concentration for one set of conditions $\left(\mathrm{g} / \mathrm{m}^{3}\right)$

$\mathrm{Fr}=$ filtration efficiency fraction (dimensionless).

$U=$ average wind speed $(\mathrm{m} / \mathrm{s})$

$V=$ indoor volume of the building $\left(\mathrm{m}^{3}\right)$

The indoor concentration is computed as the sum over wind speed and dispersion conditions:

$$
\text { Cit }=\sum_{u=1,6}\left(\begin{array}{cc}
\Sigma & C i \\
s=1,6 &
\end{array}\right)
$$

where Cit $=$ indoor air concentration $\left(\mathrm{g} / \mathrm{m}^{3}\right)$

$$
\begin{aligned}
& u=\text { wind speed groups } \\
& s=\text { stability classes } .
\end{aligned}
$$

This short distance indoor air concentration component has not been incorporated into the MEPAS shell. This component currently is only available for special applications where long-term routine residential exposures need to be evaluated at distances less than $100 \mathrm{~m}$. As with the initial source dispersion module described above, this module is not expected to be a major factor in determination of rankings. 


\subsection{DISPERSE REGIONAL RELEASE}

For some applications, the source of the contaminant emissions may be many release points spread over the region. The emissions from home heating furnaces are an example of such a source. A detailed evaluation of the thousands of release points is, at best, a difficult task.

A component was developed for consideration of cases with a disperse regioral source term. This component operates in a three-step process. First, the concentration and deposition patterns for a single typical release point are defined. Second, scaled patterns from the first step are superimposed to define the maximum cumulative impact of sources over the region on a typical single receptor located in the center of the region. Third, the air-as-source option described above is used to evaluate impacts over the region.

This analysis requires definition of the density and intensity of sources in annular segments as a function of distance and direction from the facility. The component allows use of a correlation with population to define the density of sources. The single typical release computation results define air and surface concentrations as a function of distance and direction. These concentrations can be used to compute approximate downwind concentrations from multiple sources within an area using

$$
\begin{aligned}
& C=C f C d A d \\
& D=D f C d A d
\end{aligned}
$$

$$
\text { where } \begin{aligned}
C & =\text { air concentration }\left(\mathrm{g} / \mathrm{m}^{3}\right) \\
D & =\text { surface deposition }\left(\mathrm{g} / \mathrm{m}^{2}\right) \\
C f & =\text { air concentration for typical unit source } \\
D f & =\text { surface concentration for typical unit source } \\
C d & =\text { density of unit sources in area }\left(1 \mathrm{~b} / \mathrm{m}^{2}\right) \\
\text { Ad } & =\text { area }\left(\mathrm{m}^{2}\right) .
\end{aligned}
$$


This formulation assumes the sources all have the same, or nearly the same, release characteristics as the typical unit release. Then by adding the contributions from each of the annular segment areas surrounding the central receptor point, the cumulative exposure of the disperse sources is computed:

$$
\left.\begin{array}{l}
C c=\operatorname{dir}=1,16_{\operatorname{dis}=1,20}
\end{array}\right)
$$

$$
\text { where } \begin{aligned}
C c & =\text { cumulative air concentration }\left(g / \mathrm{m}^{3}\right) \\
D c & =\text { cumulative soil deposition }\left(g / \mathrm{m}^{2}\right) \\
\text { dis } & =\text { distance from the center of the area }(\mathrm{m}) \\
\text { dir } & =\text { direction from the center of the area }(\mathrm{m}) .
\end{aligned}
$$

Then $C C$ and $D C$ are used as air-as-source inputs to evaluate impacts over the region.

The disperse regional source term provides a convenient method of handling cases with numerous release points over the region. Although the approach of using densities of release points greatly simplifies the data requirements, the approach also limits the resolution of applications. This approach will work best for many similar sources spread relatively uniformly over the region in question. The approach should not be used for cases with either a limited number of sources or a non-uniform regional distribution of sources. The key to deciding if an application is appropriate is to decide if the sources are numerous and disperse enough that a uniform concentration pattern can be used to evaluate exposures. The disperse regional source-term component has not been incorporated into the MEPAS shell and currently is run only for special applications. 


\subsection{COMPLEX TERRAIN COMPONENT}

MEPAS is designed to consider environmental emissions of potentially hazardous materials. When such materials are released to the atmosphere at sites surrounded by flat uniform terrain, the atmospheric MEPAS component as described in Whelan et a1. (1987) can be used to compute potential airborne concentrations and surface deposition rates. For sites with complex nonuniform surrounding terrain, additional enhancements have been added that allow for the influence of such terrain features. This section presents mathematical formulations and assumptions adopted within MEPAS for complex terrain applications.

The complex terrain components described below are only approximations of the major consequences of local terrain effects on atmospheric transport and dispersion. In his overview of processes in complex terrain, orgill (1981) describes specific terrain-induced airflow phenomena over various types of landforms along with the technical difficulty of modeling these phenomena. Case-specific models of flow in complex terrain tend to be computer-intensive models. However, such models were not considered appropriate for generating the long-term average concentration patterns needed in MEPAS,

\section{7 .1 Background}

The trajectory and diffusion of an atmospheric plume are known to be influenced by complex terrain. A number of models have been developed to emulate special processes in complex terrain (i.e., Burt 1977; Hovind et al. 1979: Strimaitis et al. 1983; Allwine and Whiteman 1988; Bader and Whiteman, 1989). The effects of the underlying surfaces can modify the transport, dispersion, and deposition processes. Areas with high ground-level concentrations can occur as the result of two different complex terrain effects. First, under moderate or high wind conditions, an elevated plume may impinge on local topographical features resulting in localized high-level concentrations. Second, under low wind or stable atmospheric conditions, a channeling of releases in a single direction can maximize ground-level concentrations.

MEPAS accounts for the effects of underlying surfaces on the vertical wind structure and the deposition rate of airborne pollutants onto these 
surfaces. These formulations are designed to improve the computations of climatological transport, dispersion, and deposition for a given site by using site-specific input data.

A straight-line Gaussian atmospheric model, which assumes the plume trajectories are in straight lines from a central release point, cannot account for the processes in complex terrain where the winds tend to follow local topographical features (valleys, gorges, slopes, etc.). A modified model has been developed that incorporates the major influences of local channeling. The formulations for wind channeling in the inmediate vicinity of the release are given in Section 6.7.3.

An elevated release which is lower than surrounding terrain may intersect local topographical features. Studies have shown that the tendency for the plume to intersect a hill is a function of the ambient meteorological conditions. The techniques described by Hanna et al. (1983) for accounting for topographical interactions in complex terrain have been adapted for application in the MEPAS climatological dispersion component. The formulations given in Section 6.7.2 account for the tendency for winds to intersect or flow over terrain features depending on ambient atmospheric conditions.

\subsubsection{Plume Intersection with Topographical Features}

The algorithms for plume intersections with local topography closely follow techniques suggested by Hanna et al. (1982). For unstable and neutral conditions, the plume height is reduced by up to $50 \%$ based on the height of local terrain. That is

$$
H^{\prime}=H-H_{t} \quad \text { for } H_{t}<H / 2(6.29)
$$

or

$$
H^{\prime}=H / 2 \quad \text { for } H_{t} \geq H / 2
$$

where $H^{\prime}=$ plume height over local terrain (m)

$H=$ plume height based on elevation of release point (m)

$H_{t}=$ height of local terrain over elevation of release point (m). 
For stable conditions, the plume is assumed to impinge directly on local topographical features and subsequently follow the features. The plume height is computed as

$$
H^{\prime}=H-H_{t} \text { for } H_{t}<H(6.30)
$$

or

$$
H^{\prime}=0 \quad \text { for } H_{t} \geq H
$$

with an additional restriction that the plume height is never allowed to increase as a function of distance as a result of terrain effects. If the terrain would result in a plume rise increase at a given distance, then the plume is maintained at the plume rise computed for the previous distance.

\subsubsection{Local Climatological Plume Channeling}

The importance of local circulations on exposures is a function of the size of the plume relative to the scale of the local circulations. Initially the plume is smaller than the local circulation, and the entire plume trajectory will be determined by the local circulation. As the plume travels, the dimensions of the plume increase and the local circulations become progressively less important in computing exposures.

The trajectories of ground-level releases will be affected by local wind channeling. The trajectories of elevated releases will be affected except in cases where the height of the plume is not within the local circulation.

Depending on the local topographical conditions, the trajectories in the immediate vicinity of the release can be important for the computation of both maximum individual and total exposures. The consideration of local channeling is most important in cases where the exposures to people will be significantly changed. In the absence of local populations, the local channeling may still be needed if predicted air concentrations are being evaluated.

The frequency of occurrence of winds in the direction of the downslope flow from the release point are assumed to be enhanced by the local channeling effects. Downslope winds driven by nocturnal cooling are assumed to occur mainly under stable atmospheric conditions. The winds are 
progressively coupled back into the regional winds either when the plume has dispersed to the height of the channel or at the end of the channel.

Upslope winds are driven by the tendency of warmer air to rise, whereby downslope winds are driven by the tendency of cooler air to fall. The natural warming and cooling processes at the surface make the overlying air layer unstable and stable, respectively. Hence the upslope winds tend to have fast dispersion rates and downwind winds tend to have slow dispersion rates.

The MEPAS atmospheric component computes total exposure to people in the region surrounding the release. This total exposure is the sum of a matrix of stable, neutral, and unstable conditions. The MEPAS local channeling module accounts for the channeling under the slow dispersion (stable) conditions. For neutral and unstable conditions, no special formulations are used to account for channeling.

All stable conditions (Pasquill categories $E, F$, and $G$ ) are assumed to be nocturnal drainage conditions for the site. The winds for these stable conditions are assumed to flow in the downslope direction with a nominal initial wind speed of $2.0 \mathrm{~m} / \mathrm{s}$ at $1-\mathrm{m}$ height, which is consistent with typical wind observations in complex terrain (Orgill 1981).

Within the channel, the air concentrations for stable conditions are computed using

$$
C=Q / \sigma_{Z} / Y
$$

where $Q$ is emission rate $(g / s)$

$C$ is air concentration $\left(\mathrm{g} / \mathrm{m}^{3}\right)$

$Y$ is the horizontal dispersion width $(m)$.

Once the plume becomes as deep as the channel, the plume is assumed to start dispersing out of the channel. The plume is approximated using a sector average "release" of material with initial dispersion equal to the depth of the channel. An initial width equal to the channel width is used. The coordinates of this "release" are centered at the point where the vertical dispersion parameter, $\sigma z$, has increased to the depth of the channel. 
Figure 6.1 illustrates the channeling model for the case where the plume reaches the end of the channel before dispersing out of the channel. A release within the channel occurs at radius $=0$, which travels in the downslope direction of the channel, $T$.

Between $r=0$ and $r=L$, the dispersion width is defined as follows:

$$
Y=\sigma_{y} \quad \text { when } W>\sigma_{y}(6.32)
$$

or

$$
Y=W=\sigma_{y} \text { when } W=2 \sigma_{y} \text { or } W<\sigma_{y}
$$

where, $\sigma_{y}=$ lateral dispersion parameter (m).

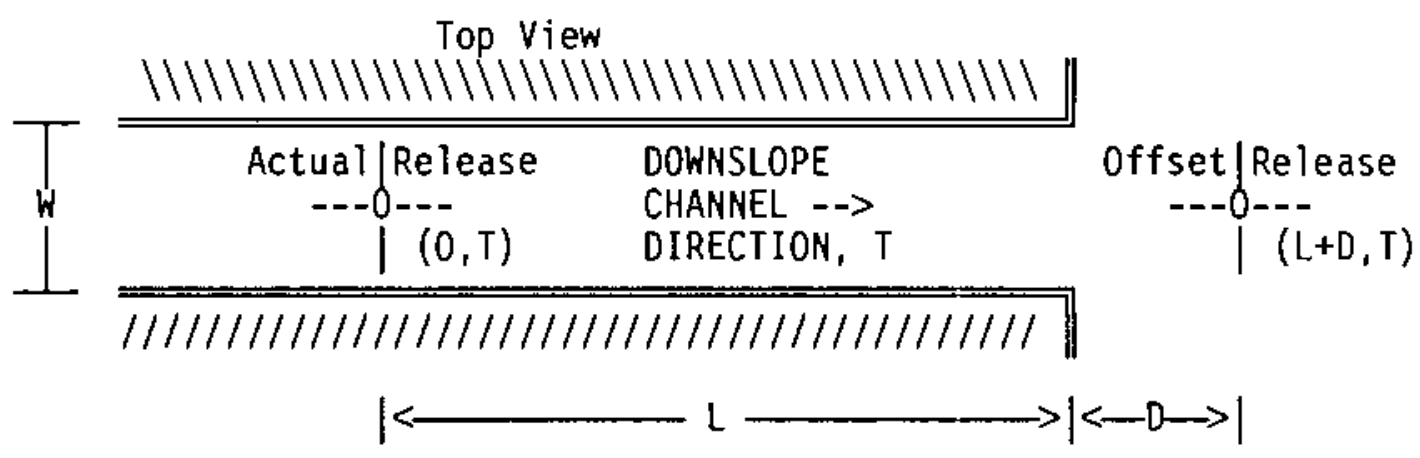

FIGURE 6.1. Schematic of Climatological Nocturnal Wind Channeling Component

To simulate the transition in flows at the end of the channel and avoid an abrupt concentration change between the channeled flow and the regional climatological dispersion, a linear interpolation is made between channel and regional concentrations for the direction, $T$, over the distance, D. This transition distance is assumed to be equal to the channel width, W.

This channeling module is designed to improve the performance of the atmospheric component by accounting for the gross aspects of local channeling in the computation of long-term average exposures. The channeling module provides for directed local plume movement under nocturnal conditions with limited dispersion. Given the complex atmospheric processes found in complex terrain, this module only provides for first-order effects that directly 
influence the initial movement of the release. If significant wind channeling is expected in the immediate vicinity of the release, this module provides a means of accounting for the local channeling effects.

\subsubsection{Limitations}

The complex terrain components use approximations based on average conditions to improve the accuracy of simulation of environmental conditions. Although the components described above will provide a reasonable estimate of the average exposures, these components involve gross simplifications of the atmospheric processes. Case studies of air movements in complex terrain demonstrate the need for much more sophisticated models to predict detailed exposure patterns. The MEPAS atmospheric component is only designed to provide order-of-magnitude estimates of exposures in complex terrain.

The computation of the maximum individual exposure generally will be more sensitive to the effects of complex terrain than the population exposure. However, in situations where the tendency for air to flow (or not to flow) from the release to surrounding population centers is controlled by terrain effects, the complex terrain features can significantly affect population exposures as well.

\subsection{TRANSPORT, DISPERSION, AND DEPOSITION}

The formulations for the atmospheric pathway component of MEPAS that simulates long-term average exposures from atmospheric emissions to the regional human population are described in whelan et al. (1987). A standard straight-line, sector-averaged Gaussian model is used as the basis of the atmospheric pathway model. This section contains additions and clarifications to the framework given in that document.

\subsubsection{Calm and Missing Wind Conditions}

The MEPAS atmospheric component uses six classes of atmospheric stability to characterize the dispersion rates. The atmospheric stability classes are designated by the letters A to $F$ (Slade 1968) and are commonly referred to as the Pasquill Stability Categories (Pasquill and Smith 1983).

In the characterization of frequency of winds in each of these stability classes, often some fraction of the reported cases are for calm, or zero wind 
speed conditions. Since the formulations for the climatological atmospheric component require a non-zero wind speed, a method was adopted for handling the reported calm conditions based on assigning these conditions a low, nonzero wind speed in a manner that reflects the occurrences of winds with low wind speeds. This procedure is appropriate because calm conditions are more correctly defined as conditions when the winds were less than the starting speed of the anemometer--the atmosphere is very seldom really calm with no air movements.

The occurrences of calm conditions in each stability class are distributed in a special wind speed class. The relative frequencies of occurrence of winds in the lowest wind speed class are used to distribute calms as a function of direction. If the lowest wind speed class has no entries, then the calms are distributed equally over the 16 direction sectors. Calm conditions are modeled with a wind speed of $0.5 \mathrm{~m} / \mathrm{s}$.

The input table of dispersion conditions is nomalized to represent all conditions. That is, missing conditions are distributed according to the input frequencies of occurrence.

\subsubsection{Constituent Decay and Removal}

The formulations for constituent decay and removal in the atmospheric pathway component of MEPAS are described in whelan et al. (1987). This section contains application clarifications to the framework given in that document.

\subsubsection{Radioactive and Chemical Decay}

The radioactive decay and production of decay products are incorporated in the computation of an area release in the atmospheric transport component. The source decay formulations are the same as the waterborne transport (Whelan et al. 1987). Decay processes of materials deposited on the environmental surfaces are incorporated in the exposure component.

For computation of long-term effects, the decay of radioactive materials during airborne transport is not normally expected to be important. However, in cases where fast radioactive decay occurs, the radioactive decay plume depletion fraction is computed using 


$$
f_{d}=e-u D / d
$$

where $f_{d}=$ decay depletion fraction

$$
\begin{aligned}
& u=\text { mean wind speed }\left(m s^{-1}\right) \\
& d=\text { the downwind distance }(m) \text { and } \\
& D=\text { decay constant }\left(s^{-1}\right) .
\end{aligned}
$$

In the current MEPAS shell implementation, the default is to assume that decay during atmospheric transport is trivial (i.e., $D$ is equal to 0 ).

Chemical reactions can reduce the source term for area releases in the atmospheric transport component. Decay processes of materials deposited on the environmental surfaces are incorporated in the exposure component.

For computation of long-term effects, chemical reactions during airborne transport are not expected to be important for most materials. However, in special cases, the resultant plume depletion fraction is computed using the same relationship as for radioactive decay [Equation (6.36)] with a chemical reaction half-life rather than radioactive decay half-life.

\subsubsection{Dry and Wet Deposition}

As described in whelan et al. (1987), the dry and wet deposition rates are computed in MEPAS. A mass budget approach is used to compute the net Gaussian plume source depletion fractions deposition as a function of distance from the release.

The implementation of removal rates are accomplished in MEPAS using seven deposition classes which represent the constituent properties shown in Table 6.1. The air concentration and deposition patterns are computed for each of these classes based on a unit emission rate. Depending on the properties of a constituent, each constituent is assigned to a dispersion class. Then the air concentration and deposition patterns for each constituent are computed using the appropriate nomalized concentration patterns and the constituent emission rate. 
TABLE 6.1. Definition of Deposition Classes

\section{Deposition}

\begin{tabular}{|c|c|}
\hline Class & Class of Constituent \\
\hline $\begin{array}{l}1 \\
2 \\
3 \\
4 \\
5 \\
6 \\
7\end{array}$ & $\begin{array}{l}\text { particles with average radius }=7.5 \mu \\
\text { particles with average radius }=3.0 \mu \\
\text { particles with average radius }=0.3 \mu \\
\text { gas with moderate surface resistance }(\mathrm{s} / \mathrm{cm}) \\
\text { nondepositing gas } \\
\text { gas emission that deposits as a Class } 1 \text { particle } \\
\text { gas with fast deposition rate (zero surface resistance) }\end{array}$ \\
\hline
\end{tabular}

The selection of which deposition classes apply in a given case depends both on the current application and the constituent properties. In the MEPAS shell the dispersion classes are allocated in the following manner.

The constituent data base contains a "default" entry for deposition class for each constituent. If the material is released in a particulate form, this value is 1 indicating that one of the first three classes are appropriate. The MEPAS shell assumes that Class 1 is most appropriate for area releases of suspended soil materials and that Class 3 is most appropriate for point releases (stack and vent releases). If the material is released in a gaseous form, then the constituent data base contains the most appropriate value from $\mathrm{Classes} 4,5,6$, and 7 .

\subsubsection{Source Mass Budget}

The emission of a constituent will deplete the inventory of that constituent at the site. With one exception, the depletion of the mass in the irventory of an area source is assumed to proportionally reduce the emission rate. The exception is for the case of an old spill volatilization computation where a constant emission rate is assumed with a linear reduction in the inventory.

For sites where the inventory is known, or can be estimated, the proportional depletion is computed using,

$$
f_{m}=e^{-t / H}
$$


where $f_{m}=$ mass emission depletion fraction

$$
\begin{aligned}
t & =\text { elapsed time } s \\
H & =\text { mass removal half-life } s .
\end{aligned}
$$

In the current MEPAS shell implementation, the default is to assume that source depletion occurs for all constituents in an area source case for which inventories are input. The investigator has the option of defining an average emission rate for a 70-year period with no inventory, or an initial emission rate with the inventory. The former requires that the investigator externally account for mass depletion, and the latter allows use of MEPAS formulations to account for the source depletion.

\subsection{REFERENCES}

Allwine, K. J., and C. 0. Whiteman. 1988. "Ventilation of Pollutants Trapped in Valleys: A Simple Parameterization for Regional-Scale Dispersion Models." Atmos. Environ. 22(9): 1839-1845.

Bader, D. C. and C. D. Whiteman. 1989. "Numerical Simulation of CrossValley Plume Dispersion During the Morning Transition Period." J. Appl. Meteor. 28, 652-664.

Burt, E. W. 1977. Valley Model User's Guide. EPA-450/2-77-018, U.S. Environmental Protection Agency, Research Triangle Park, North Carolina.

Cohen, Y., W. Cocchlo, and D. MacKay. 1978. "Laboratory Study of Liquidphase Controlled Volatilization Rates in Presence of Wind Waves." ES\&T $5: 553$.

Dewalle, F. B., E. S. K. Chian, and E. Hammerburg. 1978. "Gas Production from Solid waste in Landfills." J. Env. Eng. Div. ASCE 104(EE3):415-432.

Eagleson, P. S. 1970. Dynamic Hydrology. McGraw-Hill, New York.

EPA (see U.S. Environmental Protection Agency).

Farino, W., P. Spawn, M. Jasinsni, D. Murphy. 1983. Evaluation and Selection of Models for Estimating Air Emissions from Hazardous Waste Treatment, Storage, and Disposal Facilities. EPA 66-02-3166, U.S. Environmental Protection Agency, washington, D.C.

Farmer, W. J., M. S. Yang, J. Letey, W. F. Spencer, and M. H. Roulier. 1978. "Land Disposal of Hexachlorobenzene Waste: Controlling Vapor Movement in Soils." 4th Annual Symposium on Land Disposal, San Antonio, Texas. 
Fenn, 0. G., K. J. Hanley, and T. V. DeHeare. 1975. Use of the Water Balance Method for Predicting Leachate Generation from Solid Waste Disposal Sites. SW-168, U.S. Environmental Protection Agency, Washington, D.C.

Hanks, R. J., and G. L. Ashcroft. 1980. Applied Soil Physics. SpringerVerlag, New York.

Hanna, S. R., G. A. Briggs, and R. P. Hosker, Jr. 1982, Handbook on Atmospheric Diffusion. DOE/TIC-11223, U.S. Department of Energy, Washington, D.C.

Hovind, E. L., M. W. Edelstein, and V. C. Sutherland. 1979. Workshop on Atmospheric Models in Complex Terrain. PB80-128571, U.S. Envi ronmental Protection Agency, Research Triangle Park, North Carolina.

Hwang, S. T. 1982. "Toxic Emissions from Land Disposal Facilities." Environmental Progress 1(1).

Imboden, D. M., and S. Emerson. 1977. "Study of Transport Through the Sediment-Water Interface in Lakes Using Radon-222." In Interactions Between Sediments and Fresh Water, pp. 458-465. H. L. Gotterman, Editor, Dr. W. Junk, B. V. Publishers, The Hague.

Israelsen, 0. W., and V. E. Hansen. 1962. Irrigation Principles and Practices. Wiley, New York.

Liss, P. S., and P. G. Slater. 1974. "Flux of Gases Across the Air-Sea Interface." Nature 247:181-184.

Lyman, W. J., W. F. Reehl, and D. H. Rosebblatt. 1982. Handbook of Chemical Property Estimation Methods. McGraw-Hill, New York.

Lynsley, R. K., Jr., M. A. Kohlor, and J. L. H. Paulhus, 1975. Hydrology for Engineers. McGraw-Hill, New York.

Mackay, D., and P. J. Leinonen. 1975. "Rate of Evaporation of LowSolubility Contaminants from Water Bodies to Atmosphere." Environ. Sci. and Technol. 9(13).

Mackay, D., and R. S. Matsugu. 1973. "Evaporation Rates of Liquid Hydrocarbon Spills on Land and Water." Can J. Chem. Eng. 51:434-439.

Millington, R. J., and J. M. Quirk. 1961. "Permeability of Porous Solids." Irans. Faraday Soc. 57:1200-1207.

O'Connor, D. J., and J. A. Muller, eds. 1980. Modeling of Toxic Substances in Natural Water Systems. 25th Summer 1nstitute in Water Pollution Control, May 19-23, 1980, Manhattan College, Bronx, New York. 
Orgill, M. M. 1981. A Planning Guide for Future Studies. PNL-3656, Pacific Northwest Laboratory, Richland, Washington.

Owens, W. R., R. W. Edwards, and J. W. Gibbs, 1964. "Some Reaction Studies in Streams." Inter. J. Air Water Pollution 8:496.

Pasquill, F., and F. B. Smith. 1983. Atmospheric Diffusion. 3rd ed. Wiley, New York.

Reinhart, J. R. 1977. Gas-Side Mass-Transfer Coefficients and Interfacial Phenomena of Flat Bladed Surface Agitators. University of Arkansas, Ph.D. Thesis.

Shen, T. 1981. "Estimating Hazardous Air Emissions from Disposal Sites." Pollut. Eng. 13(8):31-34.

Slade, D. H. 1968. Meteorology and Atomic Energy. U.S. Atomic Energy Commission, TID-24190, National Technical Information Service, Oak Ridge, Tennessee.

Smith, J. H., D. C. Bomberger, Jr., and D. L. Haynes. 1979. Prediction of the Volatilization Rates of High Volatility Chemicals from Natural Water Bodies. SRI Report, Menlo Park, California.

Strimaitis, D. G., A. Venkatram, B. R. Greene, S. Hanna, S. Heisler, T. Lavery, A. Bass, and B. A. Egan. 1983. EPA Complex Terrain Model Development. EPA-600/3-83-015, U.S. Environmental Protection Agency, Research Triangle Park, North Carolina.

Thibodeaux, L. J. 1978. "Air Stripping of Organics from Waterways: A Compendium." In Proceedings of the Second National Conference on Complete Water Use, Chicago, Illinois.

Thibodeaux, L. J. 1981. "Estimating the Air Emissions of Chemicals from Hazardous Waste Landfills." J. Hazard. Mater. 4.

Thibodeaux, L. J. 1989. Theoretical Models for Evaluation of Volatile Emissions to Air During Dredged Material Disposal with Applications to New Bedford Harbor, Massachusetts. Miscellaneous Paper EL-89-3, U.S. Army Corps of Engineers, Vicksburg, Mississippi.

Thibodeaux, L. J., and B. Becker. 1982. "Chemical Transport Rates Near the Sediment in Waste Water Impoundment." Environmental Progress 1(4):296-300.

Thibodeaux, L. J., and S. T. Hwang. 1982. "Landfarming of Petroleum WastesModeling the Air Emission Problem." Environmental Progress 1(1).

U.S. Environmental Protection Agency (EPA). 1980. Land Disposal of Hexachlorobenzene Wastes: Controlling Vapor Movement in Soil. EPA 560/11-80012, U.S. Environmental Protection Agency, Municipal Environmental Research Laboratory, Office of Research and Development, Cincinnat $i$, Ohio. 
U.S. Environmental Protection Agency. 1988. Superfund Exposure Assessment Manual. OSWER Directive 9285.5-1, Office of Remedial Response, Office of Solid Waste and Emergency Response, U.S. Environmental Protection Agency.

Whelan, G., O. L. Strenge, J. G. Droppo, Jr., B. L. Steelman, and J. W. Buck. 1987. The Remedial Action Priority System (RAPS): Mathematical Formulations, D0E/RL/87-09, PNL-6200, Pacific Northwest Laboratory, Richland, Washington. 


\section{.}




\subsection{EXPOSURE AND HEALTH IMPACT}

Several enhancements have been made to the exposure and health impact components of RAPS/MEPAS since publication of whelan et al. (1987). These changes are described in this chapter.

\subsection{CONTACT EXPOSURE WITH SOILS AT MEASURED CONCENTRATIONS}

This pathway is included when practices at the site have resulted in significant soil contamination of nearby residential areas and measurements of pollutant concentrations are available for the contaminated areas. The exposure for this pathway is evaluated using the same dermal contact and inadvertent ingestion model defined for air deposition of contaminants onto soil [see Equation (8.31) of whelan et al. (1987)]. The individual dose is used in Equation (9.1) of Whelan et al. (1987) to estimate health impacts to individuals and the population, and to subsequently estimate the Hazard Potential Index (HPI) values.

To implement this exposure pathway evaluation, the investigator must define 1) the number of people living within each residential area and 2) the concentration of each contaminant in the soil at each residential area of interest.

\subsection{INGESTION EXPOSURE OF FOODS AT MEASURED CONCENTRATIONS}

Several site evaluations performed using the MEPAS computer program have measured food contaminant levels. Examples of food types for which measured concentrations may be available are deer or elk related to hunting activities, sport or commercial fishing, milk from commercial dairies, or vegetable crops. When such information is available, a more representative estimate of exposure can be made than when food concentrations are estimated. To take advantage of measured food concentration data, a model was added to MEPAS to include the dose to selected populations from ingestion of food using the measured concentrations. The dose to an individual from ingestion of food is evaluated as follows:

$$
\text { Dmfi }=\text { Cmfi Umfi Dgi }
$$


where $\mathrm{Dmfi}_{\mathrm{i}}=$ daily intake rate of contaminant $i$ through ingestion of food type $f(\mathrm{mg} / \mathrm{kg} / \mathrm{d}$ or $\mathrm{pCi} / 70 \mathrm{yr})$

$\mathrm{Cm}_{\mathrm{f}} \mathrm{=}$ concentration of contaminant $i$ in food type $f(\mathrm{mg} / \mathrm{kg}$ or $\mathrm{pCi} / \mathrm{kg}$ )

Umf $i$ = daily consumption rate of food type $f$ by individual in the exposed population group $(\mathrm{kg} / \mathrm{d})$

$D g_{j}=$ ingestion dose conversion factor for contaminant $\mathbf{i}\left(\mathrm{kg}^{-1}\right.$ or rem/70 yr per $\mathrm{pCi}$ ingested).

The individual dose is used in Equation (9.1) of Whelan et al. (1987) to estimate health impacts to individuals and the population, and to subsequently estimate the HPI values. The population health impact estimate requires knowledge of the number of people exposed to each food type and the average daily ingestion rate for the individuals. The latter information is provided by the user of MEPAS for each food type for which measured concentrations are available.

\subsection{EXTERNAL DOSE USING MEASURED RADIATION DOSE RATES}

Sites involved with handling of radioactive materials often have environmental surveillance programs that provide measurements of radiation doses in the vicinity of the site. If such information is available, estimates of radiation doses to individuals and the population living in the area may be made. The average daily radiation dose to an individual exposed to a known radiation field is estimated as follows:

$$
D e_{g}=6.136 \times 105 \mathrm{Dr}_{\mathrm{g}}
$$

where $D e_{g}=$ average external radiation dose to an individual in exposed group $g$ (rem/70-yr lifetime)

\section{$6.136 \times 105=$ units conversion factor $(24 \mathrm{hr} / \mathrm{d} \times 365.25 \mathrm{~d} / \mathrm{yr}$} x 70-yr/lifetime).

$D r_{g}=$ measured dose rate for individuals in exposed group $g$ ( $\mathrm{rem} / \mathrm{h}$ )

The radiation dose is evaluated for the average individual in each exposed group identified for the site. For each group, the dose rate and population exposed are identified through input to MEPAS. The average dose 
is used in Equation (9.1) of whelan et al. (1987) to estimate health impacts to individuals and the population, and to subsequently estimate the HPI values.

\subsection{EXPOSURE TO CARBON-14}

Release of carbon-14 to the atmosphere or water may result in radiation exposure to the surrounding populations. The estimation of exposure from this radionuclide requires special consideration for the farm product pathways because transfer and uptake of carbon in the food chain is not well described by the usual model (i.e., the initial RAPS model described in Section 8.0 of whelan et a1. 1987). The following model is based on recommendations given by Napier et al. (1988) for the estimation of exposure to carbon-14.

The transfer of carbon-14 from water to plants (important for the irrigation route) is not well described by transfer factors because plants receive most of their carbon from the air. Thus, use of transfer factors is extremely conservative and not appropriate for carbon-14. The model described here is based on the ratio of grams of carbon-14 to grams of total carbon in soil and a correction for the fraction of carbon that plants obtain from soil. The concentration of carbon-14 in vegetation from irrigation is estimated as

$$
C_{i p}=0.1 C_{i j} I \text { te } p\left[1-\exp \left(-\lambda s c t e_{p}\right)\right] /(0.01 \mathrm{P} \lambda s c 30)
$$

where $C_{i p}=$ concentration of contaminant $i(14 C$ in this case) in $p l a n t$ type p, $\mathrm{pCi} / \mathrm{kg}$

$\mathrm{CW}_{j}=$ concentration of contaminant $i$ in irrigation water $(\mathrm{pC} i / L)$

$I$ = irrigation rate $\left(\mathrm{L} / \mathrm{m}^{2} / \mathrm{mo}\right)$

$\lambda s c=$ effective removal rate constant for $14 \mathrm{C}$ in soil $(d-1)$

te $p=$ duration of growing period for crop type $p$ (d)

$P=$ effective soil density in the plow layer $\left(\mathrm{kg} / \mathrm{m}^{2}\right)$

$0.1=$ the assumed uptake of $10^{\circ}$ of plant carbon from soil 


$$
\begin{aligned}
0.01 & =\text { the average fraction of soil that is carbon } \\
30 & =\text { days per month. }
\end{aligned}
$$

The transfer of carbon-14 from air to plants is calculated as follows.

$$
C_{i p}=C_{a C} F_{C p} / P_{C}
$$

where $\mathrm{CaC}=$ concentration of $14 \mathrm{C}$ in air $\left(\mathrm{pCi} / \mathrm{m}^{3}\right)$

$$
\begin{aligned}
F C_{P} & =\text { fraction of carbon in plant type } p \\
P_{C} & =\text { concentration of carbon in air }\left(\mathrm{kg} / \mathrm{m}^{3}\right) .
\end{aligned}
$$

The concentration of carbon-14 in animal products is estimated for air and water routes as follows.

$$
C_{i m}=F_{C m}\left[C_{i p} Q f+C_{w C} Q w\right] /\left[F_{C f} Q f+F_{C w} Q w\right]
$$

where $C_{i m}=$ concentration of contaminant $i(14 \mathrm{C}$ in this case) in animal product $\mathrm{p}(\mathrm{pCi} / \mathrm{kg})$

$C_{i p}=$ concentration of ${ }^{14} \mathrm{C}$ in crop used for animal feed $(\mathrm{pCi} / \mathrm{kg})$

$C_{W C}=$ concentration of $14 \mathrm{C}$ in animal drinking water $(\mathrm{PCi} / \mathrm{L})$

$\mathrm{FCf}_{\mathrm{C}}=$ fraction of carbon in animal feed

$\mathrm{F}_{\mathrm{CW}}=$ fraction of carbon in animal drinking water

$\mathrm{F}_{\mathrm{Cm}}=$ fraction of carbon in animal product $\mathrm{m}$

Qf = consumption rate of feed by the animal $(\mathrm{kg} / \mathrm{d})$

$Q_{w}=$ consumption rate of water by the animal $(L / d)$.

Values for the various constants in the above equations are given in Table 7.1. These values are as recommended by Napier et al. (1988). For airborne releases, the water concentration is zero. Also, the carbon content of plants is much higher than in water $\left(F_{C f} \gg F_{C W}\right)$. Under these conditions the animal product concentration for airborne releases becomes

$$
C_{i m}=C_{i p} F_{C m} / F_{C f} .
$$


IABLE 7.1. Parameter Values for Carbon-14 Farm Product Model

$\begin{array}{lll}\begin{array}{ll}\text { Food or Fodder } \\ \text { All vegetables }\end{array} & \begin{array}{c}\text { Fraction that is } \\ \text { Carbon (wet wt) }\end{array} \\ \text { Grass } & 0.090 \\ \begin{array}{l}\text { Grain and stored } \\ \text { animal feed }\end{array} & 0.090 \\ \text { Milk } & 0.40 \\ \text { Meat } & 0.070 \\ \text { Concentration of carbon in air. . . . . . } 1.6 \times 10^{-4} \mathrm{~kg} / \mathrm{m} 3(\mathrm{a})\end{array}$

(a) Assumes a typical atmospheric $\mathrm{CO}_{2}$ concentration of $320 \mathrm{ppm}$.

\subsection{EXPOSURE PATHWAYS}

Several modifications have been made to the exposure pathway models in an effort to better represent the transfer of contaminants from environmental media (air, water, and soil) to potentially exposed humans. Model changes have been made related to the following topics: food transfer factor correlations, deposition velocity estimation, and maximum individual exposure.

\subsubsection{Food Transfer Factor Correlations}

The models in MEPAS for estimating exposure from farm product pathways require transfer factors to describe root uptake of pollutants from soil and to describe transfer from animal intake to meat and milk. The initial correlations selected for MEPAS have been replaced with recent correlations suggested by Travis and Arms (1988). All of the new correlations relate the desired transfer factor to the octanol-water partition coefficient for a pollutant.

The beef transfer factor correlation evaluated by Travis and Arms considered 36 chemicals with $\log \left(K_{0}\right)$ ranging from 1.34 to 6.89 . The 
following correlation was obtained using a geometric mean functional regression method.

$$
\log \left(F_{m i}\right)=-7.6+\log \left(K_{o w i}\right)
$$

where $F_{m i}$ is the transfer coefficient for contaminant $i$ that relates daily intake rate by an animal to the concentration in meat (d/kg) and $K_{\text {ow }}$ is the octanol-water partition coefficient for contaminant $i$.

The milk transfer factor was based on data for 28 organic compounds with $\log \left(K_{o w}\right)$ values ranging from 2.84 to 6.89 . The geometric mean regression of these data resulted in the following correlation.

$$
\log \left(F_{m j}\right)=-8.10+\log \left(K_{\text {owi }}\right)
$$

where $F_{m i}$ is the transfer coefficient for contaminant $i$ that relates daily intake rate by an animal to the concentration in milk (d/L). The same symbol $\left(F_{\mathrm{mi}}\right)$ is used for both the meat and milk transfer factors for consistency with the nomenclature used in the original mathematical formulation report (Whelan et al. 1987).

The correlation of soil-to-plant transfer with $K_{0 w}$ was evaluated by Travis and Arms (1988) for 29 chemicals with $\log$ (Kow) varying from 1.15 to 9.35. The geometric mean regression of these data provided the following correlation.

$$
\log (B \vee i)=0.986-0.578 \log \left(K_{\text {owi }}\right)
$$

where $B v_{j}$ is the transfer factor from soil to edible plant parts for contaminant $i$ (for chemicals: $\mathrm{mg} / \mathrm{kg}$ wet plant per $\mathrm{mg} / \mathrm{kg}$ dry soil, and for radionuclides: $\mathrm{pCi} / \mathrm{kg}$ wet plant per $\mathrm{pCi} / \mathrm{kg}$ dry soil).

Note that the original correlation presented by Travis and Arms (1988) was based on plant concentration expressed as dry weight. The above correlation was obtained by assuming that the dry weight concentration is 4 times the wet weight concentration (i.e., the plant is $75^{\circ}$ water). 
A comparison of transfer factors predicted by the new formulas with those predicted by the initial formulas used in MEPAS is presented in Table 7.2. The soil-to-plant transfer factors are lower for all values of the octanol-water partition coefficient. The meat and milk transfer factors are lower using the new correlation at small kow values, but are higher at high $\mathrm{K}_{\text {ow }}$ values. The milk transfer factors are equal using both correlations when $k_{0 w}$ is about $10^{4}$, and the meat transfer factors are equal when $k_{0 w}$ is about 105 .

TABLE 7.2. Comparison of Transfer Factor Correlation Formulas

\begin{tabular}{|c|c|c|c|c|c|c|}
\hline \multirow[b]{2}{*}{ Kow__ } & \multicolumn{2}{|c|}{$-P 1$} & \multicolumn{2}{|c|}{ eed-to-Milk } & \multicolumn{2}{|c|}{ eed-to-Meat } \\
\hline & & & & & rer & Initial \\
\hline $0 \times 10^{0}$ & & & & & & \\
\hline 0 & & & & & & \\
\hline $0 \times 10^{0}$ & $.8 \times 10^{0}$ & & & & & \\
\hline $0 \times 10^{1}$ & & & & & & \\
\hline $0 \times 10^{1}$ & $1.7 \times 10^{0}$ & $10^{1}$ & $0^{-7}$ & & $10^{-7}$ & $10^{-5}$ \\
\hline $0 \times 10^{1}$ & $1.0 \times 10^{0}$ & $10^{1}$ & $10^{-7}$ & & $10^{-6}$ & $10^{-}$ \\
\hline $0 \times 10^{2}$ & $10^{-1}$ & & & & & \\
\hline $0 \times 10^{2}$ & $4.5 \times 10^{-1}$ & $10^{1}$ & $0^{-6}$ & & & $10^{-}$ \\
\hline $0 \times 10^{2}$ & $2.7 \times 10^{-1}$ & $10^{1}$ & $4.0 \times 10^{-6}$ & $10^{-5}$ & $10^{-5}$ & $\times 10^{-}$ \\
\hline $0 \times 10^{3}$ & & & & & & \\
\hline $0 \times 10^{3}$ & $0^{-1}$ & $10^{0}$ & $0^{-5}$ & & & \\
\hline $0 \times 10^{3}$ & $7.0 \times 10^{-2}$ & $\times 10^{0}$ & $10^{-5}$ & & 1.3 & $10^{\circ}$ \\
\hline $0 \times 10^{4}$ & $4.7 \times 10^{-2}$ & & & & & $10^{-}$ \\
\hline $.0 \times 10^{4}$ & $3.2 \times 10^{-2}$ & $1.1 \times 10^{0}$ & $1.6 \times 10^{-4}$ & & $5.0 \times 10$ & $\times 10^{-}$ \\
\hline $0 \times 10^{4}$ & $.9 \times 10^{-2}$ & $6.3 \times 10^{-1}$ & $4.0 \times 10^{-4}$ & 10 & $1.3 \times 10^{-3}$ & $6 \times 10^{-}$ \\
\hline $.0 \times 10^{5}$ & $1.2 \times 10^{-2}$ & $4.1 \times 10^{-1}$ & & & & \\
\hline $2.0 \times 10^{5}$ & $8.4 \times 10^{-3}$ & $2.7 \times 10^{-1}$ & $1.6 \times 10^{-3}$ & $3.3 \times 10^{-5}$ & $5.0 \times 10^{-3}$ & $3.2 \times 10^{-}$ \\
\hline $.0 \times 10^{5}$ & $4.9 \times 10^{-3}$ & $1.5 \times 10^{-1}$ & $4.0 \times 10^{-3}$ & $5.2 \times 10^{-6}$ & $1.3 \times 10^{-2}$ & $5.0 \times 10^{-}$ \\
\hline & & & & & & \\
\hline $0 \times 10^{\circ}$ & $2.2 \times 10^{-}$ & $6.4 \times 10^{-2}$ & $1.6 \times 10^{-2}$ & $1.0 \times 10^{-3}$ & $5.0 \times 10^{-2}$ & $1.0 \times 10$ \\
\hline
\end{tabular}




\subsubsection{Deposition Velocity Estimation}

The transfer of contaminants from air to plant surfaces is often an important pathway for contamination of farm products, especially leafy vegetables. The transfer is modeled in MEPAS, as described by Equations (8.10) and (8.11) of whelan et al. (1987). In these equations, the amount deposited is directly proportional to the product of air concentration and deposition velocity. The deposition velocity is defined for each constituent in the chemical database. A default value of $0.001 \mathrm{~m} / \mathrm{s}$ is appropriately used for particulate materials. Also, several gaseous compounds have experimentally determined values that are well established. However, very little information is available on the deposition rate of most volatile organic chemicals to plant surfaces.

For volatile organic pollutants, an empirical model has been developed based on limited data and theoretical considerations of partitioning between air, plant water, and plant organic material. Partitioning between air and water is described by the Henry's law constant, and partitioning between plant water and plant organic matter is describec by the octanol-water partition coefficient. A mass balance between the amount of a contaminant in air and plants is included to ensure that overprediction of deposition does not occur for organic chemicals that partition preferentially to organic phases. The semi-empirical model provides a maximum 1 imiting value of $0.001 \mathrm{~m} / \mathrm{s}$ for nonvolatile organic pollutants to be consistent with the default value for particulate materials. The empirical model is given by the following equations:

$$
\begin{aligned}
V d_{i}= & C F V_{1} \\
V 1= & 4.80349 \mathrm{E}-8\left(0.9+0.1 \mathrm{~K}_{\text {owi }}\right) /[1000 \mathrm{H}] \mathrm{C}_{j} \\
& \left.+(4.8 \mathrm{E}-5)\left(0.9+0.1 \mathrm{~K}_{\text {owi }}\right)\right] \\
C F= & \text { greater of } 1 . /(1000 \mathrm{~V} 1)^{0.25} \text { and } 1.0
\end{aligned}
$$

where $V d_{i}=$ deposition velocity for contaminant $i(\mathrm{~m} / \mathrm{s})$ 
Kowi $=$ octanol-water partition coefficient for contaminant $i$ (dimensionless)

$H \mathrm{c}_{j}=$ Henry's law constant for contaminant $i$ (atm-m $3 /$ mole) and numerical values derive from theoretical and empirical considerations. Equation (7.12) represents an empirical correction based on limited measurement data. The correlation represented by Equations (7.10) through (7.12) is used only when no value is given in the database for the deposition velocity and positive values are given for both the Henry's law constant and the octanol-water partition coefficient. The results of the above relationship should be considered as an order-of-magnitude estimate only and are not meant to replace use of experimentally determined values.

\subsubsection{Maximum Individual Exposure}

The initial formulations of MEPAS included evaluations of individual exposures for each exposure pathway (e.g., drinking water, inhalation, swimming, etc.). These exposures represented daily intake rates or radiation doses received by a member of the exposed population for each pathway. The level of exposure defined for each pathway is approximately equivalent to the maximum exposure likely for a member of the population. For example, the drinking water pathway represents exposure to contaminated drinking water at an ingestion rate of $2 \mathrm{~L}$ per day, which is usually considered to be a maximum intake rate. The results of the individual exposure analysis are presented in tables prepared by MEPAS giving the highest individual health index for each exposure pathway estimated for the current run of MEPAS.

Mathematically, the Maximum Individual Index (MII) is the sum of the risk factors as calculated by equations summarized in whelan et al. (1987), where the risk factor is based on the maximum average daily intake (Dhij, Dgij) for all usage locations and time periods.

$$
M I I i=\sum_{j=1}^{\substack{\text { exposure } \\ \text { pathway }}} \text { RFij (maximum) }
$$

where $R F i j=$ maximum risk factor for constituent $i$ and exposure pathway $j$ for all usage locations and time periods 
Therefore, MEPAS was modified to evaluate the maximum exposure based on the highest air concentration value for any spatial interval in which people are identified as residing. A similar analysis is performed for the deposition of contaminants onto ground for the exposure pathways of soi1 ingestion and inhalation of resuspended deposited material.

\subsection{REFERENCES}

Napier, B. A., R. A. Peloquin, D. L. Strenge, and J. V. Ramsdell. 1988. GENI I-The Hanford Environmental Radiation Dosimetry Software System Volume 1: Conceptual Representation. PNL-6584 Vo1. 1, Pacific Northwest Laboratory, Richland, Washington.

Travis, C. C., and A. D. Arms. 1988. "Bioconcentration of Organics in Beef, Milk, and Vegetation." Environ. Sci. Technol. 22(3):271-274. American Chemical Society.

Whelan, G., D. L. Strenge, J. G. Droppo, Jr., and B. L. Steelman. 1987. Development of the Remedial Action Priority System (RAPS): Preliminary Mathematical Formulations. PNL-6200, prepared by Pacific Northwest Laboratory for the Office of Environment, Safety, and Health, U.S. Department of Energy, Washington, D.C. 


\subsection{BIBLIOGRRAPHY}

Buck, J. W., and R. J. Aiken (U.S. DOE). 1989. "Applications of the Multimedia Environmental Pollutant Assessment System (MEPAS). "In Proceedings of HAZTECH International Conference, September 27-29, San Francisco.

Buck, J. W., B. L. Hoopes, and D. R. Friedrichs. 1989. Multimedia Environmental Pollutant Assessment System (MEPAS): Getting Started with MEPAS. PNL-7126, Pacific Northwest Laboratory, Richland, Washington.

Droppo, J. G., G. Whelan, J. W. Buck, D. L. Strenge, B. L. Hoopes, and M. B. Walter. 1989. Supplemental Mathematical Formulations: The Myltimedia Environmental Pollutant Assessment System (MEPAS). PNL-7201, Pacific Northwest Laboratory, Richland, Washington. (This Report)

Droppo, J. G., D. L. Strenge, J. W. Buck, B. L. Hoopes, R. D. Brockhaus, M. B. Walter, and G. Whel an. 1989. Multimedia Environmental Pollutant Assessment System (MEPAS) Application Guidance Volume 1 - User's Guide. PNL-7216, Pacific Northwest Laboratory, Richland, Washington.

Droppo, J. G., D. L. Strenge, J. W. Buck, B. L. Hoopes, and G. Whelan. 1989. Multimedia Environmenta7 Pollutant Assessment System (MEPAS) Application Guidance Volume 2 - Guidelines for Evaluating MEPAS Input Parameters. PNL7216, Pacific Northwest Laboratory, Richland, Washington.

Droppo, J.G. and J.W. Buck. 1988. "Characterization of the Atmospheric Pathway at Hazardous. Waste Sites." In Proceedings of DOE Model Conference, Oak Ridge, Tennessee, October 3-7, 1988.

Hartz, K. E. and G. Whelan. 1988. "MEPAS and RAPS Methodologies As Integrated into the RI/EA/FS Process." Superfund '88, In Proceedings of 9th National Conference, November 28-30, Washington, DC.

Hoopes, B.L., J.W. Buck, D.L. Friedrichs, and R.J. Aiken. 1988. "The Multimedia Environmental Pollutant Assessment System (MEPAS) User-Friendly She11." In Proceedings of DOE Model Conference, Oak Ridge, Tennessee, October $3-7,1988$.

Morris, S. C., and A. F. Meinhold. 1988. Report of Technical Support for the Hazardous Waste Remedial Action Program on Health and Environmental Risks of Inactive Hazardous Waste Sites. BNL-42339, Brookhaven National Laboratory, Long Is Tand, New York.

Poston, T. M. and D. L. Strenge. 1989. "Estimation of Sport Fish Harvest for Risk and Hazard Assessment of Environmental Contaminants." In Proceedings of The 6th National Conference on Hazardous Wastes and Hazardous Materials, April 12-14, 1989, The Hazardous Materials Control Research Institute, New Orleans. 
Strenge, D. L., and S. R. Peterson. 1989. Chemical Data Bases for the Multimedia Environmental Pollutant Assessment System (MEPAS): Version 1. PNL-7145, Pacific Northwest Laboratory, Richland, Washington.

U.S. Department of Energy (DOE). 1988. Environmenta] Survey Preliminary Summary Report of the Defense Production Facilities. DOE/EH-0072, U.S. Department of Energy, Environment, Safety, and Health, Office of Environmental Audit, Washington, D.C.

U.S. Environmental Protection Agency. 1988. Analysis of Alternatives to the Superfund Hazard Ranking System. Pepared by Industrial Economics, Incorporated, Cambridge, Massachusetts.

Whelan, G., B. L. Steelman, D. L. Strenge, and J. G. Droppo Jr. 1986. "Overview of the Remedial Action Priority System (RAPS)." In Pollutants in a Multimedia Environment, ed. Y. Cohen, Plenum Publishing, New York.

Whelan, G., D. L. Strenge, and J. G. Droppo Jr. 1988. "The Remedial Action Priority System (RAPS): Comparison Between Simulated and Observed Environmental Contaminant Levels." Superfund '88, In Proceedings of 9th National Conference, November 28-30, Washington, DC.

Whelan, G., R. D. Brockhaus, D. L. Strenge, J. G. Droppo Jr., M. B. Waiter, and J. W. Buck. 1987. "Application of the Remedial Action Priority System To Hazardous Waste Sites." Superfund '87, In Proceedings of 9th National Conference, November 28-30, Washington, DC.

Whe 1an, G., D. L. Strenge, J. G. Droppo Jr., and B. L. Steelman. 1987. The Remedial Action Priority System (RAPS): Mathematical Formulations. PNL-6200, Pacific Northwest Laboratory, Richland, Washington.

Whelan, G., J. G. Droppo Jr., D. L. Strenge, M. B. Walter, and J. W. Buck. 1989. A Demonstration of the Applicability of Implementing the Enhanced Remedial Action Priority System (RAPS) at Hazardous Waste Sites. PNL-7102, Pacific Northwest Laboratory, Richland, Washington. 
APPENDIX

ERRATA FOR 1987 RAPS FORMULATION DOCUMENT 


\section{APPENDIX}

\section{ERRATA FOR 1987 RAPS FORMULATION DOCUMENT}

The Appendix presents corrections to the Remedial Action Priority System (RAPS) Mathematical Formulations document by whelen et al. (1987). These corrections are presented by chapter and are as follows:

\section{CHAPTER 5: GROUNDWATER PATHWAY}

1. Page 5.17, written line $6,1 / 2$ way down the page

Change: Equation (5.25)

To: Equation (5.24)

2. Page 5.17, Equation (5.40)

Change:

$$
F i_{3}=\left[\frac{z+w^{\star} t}{\left(16 \Pi D_{z}^{\star} t^{3}\right)^{1 / 2}}\right] \exp \left[-\left(\frac{\left(z-w^{\star} t\right)^{z}}{4 D_{z}^{*} t}+\lambda t\right)\right]
$$

To:

$$
F i_{3}=\left[\frac{z+w^{\star} t}{\left(16 \Pi D_{z}^{\star} t^{3}\right)^{1 / 2}}\right] \exp \left[-\left(\frac{\left(z-w^{\star} t\right)^{2}}{4 D_{z}^{*} t}+\lambda t\right)\right]
$$

3. Page 5.27, written lines 6 through 12

Change: Equation (5.75) usually provides a good estimate of the travel time of a contaminant; it assumes, however, that dispersion in the flow direction and degradation/decay are negligible.

A more precise estimate of the travel times of a contaminant that does account for dispersion and degradation/decay can be developed; this estimate computes the travel time of the peak contaminant concentration. By doing so, the highest concentration is known. 
To: Equation (5.66) usually provides a good estimate of the time to peak of the instantaneous solute concentration of a contaminant; it assumes, however, that dispersion in the flow direction and degradation/decay are negligible.

A more precise estimate of the time to peak of a contaminant that does account for dispersion and degradation/decay can be developed.

4. Page 5.29, Equation (5.69)

Change:

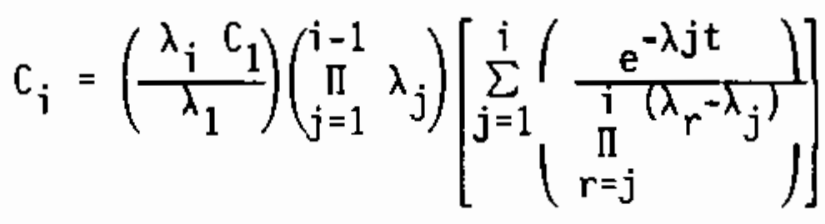

To:

$$
\left.c_{i}=\left(\frac{\lambda_{i} c_{1}}{\lambda_{1}}\right)\left(\prod_{j=1}^{i-1} \lambda_{j}\right)\left[\sum_{j=1}^{i} \frac{e^{-\lambda j t}}{\prod_{\substack{r=1 \\ r \neq j}}^{i}\left(\lambda_{r}-\lambda_{j}\right)}\right)\right]
$$

5. Page 5.29, two lines before Section 5.8

Change: where $C_{1}=$ parent concentration $(g / m L$ or $C i / m L)$

To: where $C_{1}=$ parent concentration $(C \mathrm{i} / \mathrm{mL})$

6. Page $6.5,13$ th line in Section 6.3

Delete: (where $y$ is equivalent to $B$ ) (cm)

7. Page 6.6, Equation (6.5)

Change:

$$
c=\left(\frac{Q_{c}}{u \ell_{m}^{h}}\right) \exp \left(-\frac{\lambda x}{u}\right) 1+\left[2 \prod_{n=1}^{\infty} \exp \left(\frac{n^{2} \Pi^{2} E_{y} x}{u B^{2}}\right)\right]
$$


To:

$$
C=\left(\frac{Q_{c}}{u l_{m} h}\right) \exp \left(-\frac{\lambda x}{u}\right) 1+\left[2 \prod_{n=1}^{\infty} \exp \left(\frac{n^{2} \Pi^{2} E_{y} x}{u\left(\ell_{m}\right)^{2}}\right)\right]
$$

\section{CHAPTER 7:}

1. On page 7.12, Equation (7.7), the expression

$$
E 10=(0.85)^{3}\left(\frac{S}{I 0}\right)\left(\frac{S}{24}\right)^{0.8}\left(\frac{W}{T}\right)^{0.3}\left(\frac{W}{\sigma}\right)^{1.2}\left(\frac{365-p}{365}\right)
$$

Should read:

$$
E 10=(0.85)\left(\frac{S}{10}\right)\left(\frac{S}{24}\right)^{0.8}\left(\frac{W}{T}\right)^{0.3}\left(\frac{W}{\sigma}\right)^{1.2}\left(\frac{365-p}{365}\right)
$$

2. On page 7.15, the two occurences of

OSWFR should read:

OSWER

3. In addition, the footnote (a) is now available as EPA (1988).

\section{CHAPTER 8:}

1. On page 8.9, Equation (8.7), the expression

$$
D a_{i}=\sum_{f=1}^{n}\left[u_{f} C w_{i} B_{i f} \exp \left(-\lambda w_{i} t_{f}\right)\right]
$$

should read:

$$
D a_{i}=\sum_{f=1}^{n}\left[u_{f} C w_{i} B_{i f} \exp \left(-\lambda w_{i} t_{f}\right)\right] D g_{i}
$$



PNL-7201

UC-602, 630

\section{DISTRIBUTION}

No. of

Copies

2 DOE/Office of Scientific and Technical Information

P. Brush

Acting Assistant Secretary for Environment, Safety and Health

U.S. Department of Energy, EH-1 1000 Independence Ave., SW

Washington, DC 20585

10 R. J. Aiken

Program Manager, Survey

Prioritization Office of Environmental Audit U.S. Department of Energy, EH-24 1000 Independence Ave., SW Washington, DC 20585

N. C. Aquilina, Manager Nevada Operations Office U.S. Department of Energy P.0. Box 98518

Las Vegas, NV 89193-8518

ONSITE

4 DOE Richland Operations office

D. Dunigan

M. J. Lawrence

A. J. Rizzo

C. Trader
No. of

Copies

38 Pacific Northwest Laboratory

J. W. Buck (2)

P. G. Doctor

J. G. Droppo (20)

J. W. Falco

M. D. Freshley

P. C. Hays

B. L. Hoopes

W. T. Pennell

D. L. Strenge (2)

M. B. Walter

G. Whelan Publishing Coordination

Technical Information (5) 
